MIT-3944-2

MITNE-97

\title{
GAMANL, A COMPUTER PROGRAM APPLYING \\ FOURIER TRANSFORMS TO THE ANALYSIS OF GAMMA SPECTRAL DATA
}

T. Harper, T. Inouye and N.C. Rasmussen

\section{NUCLEAR ENGINEERING READING ROOM - M.IT.}

Department of Nuclear Engineering Massachusetts Institute of Technology

Cambridge, Massachusetts 02139

August 1968

Contract $A T(30-1)-3944$

United States Atomic Energy Commission 


$$
\text { Safar Ahma Alo. Aug } 22,1769
$$

\title{
GAMANL, A Computer Program Applying Fourier Transforms To The Analysis of Gamma Spectral Data
}

\author{
T. Harper, T. Inouye and N. C. Rasmussen \\ August 1968
}

\begin{abstract}
Massachusetts Institute of Technology
Department of Nuclear Engineering
\end{abstract}

Contract AT(30-1) -3944

United States Atomic Energy Commission

\footnotetext{
*Work done while on leave from Tokyo Shibaura (TOSHIBA) Electric Company, Ltd., Japan
} 
GAMANL, A COMPUTER PROGRAM APPLYING FOURIER TRANSFORMS TO THE ANALYSIS OF GAMMA SPECTRAL DATA

by

T. Harper, T. Inouye*, and N. C. Rasmussen

Abstract

GAMANL, a computer code for automatically identifying the peaks in a complex spectra and determining their centers and areas, 1s described. The principal feature of the method is a data smoothing technique employing Fourier transforms. The smoothing eliminates most of the random fluctuations without effecting the spectral resolution and makes identification of maxima using a zero slope criterion possible. Using the same Fourier transform with different constants it is possible with a second transformation to improve the spectral resolution. The computer program has been written in FORTRAN IV for the M.I.T. IBM 360 model 65 computer and also for the Toshiba Electric Company G.E. 635 computer. The complete analysis of a 4096 channel spectrum containing one hundred twenty peaks requires about 75 seconds of computation time.

*Work done while on leave from Tokyo Shibaura (TOSHIBA) Electric Company, Ltd., Japan. 
TABLE OF CONTENTS

Abstract 2

Figure Captions $\quad 4$

1. Introduction 6

2. Theory 7

2.1 Data Smoothing 7

2.2 Background Subtraction 8

2.3 Resolution Improvement 9

2.4 Peak Selection and Intensity Determination 10

3. Application of Method 12

3.1 Choice of Smoothing Filter Function 12

3.2 Choice of Resolution Improvement Filter $\quad 16$ Function

3.3 Transform Algorithm 23

4. GAMANL - Description 24

5. Conclusion 28

Appendix A GAMANL List in FOURTRAN IV 29

Appendix B List of GAMANL Input $\quad 74$

Append1x C Output From GAMANL, PKANAL Subroutine 80

Appendix D Correction for System Nonlinearity 83

Appendix E Background Calculation 84

Appendix F Intensity Calculation $\quad 85$

References $\quad 86$ 
Figure Captions

Figure 1 The absolute value of the Fourler transforms for two different 4096 channel $\gamma$-ray spectra. The energy width of a channel was changed as indicated. The solid lines indicate the approximate shape of the two components of $|F(\omega)|$.

Figure 2 The smoothing filter function $P(\omega)$ showing the shape for 3 different cutoffs used for the runs plotted in Fig. 3. A Gaussian shape with a $\sigma$ of $128\left(\frac{2 \pi}{4096}\right) \mathrm{radian} / \mathrm{channel}$ is used to reduce function from unity to zero.

Figure 3 The effects of the three different filter functions of Fig. 2 on a doublet taken from the $0.971 \mathrm{keV} /$ channel data. Curve (a) is the original data, curves ( $b, c$ and $d$ ) result when filter functions (b, $c, d$ ) are used. The four curves are arbitrarily displaced by $10^{3}$ counts for clarity of presentation.

Figure 4 The Fourler transform of a single peak and an unresolved doublet from the $0.724-\mathrm{keV} / \mathrm{channel}$ spectrum.

Figure 5 The upper curve $|G(\omega)|$ is the absolute value of Fourier transform of the smoothed background subtracted data of the $0.724-\mathrm{keV} /$ channel spectrum. The lower curve $W(\omega)$ is the resolution improvement filter function used to produce Fig. $8 . I / H(\omega)$ is the inverse of the transform of a single spectral peak.

Figure 6 The observed data of an unresolved doublet from a 
Figure Captions (Continued)

4096 channel spectrum having a $0.724-\mathrm{keV}$ channel width.

Figure 7 The doublet of Fig. 6 following smoothing and background subtraction.

Figure 8 The unresolved doublet of Fig. 6 showing the effect of the Fourler transformation using the filter function $W(\omega)$ shown in Fig. 5. The small peaks on either side are spurious peaks introduced by the transformation process.

Figure 9 GAMANL Flow Diagram 
1. Introduction

This paper describes a computer code employing Fourier transforms for analyzing complex $\gamma$-ray spectra such as those obtained with a $G e(L i)$ detector, multichannel analyzer system. The code was originally developed to analyze the capture $\gamma$-ray spectra obtained with the M.I.T. triple coincidence spectrometer (1), but has since been used successfully on a variety of other spectral data. The object of the program is to automatically locate all the spectral peaks and determine their centers and areas. This problem has existed for a long time in spectroscopy and a number of methods for doing all or part of these operations have been proposed $(2,3)$. Most of them were developed for NaI spectra where the total number of peaks was small and the peaks were identified by hand. In a $G e(L i)$ spectra there are often more than a hundred peaks so it becomes important to have a fast method for automatically identifying each peak. One method for doing this described by Mariscotti (4) uses a second difference to locate the peak. Our experience with second differences indicated that they tended to obscure weak peaks. Mariscotti has handled this problem by doing a multipoint smoothing of the second difference. In the approach described below we have chosen to smooth the original data by a Fourier transform method. Although the Fourier method was found to be a quick accurate way to locate the peaks, we had no runs on similar data using the Mariscott1 code which would give a meaningful comparison of the two methods.

Section 2 of this paper describes the theory underlying the Fourier transform method. Section 3 indicates how the theory is applied to the actual data and shows typical results. Section 4 describes the computer code GAMANL. The appendices give the program list, input and partial output. 


\section{Theory}

The method described here is an improved version of one we described earlier (5). It can be divided into four steps: 1) data smoothing, 2) background subtraction, 3) resolution improvement, and 4) energy and intensity determination of the peaks.

\subsection{Data Smoothing}

The smoothing of the observed data is accomplished by a Fourier analysis technique similar to that often used to separate the signal from the noise in communication theory. In communication theory a function of time is transformed into frequency space, multiplied by an appropriate filter function and then transformed back into time space. In the present case the original data is a function of energy or more exactly a function of channel number so the transformation is into inverse channel number space. By analogy we shall call this "energy frequency space", and use the symbol $\omega$ which has units of radians/channel for the variable.

To describe the method mathematically, let the observed data $f(E)$ be represented as the sum of two components

$$
f(E)=s(E)+n(E)
$$

where $s(E)$ is the true spectral information and $n(E)$ is the noise which in this case is due principally to random fluctuations in the number of counts in a channel. The Fourler transform of $f(E)$ denoted $F(\omega)$ can be written in the usual notation as

$$
F(\omega)=\int_{-\infty}^{\infty} f(E) e^{-1 \omega E} d E
$$


or

$$
F(\omega)=S(\omega)+N(\omega)
$$

where $S(\omega)$ and $N(\omega)$ stand for the Fourier transforms of the components of $f(E)$.

The success of the method depends upon $S(\omega)$ and $N(\omega)$ being different functions so that a filter function can be chosen which will eliminate at least part of $N(\omega)$ without seriously affecting $S(\omega)$. Fortunately this is true in most spectra since the spectral peaks are spread over a number of channels and so $S(\omega)$ is made $\leftarrow$ up principally of low frequencies. The noise on the other hand is channel to channel fluctuations and so $N(\omega)$ contains many higher frequencies. Thus there will be a significant difference in $N(\omega)$ and $S(\omega)$ for cases when the spectral peaks are several or more channels wide and the method will be applicable.

Let us define the inverse transform

$$
s(E)=\frac{1}{2 \pi} \int_{-\infty}^{\infty} F(\omega) P(\omega) e^{1 \omega E} d \omega
$$

where $P(\omega)$ is the filter function and $s(E)$ will be a smoothed version of the original spectrum. The method of choosing $\mathrm{P}(\omega)$ is discussed later. For simplicity we have expressed all the transforms in their integral form; however, when the technique is applied to discrete data the transformations must be used in their discrete form.

\subsection{Background Subtraction}

In most cases the spectral peak sits on a background which must be subtracted in order to accurately determine the peak area. This background is the result of a number of processes in the source and in the detector and it often can not be expressed accurately 
analytically. We have found that to a good approximation the background can be represented as a slowly varying function which connects all the minima in the smoothed data $s(E)$. Care must be exercised in applying this definition, however, since the minima which occur in the case of partially resolved peaks must be excluded. This is accomplished by setting a maximum value for the slope of the background. When the slope connecting two successive minima exceeds this maximum value the minima is ignored and the background line is connected to the next minima which will give an acceptable slope. The smoothed background subtracted data is designated $g(E)$.

\subsection{Resolution Improvement}

In complicated spectra such as those from $(n, \gamma)$ reactions there are a number of cases where lines are only partially resolved. In order to determine the peak centers accurately, it would be helpful to have a higher energy resolution. Because of our knowledge of the response of the detector to a monoenergetic $\gamma$ ray the mathematical limit of resolution is somewhat better than the apparent limit usually expressed as the FWHM (full width of half maximum) of a peak. The detailed theory underlying this method has already been described in the literature by Inouye (6) where it was applied to NaI spectra. Here we briefly restate the results and show their applicablilty to Ge(LI) spectra as well. To understand the method let us consider Eq. 5 .

$$
g(E)=\int_{-\infty}^{\infty} h\left(E^{-}-E^{\prime}\right) f\left(E^{\prime}\right) d E^{\prime}
$$

where $g(E)$ is the smoothed background subtracted data which can be expressed analytically as the integral where $h\left(E-E^{\prime}\right)$ is the response function of the detector and $j\left(E^{\prime}\right)$ is the incident spectra which in this case may 
be considered to be a series of $\delta$ functions in energy as expressed in Eq. 6.

$$
f\left(E^{\prime}\right)=\sum_{1} A_{1} \delta\left(E^{\prime}-E_{1}\right)
$$

Since Eq. 5 is a convolution integral, its transform can be expressed as

$$
G(\omega)=H(\omega) J(\omega)
$$

Now since we can experimentally determine $g(E)$ and $h\left(E^{\prime}-E\right)$ we can calculate $G(\omega)$ and $H(\omega)$ and can therefore determine $f(E)$, the incident spectrum as shown by Eq. 8 .

$$
\begin{aligned}
f(E) & =\frac{1}{2 \pi} \int_{-\infty}^{\infty} G(\omega) / H(\omega) e^{I \omega E} d \omega \\
& =\frac{1}{2 \pi} \int_{-\infty}^{\infty} G(\omega) W(\omega) e^{i \omega E} d \omega
\end{aligned}
$$

where $W(\omega)=\frac{1}{H(\omega)}$ is the resolution improvement filter function. The problem in practice is that $g(E)$ has some noise in it since the smoothing processes eliminate only part of noise $n(E)$ and the background subtraction also introduces some error. Thus there is no function $W(\omega)$ which will exactly reproduce the input $\delta$ functions. Nevertheless, as will be evident in the next section, it is possible to obtain a significant increase in the apparent resolution using this procedure. The principal thing which limits this procedure is the statistical accuracy of the original data.

$\Longrightarrow 2.4$ Peak Selection and Intensity Determination

The peak selection is accomplished by identifying each maximum in the smoothed background subtracted data $g(E)$. The peak center is obtained by finding the point of 
zero slope of a 2nd order fit to the top of the peak. The accuracy of this procedure was checked by comparing the results for a number of peaks to those obtained by finding the centrold of a Gaussian which had been fit to the peak by a least squares method. The results agreed within \pm 0.1 channels on peaks with a $\sigma=1.5$ channels. In terms of energy this was an accuracy of about $\pm 0.2 \mathrm{keV}$ and was considerably better than the overall reproducibility of about $0.7 \mathrm{keV}$ of typical runs. However, where greater accuracy is required more sophisticated peak fitting methods (e.g., Ref. (3)) can be used. The peak center in channel number is converted to energy using calibration lines of known energy and a correction is made for the small nonlinearities of the system.

To determine the intensity of a $\gamma$ ray it is necessary to know the peak area and both the intrinsic and geometric efficiency of the system. In addition, in the capture $\gamma$-ray work it was desired to convert this intensity into the number of $\gamma$ rays per 100 captures. The number of captures was calculated by the code using a measured incident flux and the known cross section.

The area under a spectral peak was determined by two different methods. The first method simply added up all the counts between successive zeros in the smoothed background subtracted data. As noted earlier, cases of doublets and triplets were identified and treated separately. In a majority of the cases this method worked very well. However, $\rightarrow$ occasionally a peak will have a small bump in its tail that is not picked up by the doublet identification method. When this happens in small peaks it can lead to a large error in peak area. To check this a second method of peak area determination developed by Hamaw1 ( 7 ) was added to the program.

The second method takes advantage of the fact that we know that spectral peaks are very nearly true Gaussians, and further, from a careful study of strong isolated peaks in the spectrum, the standard deviation as a function of energy can be determined. The peak area is then determined by 
finding the peak center as before. Using the height of the peak and its standard deviation, the area is calculated.

3. Application of Method

\subsection{Choice of Smoothing Filter Function}

To determine the proper smoothing filter function it is useful to plot $|F(\omega)|$ vs. $\omega$. Such a plot for two typical 4096 channel spectra are shown in Fig. 1. The actual transformation used gives one $\omega$ point for each energy point. For clarity of presentation we have actually plotted only every fiftieth point in $\omega$ space. The $x^{\prime}$ 's represent a run where the gain was adjusted to produce a channel width of 0.971 $\mathrm{keV}$. The circles represent a lower gain which gave a 2.063$\mathrm{keV}$ channel spacing. The approximate shape of the components of $F(\omega)$ are shown as the solid lines. As expected in the $0.971-k e V$ run where the peaks contain more channels the signal component $S(\omega)$ contains less high frequencies. The filter function must be of a form that passes frequencies below the break in the curve but eliminates those frequencies above the break where the noise component $N(\omega)$ dominates. A filter function shape that was found to work well is shown in Fig. 2. The three different curves represent functions with different cutoffs. A Gaussian shape used to reduce the curve from unity to zero has a $\sigma=128$. It is important that the filter function be a smoothly varying function in order that oscillations not be introduced in the inverse transformation. To illustrate the effect of changing the cutoff frequency that data used to obtain the $0.971 \mathrm{keV} / \mathrm{channel}$ curve of Fig. 1 was processed using the three different filter functions shown in Fig. 2. A portion of the 4096 channel spectrum showing the effect of each of these filter functions on a doublet is shown in Fig. 3. The cutoff that begins at $412\left(\frac{2 \pi}{4096}\right) \mathrm{rad} / \mathrm{channel}$ is the one predicted from Fig. I and it produces considerable smoothing action without decreasing the peak to valley ratio in the doublet. For clarity the curves were arbitrarily shifted by 1000 counts/ 


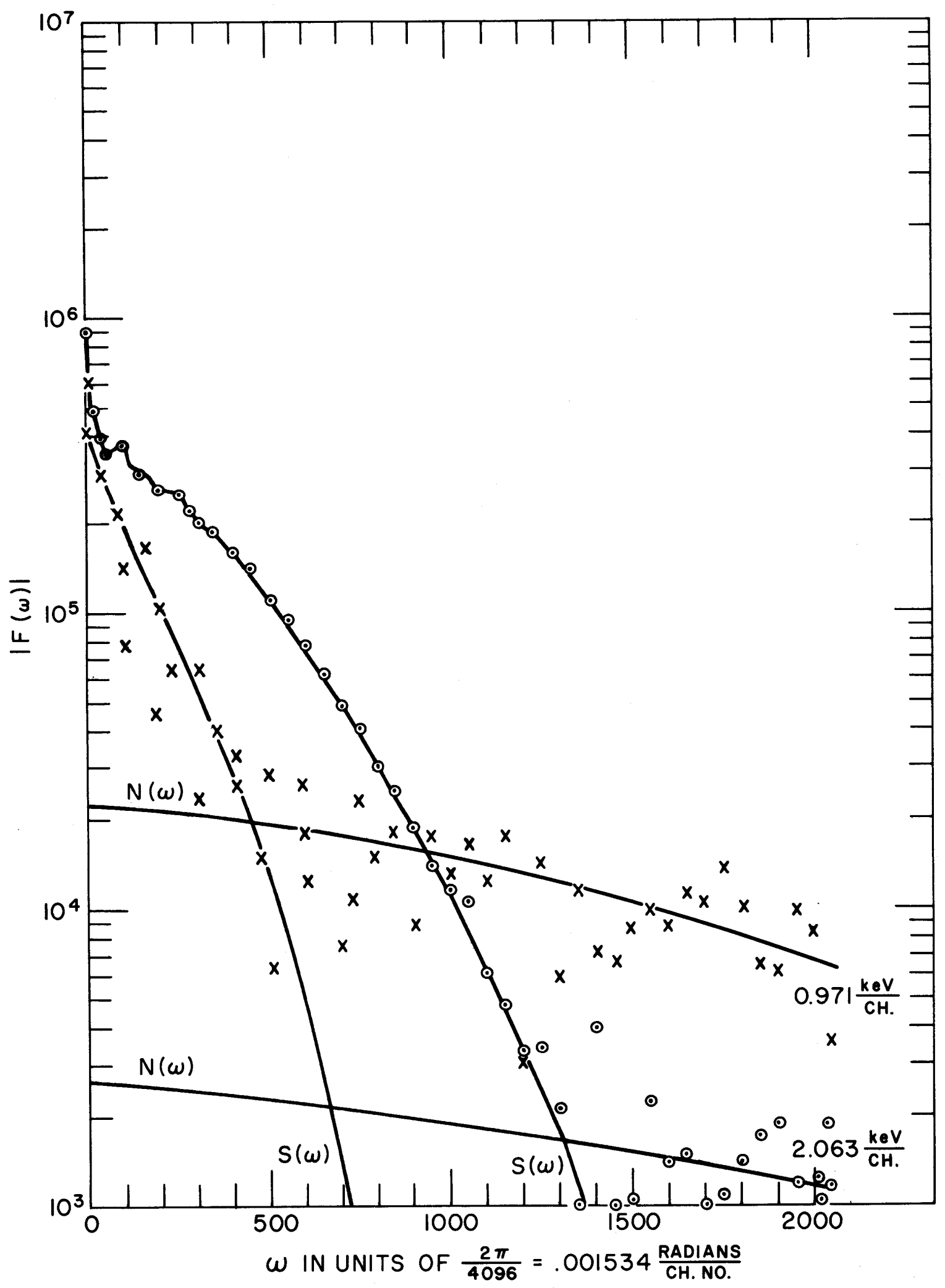

Figure 1 


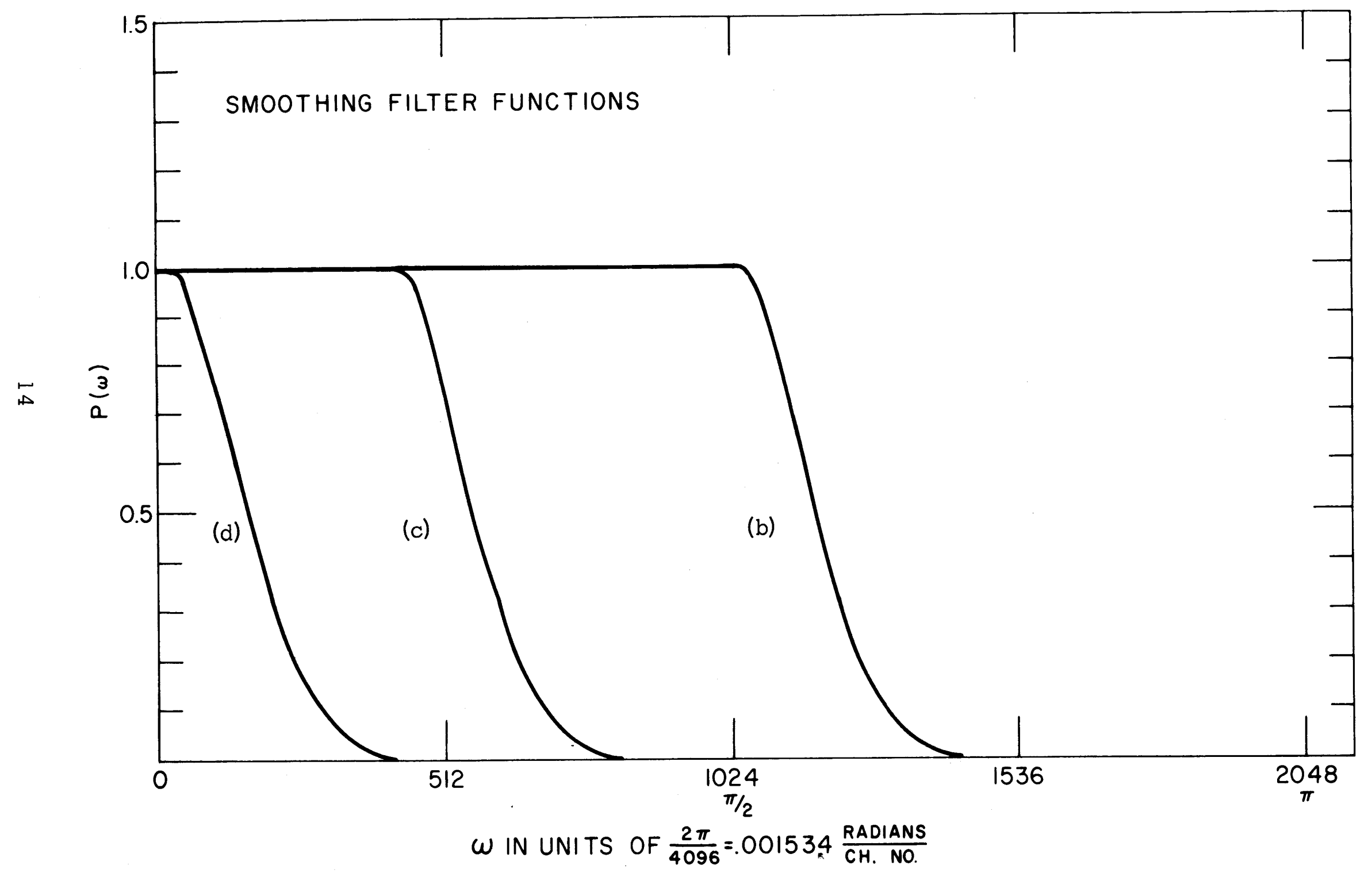

Figure 2 


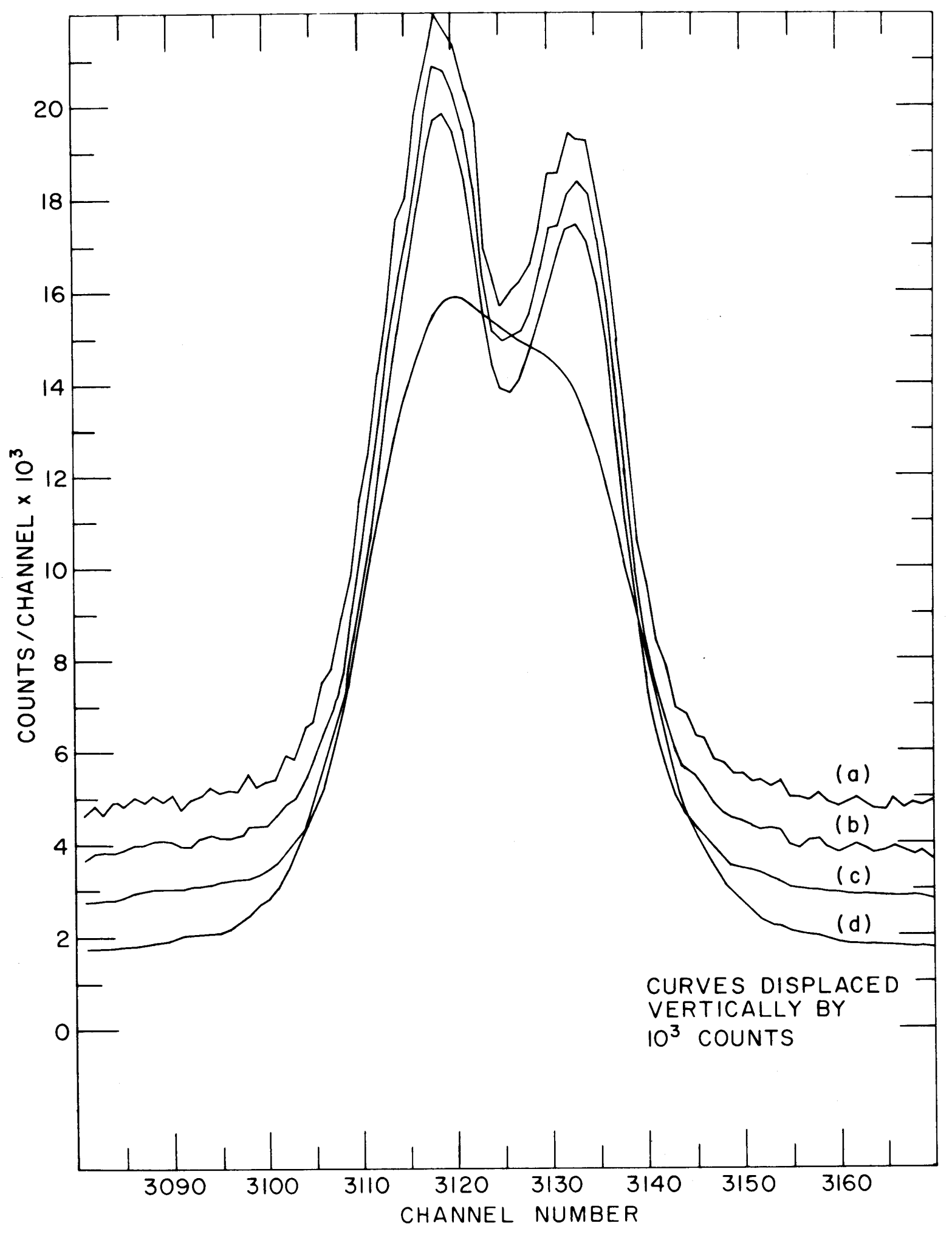

Figure 3 
channel. Careful analysis also revealed that the peak centers were not shifted by the smoothing process. In addition the smoothing action is rather insensitive to both the location of the cutoff and $\sigma$ of the Gaussian. Variations of 10 to $15 \%$ in elther of these quantities gave appreciably the same results. Thus the same filter function can be used on all runs of approximately the same gain. As expected the function with the higher cutoff does not produce as much smoothing and the very low cutoff produces so much smoothing that considerable spectral information is lost.

\subsection{Choice of Resolution Improvement Filter Function}

According to the theory discussed above $W(\omega)=1 / H(\omega)$ where $H(\omega)$ is the transform of the response of the system to a unit $\delta$ function input. The $H(\omega)$ can be determined by carefully analyzing the response of the system to a single $\gamma$ ray. Flgure 4 shows the transformation for a large single peak and also for an unresolved doublet. The case of the unresolved doublet will be discussed later. The function $1 / \mathrm{H}(\omega)$

is obtalned using the normalized $A \cdot H(\omega)$. In Figure 5 the normalized function $1 / H(\omega)$ is plotted for the singlet shown in Fig. 4. The function $|G(\omega)|$ is the transform of the smoothed data for the entire spectrum from which the single line was taken. Its cutoff is different from the previous examples because the gain for this run was set to give $0.724 \mathrm{keV} /$ channel.

Although the theory predicts that $1 / H(\omega)$ is the best filter function to use, in practice this is not the case because of the noise. As can be seen the function $1 / H(\omega)$ increases without limit as the frequency increases. This would create no problem in the absence of nolse since the signal tends toward zero equally rapidly but when the noise is multiplied by this very large value it produces many artificial peaks when the inverse transform is carried out. To eliminate this problem we have found that it is necessary 


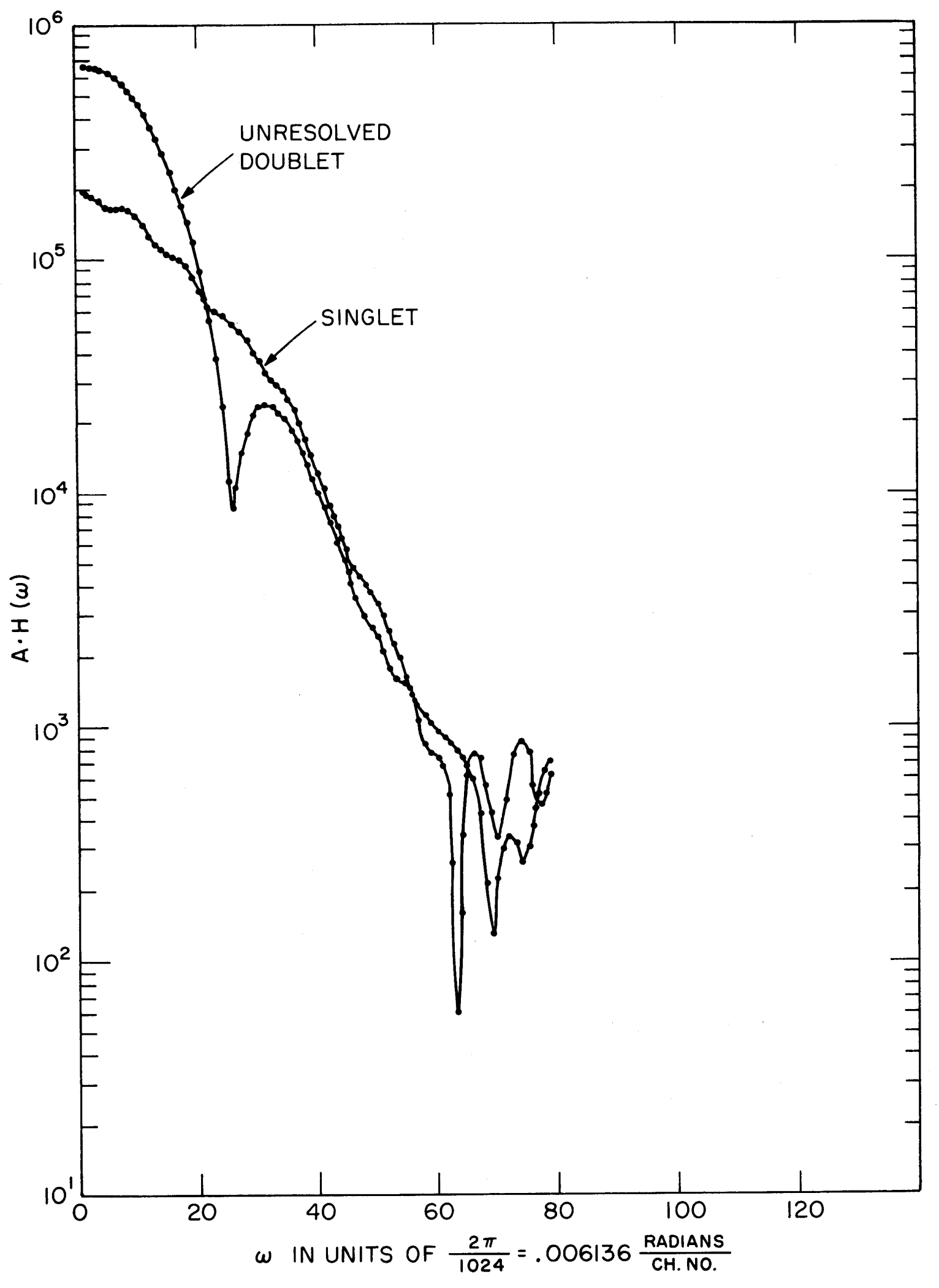

Figure 4 


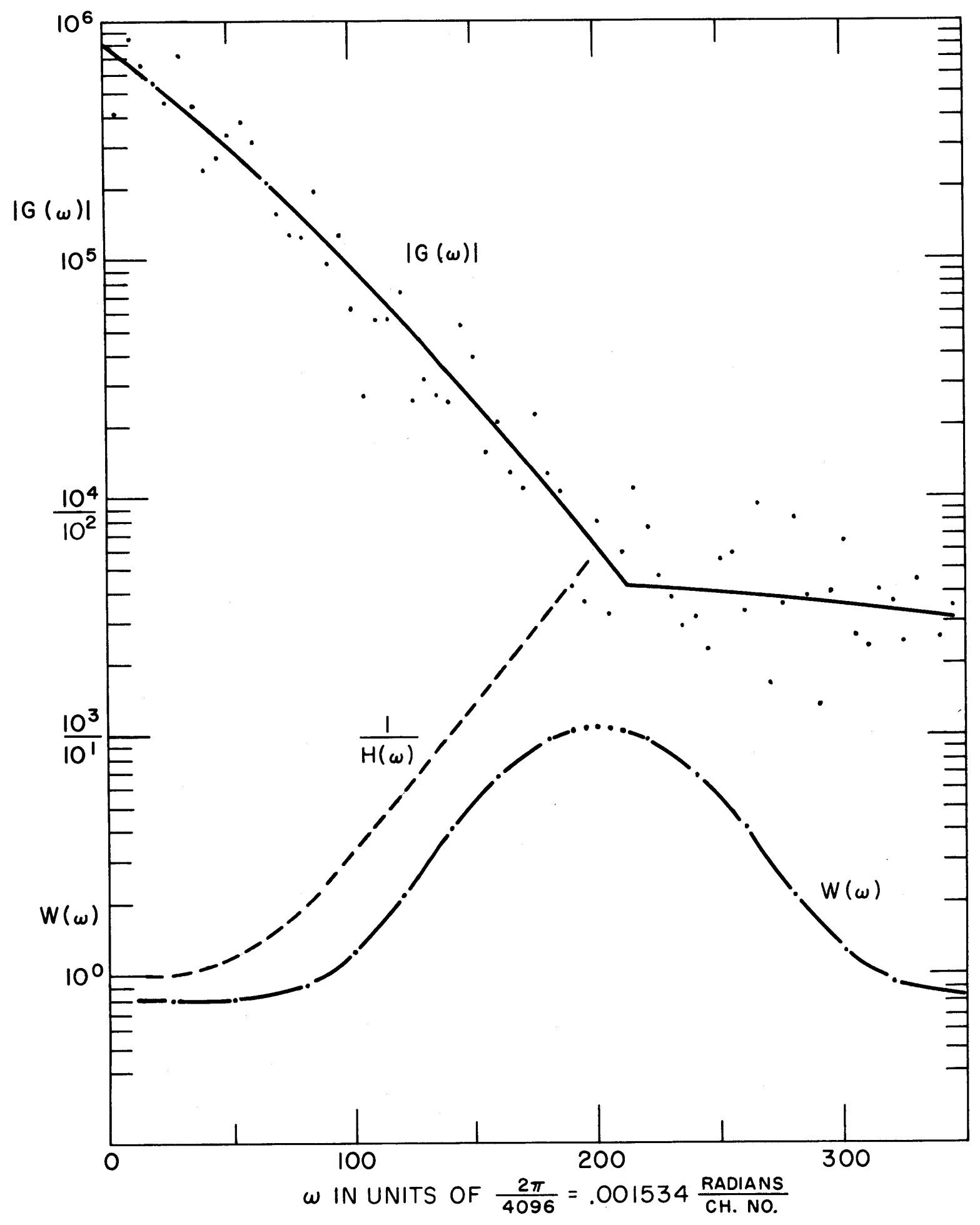

Figure 5 
that $1 / H(\omega)$ return to zero at frequencles above the cutoff in $G(\omega)$. By trial and error it has been found that a Gaussian plus a constant is a very satisfactory function for accomplishing the desired result. This function has four adjustable parameters: the center, amplitude, standard deviation of the Gaussian and the constant, all of which must be optimized for the data being analyzed. Once this is done for runs of a given gain it works equally well for subsequent runs at approximately the same gain.

In order to demonstrate the method the doublet of Fig. 3 was recorded under conditions which produced a much worse energy resolution in the system. The original data from this run in the region of the doublet are shown in Fig. 6. Figure 7 shows the results of smoothing and background subtraction as described above. The curve marked $|G(\omega)|$ in Fig. 5 is the transform of the smoothed background subtracted data. This was multiplied by the function $W(\omega)$ and the inverse transformation produced the doublet shown in Fig. 8 . Note that although a dramatic increase in resolution is possible the process introduces small fictitious peaks on either side of the doublet. The result is that the technigue is fine for examining a specific doublet to determine its components but it cannot be applied in this drastic a manner to the entire spectrum without introducing a number of small spurious peaks which will interfere with the identification of real, small peaks. In addition the area under a peak is sometimes changed by a spurious peak from a nearby true peak. In practice, therefore, all peaks are identified and their areas, centers and widths determined prior to the second transformation. Then those peaks with widths greater than expected are examined by the above process to locate the position of their components. The amplitude of the components is then determined by adjusting them to best fit the unresolved doublet in the smoothed data.

It has been found that if the function $W(\omega)$ is not properly chosen it can shift the position of the components 


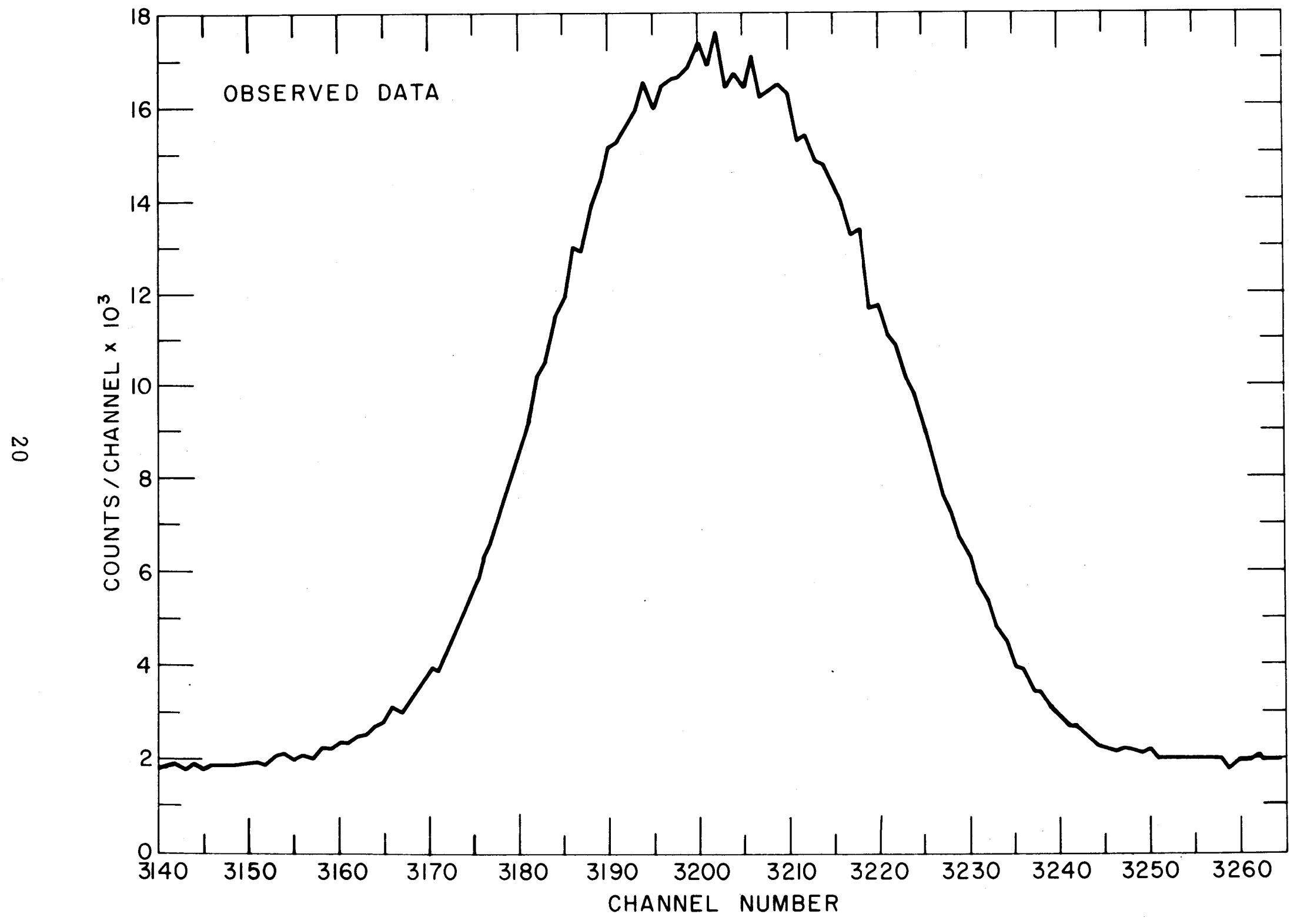

Figure 6 


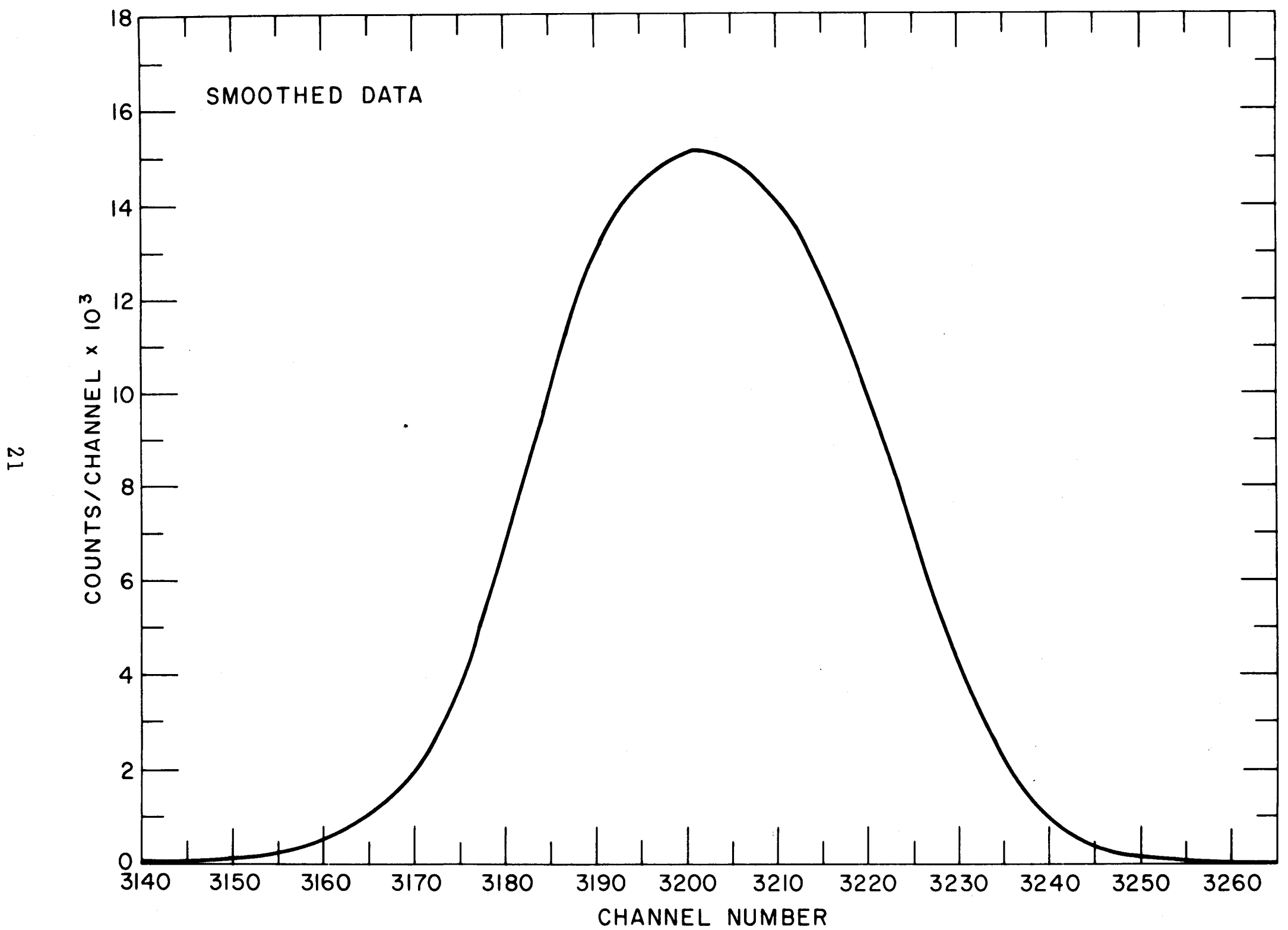

Figure 7 


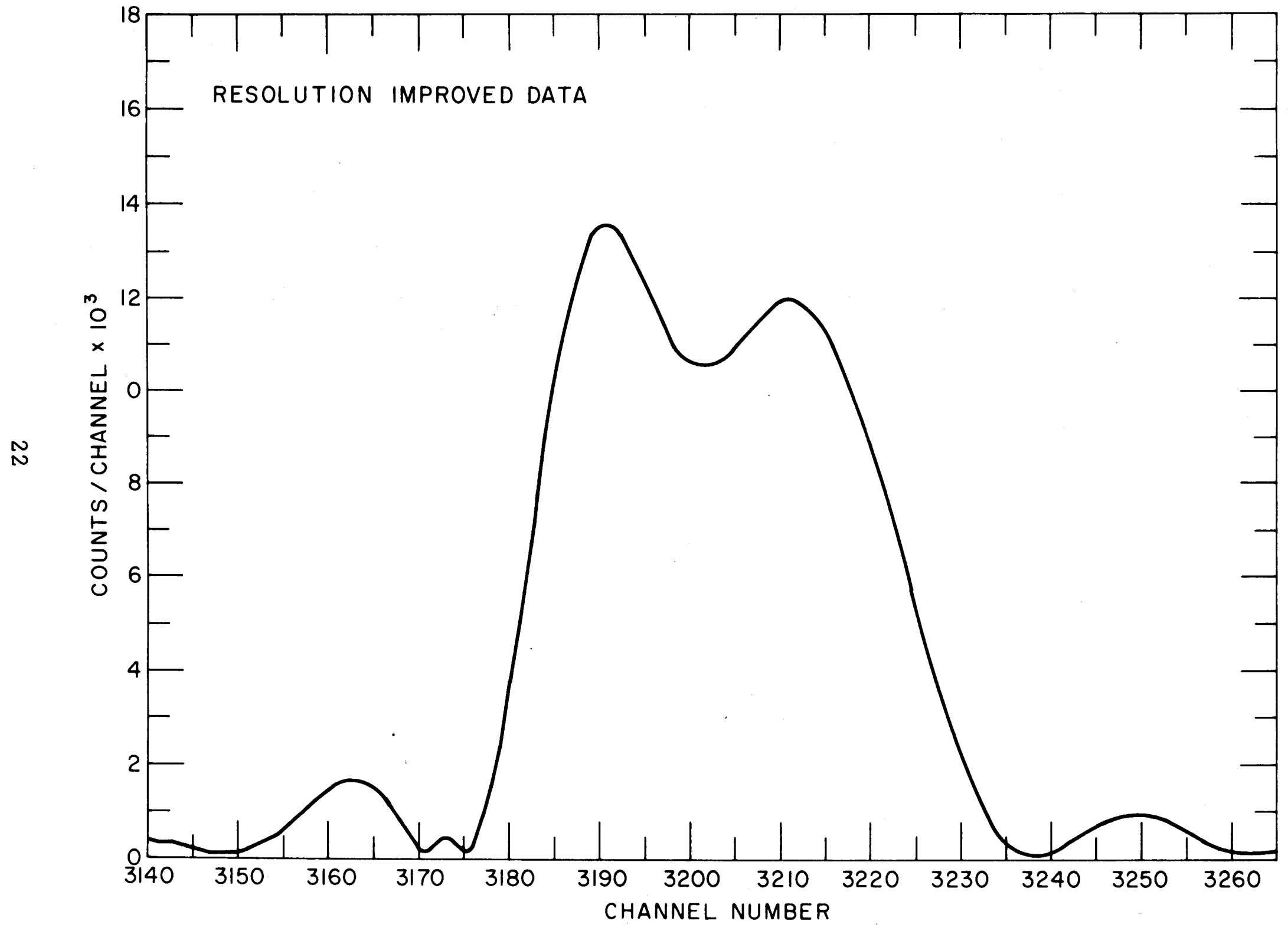

Figure 8 
by as much as 1 to 2 channels in data of the type shown here. It is necessary, therefore, to test the function prior to using it. The check that has been used consists of locating the peak centers of the single isolated peaks of the spectrum as described earlier and then performing the transformation using the proposed $w(\omega)$. If there is no resulting shift in the centers of single isolated peaks then the function is assumed to be satisfactory.

It is not always possible to know if the peak is an unresolved doublet. It is possible to check this, however, by looking at the transform of the peak in question. The transform of the unresolved doublet of Fig. 7 is shown in Fig. 4 where it is compared to a singlet peak from the same spectrum. The very noticeable minimum characteristic of doublets is explained by Inouye in Ref. 6 .

\subsection{Transform Algorithm}

A computer code, GAMANL, has been developed for carrying out the gamma spectra analysis discussed above and is described in Section 4. One of the problems encountered with the use of the Fourier Transform equations in their usual form is that $\mathrm{N}^{2}$ computation operations are required where $N$ is the number of points in energy space, i.e. the number of channels in the spectrum. This means that for $\mathrm{N}=4096$ the computing time becomes quite long, being on the order of $1 / 2$ hour. Two methods have been used to greatly reduce this computation time. The first method used was to section the data into $\mathrm{n}$ smaller segments and to take the transform of each segment separately. This results in $\mathrm{n}\left(\frac{N}{n}\right)^{2}$ operations and reduces the computation time by a factor of $\frac{1}{n}$. For a section length of 16 channels flanked by 10 and 11 channels on each side to correct for end effects, the sectioning method for $\mathrm{N}=4096$ channels required $256(37)^{2}$ operations or time reduction of a factor of $\frac{256(37) 2}{(4096)^{2}} \simeq \frac{1}{210}$ as compared to the direct method. 
The second method used the Fast Fourier Transform (FFT) as developed by Cooley and Tukey (8). The time required by the FFT to transform $N$ energy points is $N\left(\log _{2} N\right)$, which reduces the computation time by a factor of $\log _{2} \mathrm{~N} / \mathrm{N}$ as compared with the usual transformation. Thus for a 4096 channel spectra the time used by the FFT is $\log _{2} 4096 / 4096=1 / 256$ of the direct transform. In addition it gives a complete set of Fourier coefficients in $\omega$ space useful in the filter function determination. The sectioning does not give these coeficlents in as convenient a form.

4. GAMANL - Description

The block diagram of GAMANL is given in Fig. 9. The program described here uses the FFT method of carrying out the transformation. The data for calculating the linearity of the multichannel analyzer system is read in first and calculated using subroutine IINEAR. A description of this subroutine is given in Appendix $D$. These correction factors are stored in the CNTR and CORR array. They are used later in determining the energy of a gamma peak.

The Smoothing and Improved Resolution parameters are then read in along with the efficiency data, run parameters and the gamma spectra input data. The spectra data is printed out and the smoothing filter function (determined by the input parameters) is calculated.

The data is smoothed by the use of the CTFFT subroutine. The Fast Fourier Transform is carried out by FOURT, a subroutine supplied by the MIT Computation Center and written by N. Brenner (9). Subroutine CTFFT performs the actual filtering of the data in which FOURT is used twice, once for the direct transform and again for the inverse transform after the data has been multiplied by the smoothing filter function. The magnitude of the Fourier coefficients in $\omega$ space are also printed out in CTFFT. 


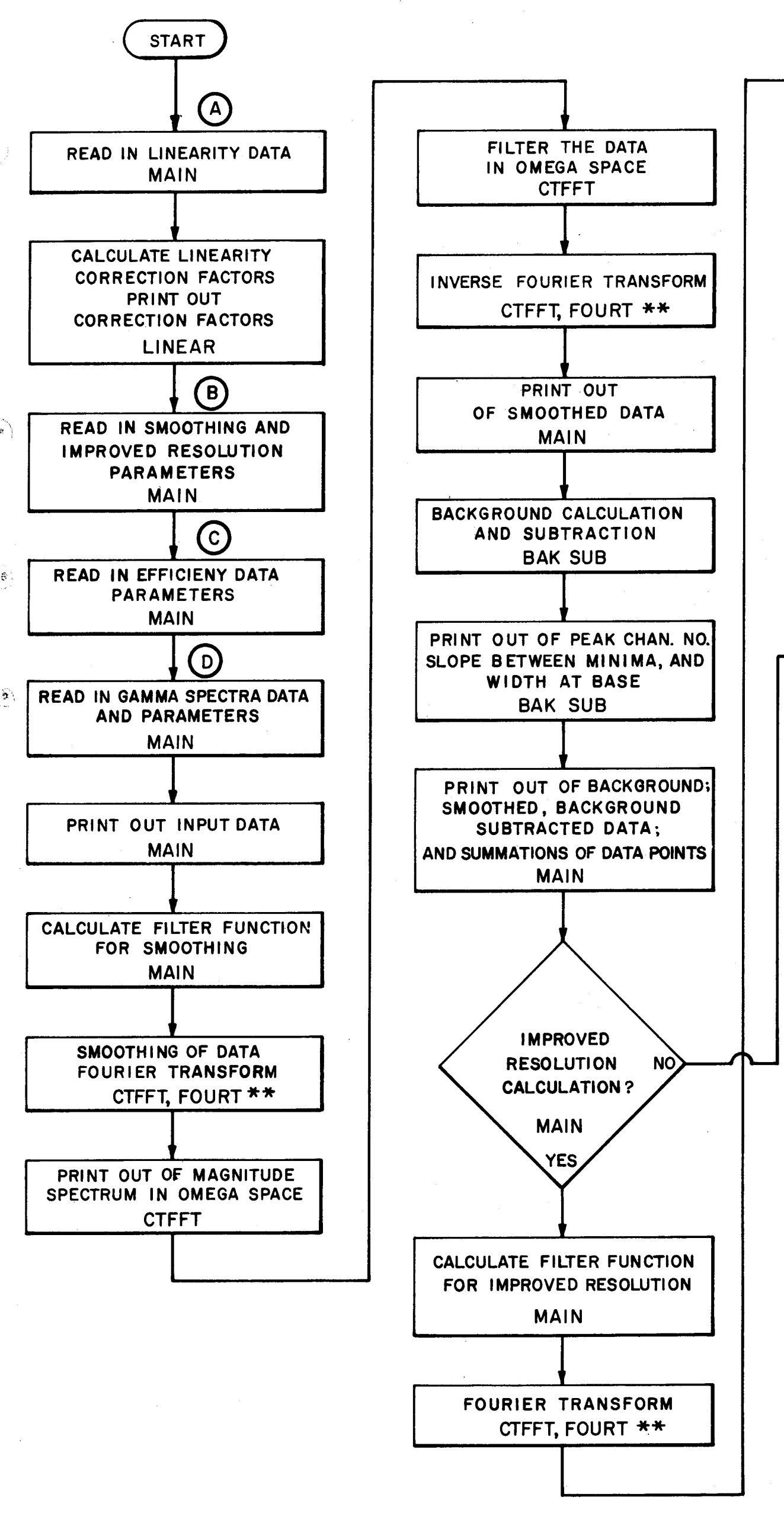

25

GAMANL FLOW DIAGRAM

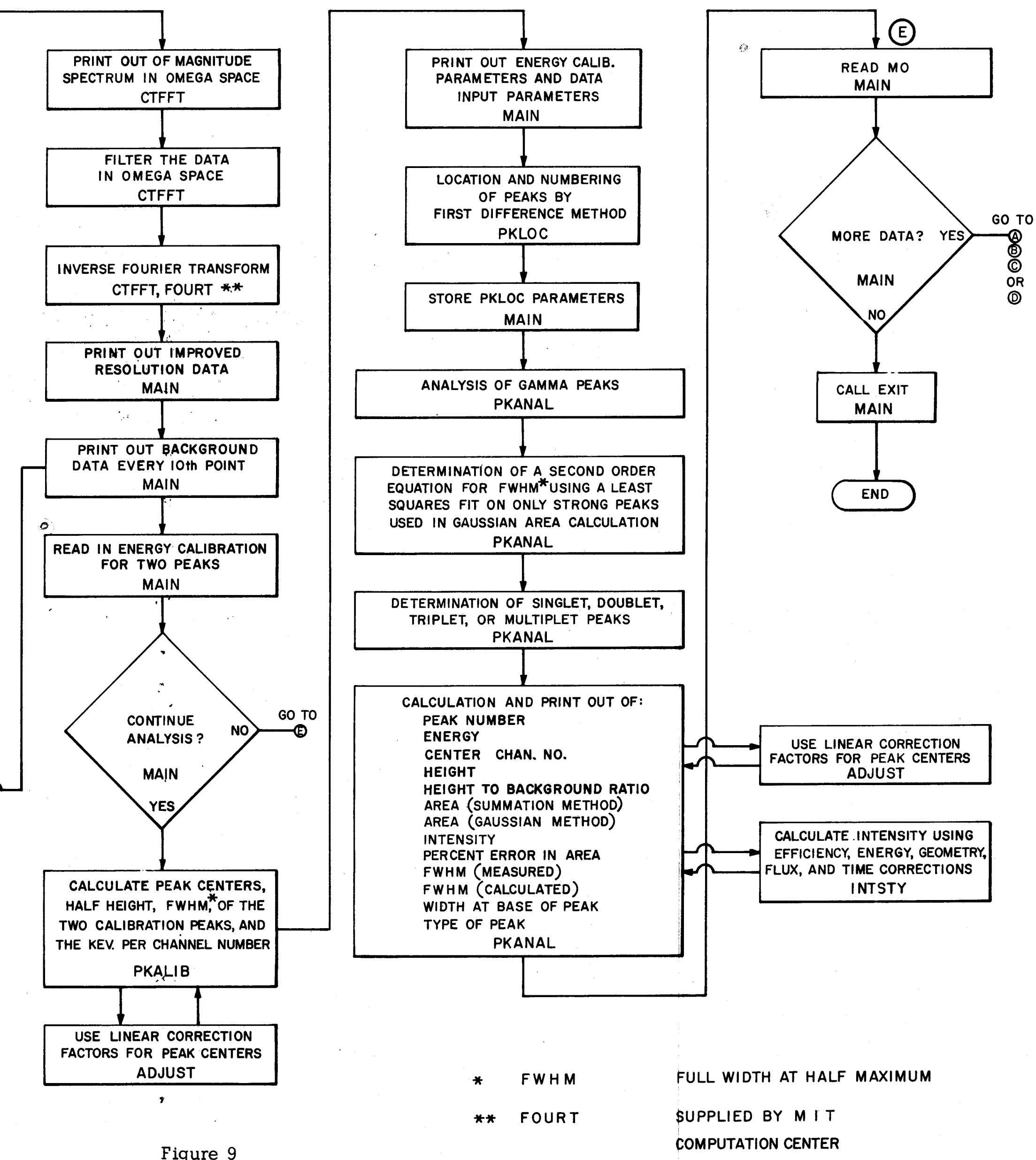


Upon return to the MAIN program the smoothed data is printed out and the background calculation and subtraction are carried out in subroutine BAKSUB, described in Appendix E.

Returning to the MAIN program the background and the smoothed, background-subtracted data are printed out. If no improved resolution is performed the program skips to the printing out of the background for every $10^{\text {th }}$ point. This is done so as to be able to use the array storing the background, TBL, for other purposes such as storing. the peak parameters. in PKANAL.

If improved resolution is carried out, the improved resolution filter function is calculated using the input parameters. The Fourler Transform of the smoothed, background-subtracted data is calculated using CTFFT and FOURT. The magnitudes of the Fourier Coefficients are printed out. The data in $\omega$ space is filtered using the improved resolution filter function. The inverse Fourier Transform is carried out by FOURT and CTFFT. Returning to the MAIN program the improved resolution, background-subtracted, smoothed data is printed out along with the background for every $10^{\text {th }}$ point.

The energy calibration data for two peaks is read in; If the analysis is to be stopped the program transfers to the end of MAIN and stops. If the analysis is to continue subroutine PKALIB is called and the peak center, height and variance of the two energy calibration peaks are calculated. The linearity correction factors as calculated in LINEAR are used in subroutine ADJUST to calculate the corrected peak centers for the calibration lines. From the two calibration peaks the linear relation between channel number (corrected for linearity) and energy is determined. The calculated calibration data and other data parameters are printed out and subroutine PKLOC is called. PKLOC locates and numbers the peaks using a first difference calculation; and prints out the number of peaks in the 
spectra.

Subroutine PKANAL performs the analysis of the spectral peaks. It is broken into two main parts. The first of which is the determination of a second order equation to determine the full width at half-maximum, FWHM, as a function of energy (channel number). A least squares fit is used using only the strong peaks of the spectra. From the equation so determined the FWHM of any peak can be calculated. It is this FWHM that is used in the Gaussian area calculation. The second part analyzes each peak in order of increasing energy. The data from PKLOC are used to determine if the particular peak considered is in singlet, doublet, triplet, or higher multiplet form. Each case is considered separately, while in the higher multiplet case the three strongest peaks are identified and then considered as a triplet case. Certain criteria are applied to the peak being considered, namely that it must have an area error less than a specified maximum value as determined from the input data. If it satisfies this criteria then the peak number, energy, center (channel number), helght in counts, height to background ratio, area by summation method, area by Gaussian method, intensity, percent error in area by Gaussian method, FWHM measured, FWHM calculated by $2^{\text {order }}$ equation, width at base and multiplet order of peak are calculated and printed out.

The energy and peak center calculation use the linearity correction factors from LINEAR with the calculation being done in subroutine ADJUST. The intensity calculation uses the efficiency versus energy data, flux, cross section, time, and geometry corrections, and is performed by subroutine INTSTY, described in Appendix F.

After completing PKANAL the program returns to MAIN and reads a dummy variable MO. If there is more data, the program returns and reads the new data. If there is no more data the program is ended. Compilation of the entire program required 50 seconds 
on the MIT System $360 / 65$ computer. Execution of a 4096 channel data deck containing approximately 120 peaks with the improved resolution section being used, and thus requiring four transforms of 4096 channels took 74.8 seconds using the complled machine deck. The final tabular output of PKANAL of this run is shown in Appendix $C$. An input list to GAMANL is given in Appendix $B$. The program list of GAMANL in FORTRAN IV is given in Appendix $A$.

\section{Conclusion}

The above program has been used at both M.I.T. and the Central Research Laboratory of Toshiba Electric Company on a wide variety of $\gamma$-ray spectra (10). In all these applications it has been found to be a fast, accurate method for automatically locating peaks and determining their centers and areas. As noted the smoothing allows the use of approximate methods for determining peak centers and the background function without serious loss of accuracy. In some very precise applications it may be desirable to use more exact methods for this but for the spectra studied the accuracy of the approximate methods was acceptable. The program is available in FORTRAN IV. 
APPENDIX A

Iist of GAMANL, gamma analysis program, by subroutine. Subroutine FOURT was supplied by the M.I.T. Computation Center. 


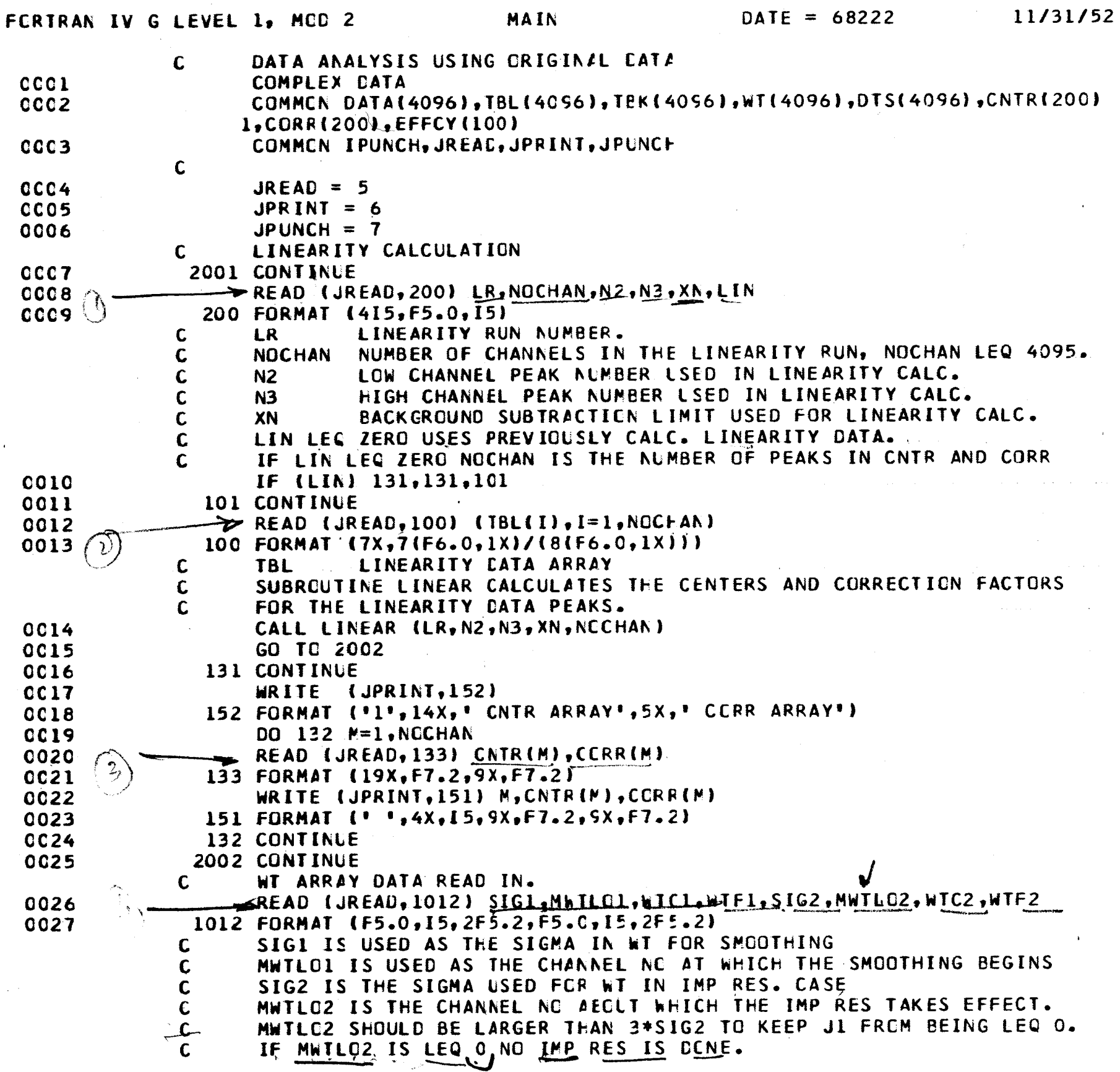




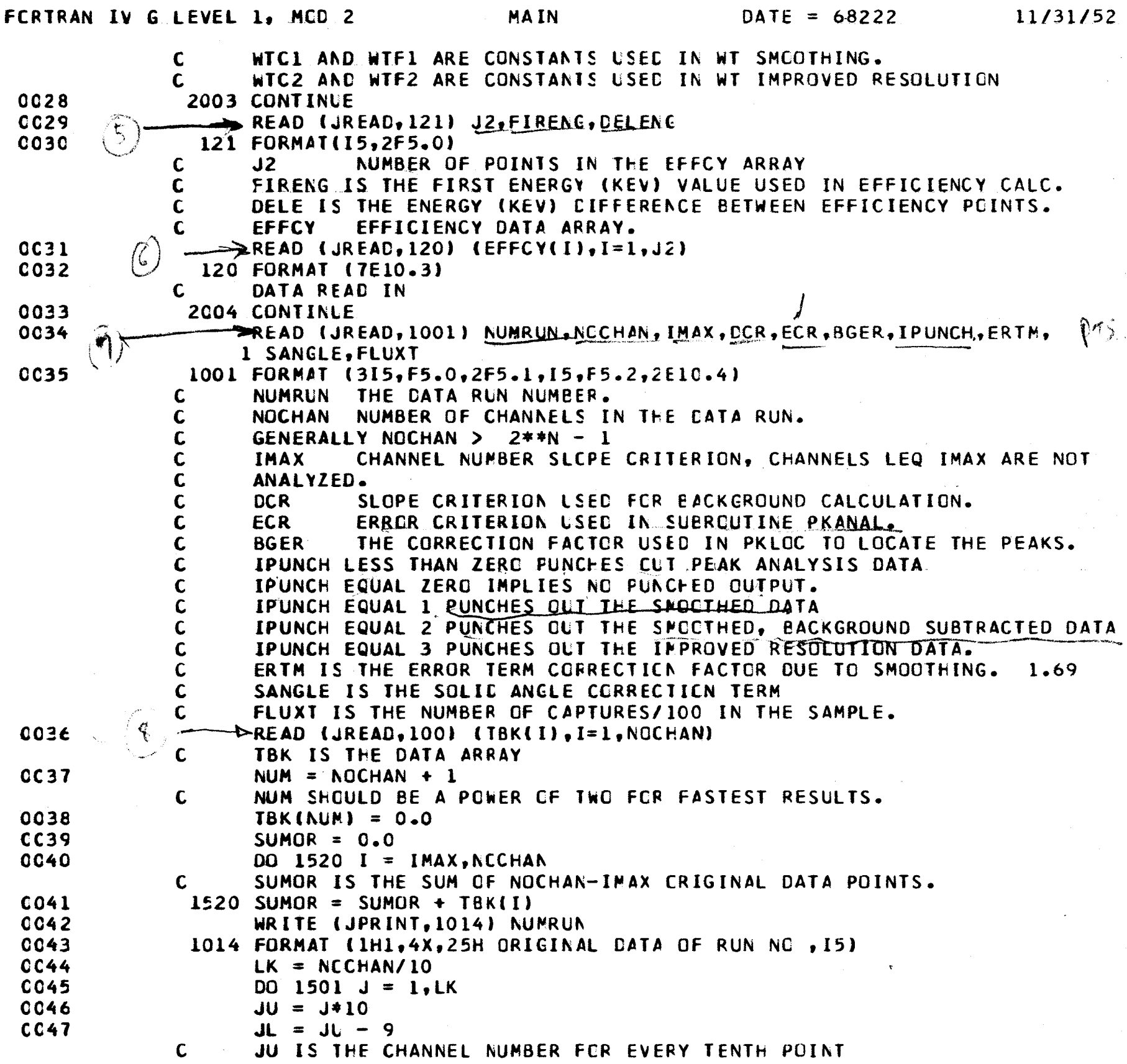




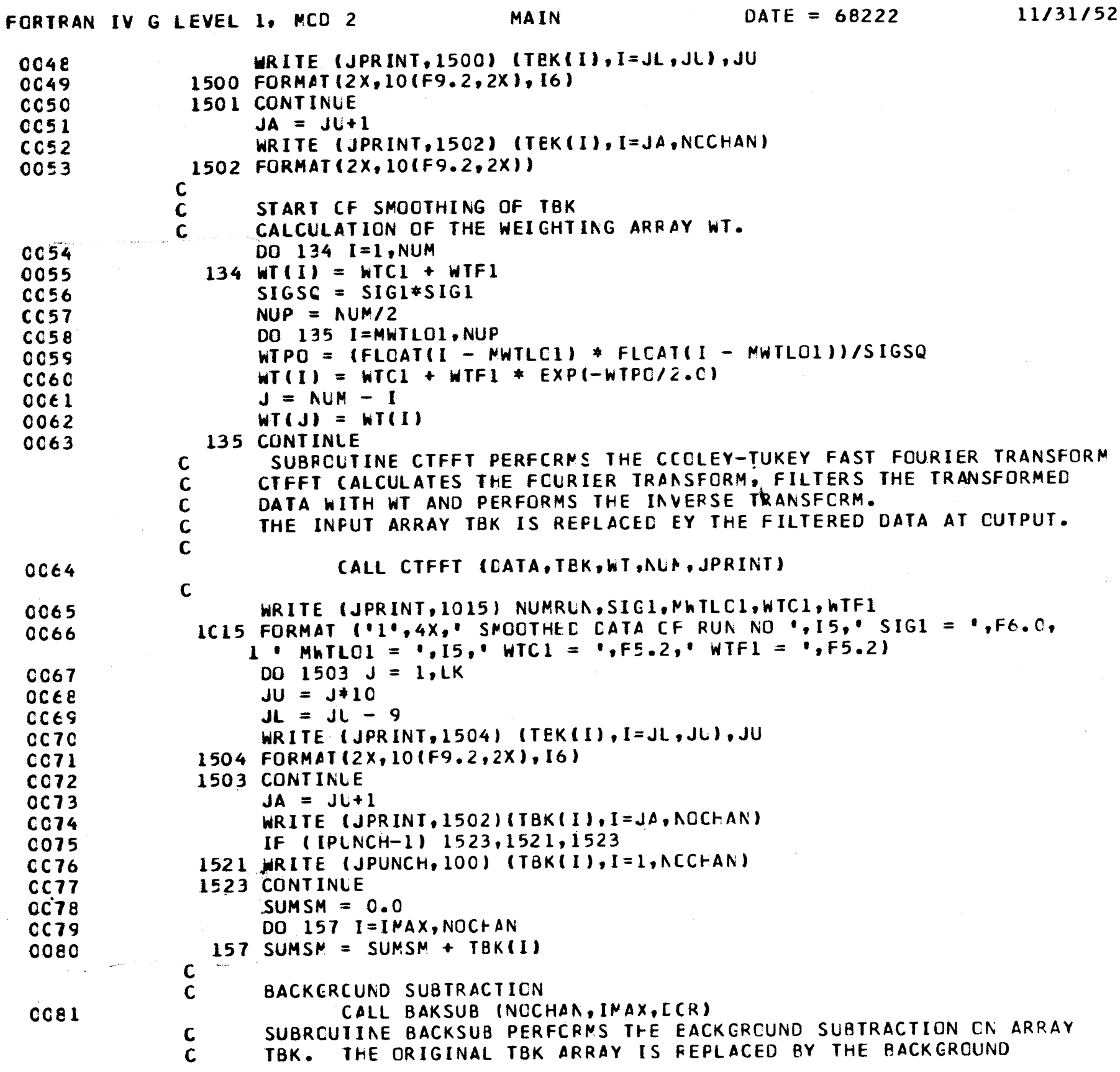

C071

c072

$0<73$

CC74

0075

CC76

CC77

Cci 8

CC79

0080

$\cos 1$

(ALL CTFFT (CATA,TEK,WT, NUP, JPRINT)

C

WRITE (JPRINT, 1015 ) NUMRUA,SIC1,NhTLC1,WTC1, WTFI

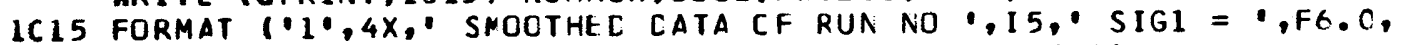

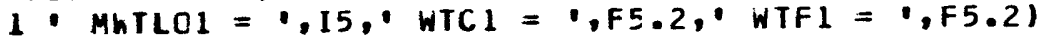

DO $1503 \mathrm{~J}=1, \mathrm{LK}$

$J U=J * 10$

$J L=J l-9$

WR I TE (JPR INT, 1504) (TEK (I),I=JL, JU),JU

1504 FORMAT $(2 x, 10(F 9,2,2 x), 16)$

1503 CONTINLE

$J A=J U+1$

WRITE (JPRINT, 1502) (TBK (I),I =JA, AOCFAN)

IF (IPLNCH-1) $1523,1521,1523$

1521 WRITE (JPUNCH,100) (TBKI I), I =1, NCCHAN)

1523 CONTINLE

SUMSM $=0.0$

DO $157 I=$ INAX, NOCHAN

157 SUMSN = SUMSM + TBK(I)

C

C BACKERCUND SUBTRACTICN

CALL BAKSUB (NCCHAN, INAX,LCR)

C SUBRCUIIAE BACKSUB PERFCRMS THE EACKGRCUND SUBTRACTION CN ARRAY

C TBK. THE ORIGINAL TBK ARRAY IS FEPLACED BY THE BACKGROUND 


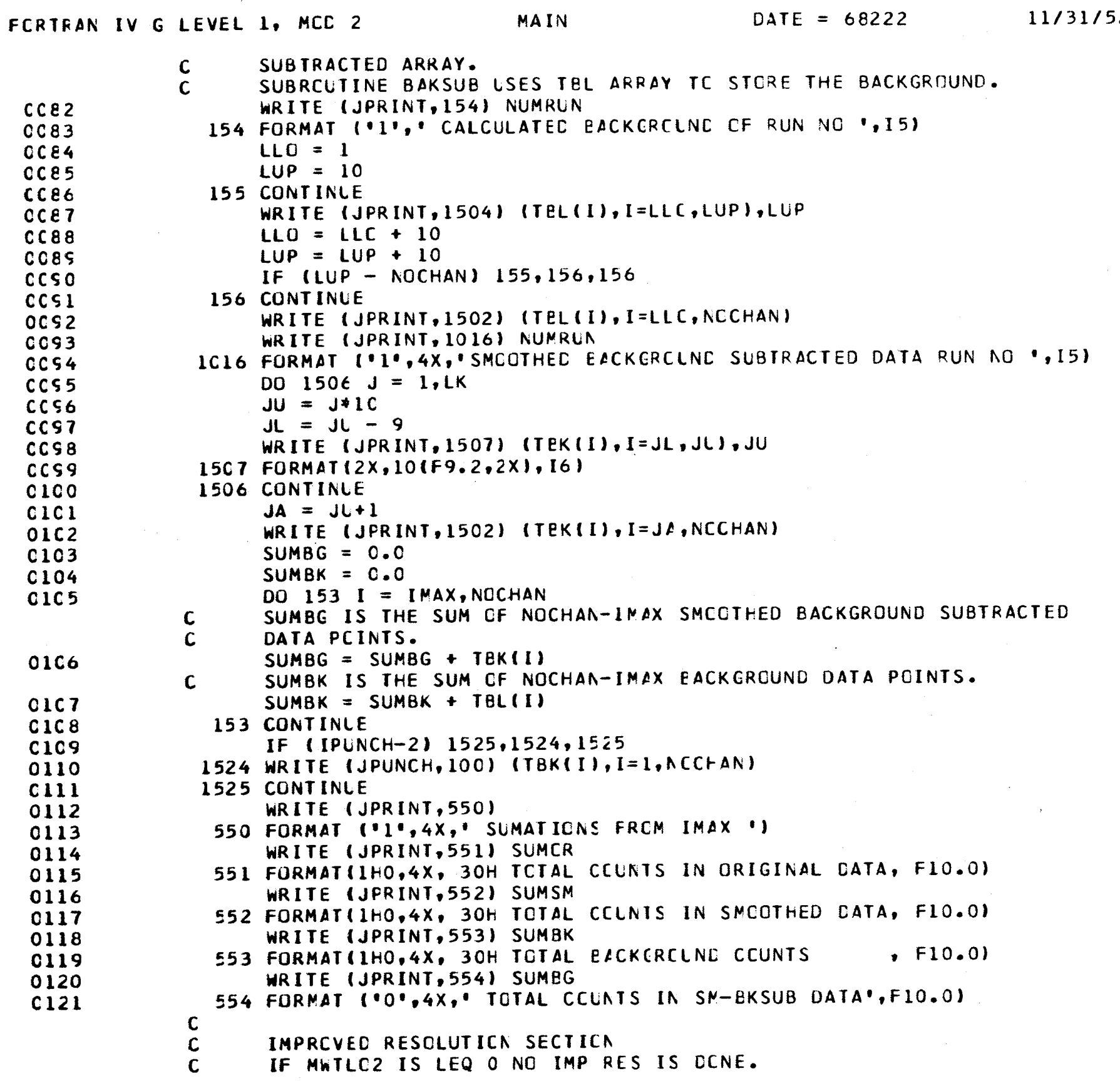




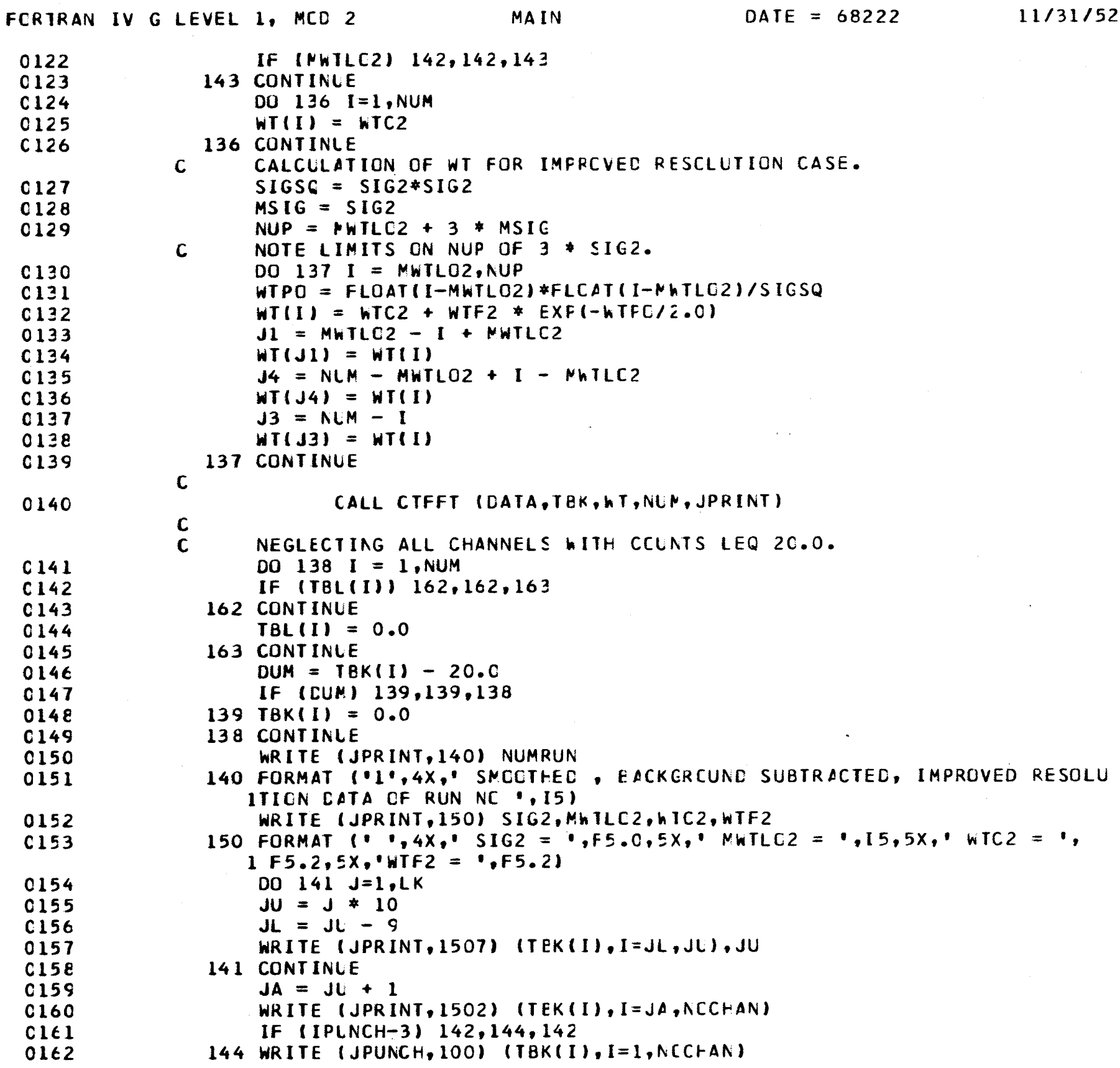




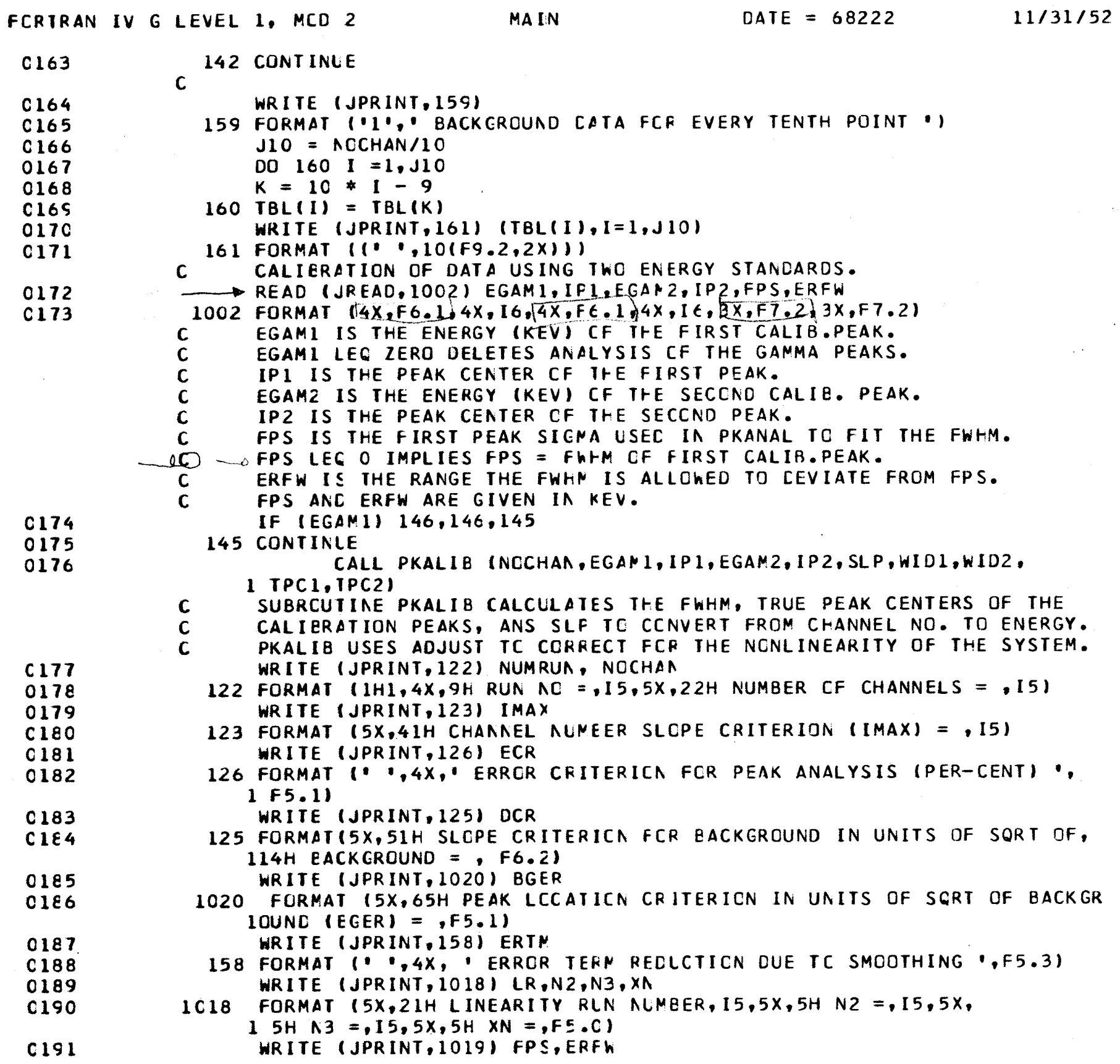

C163

C 164

C 165

C 166

0167

0168

C165

0170

0171

0172

C173

0174

0175

0176

C 177

0178

0179

C 180

C 181

0182

C 183

C $1 E 4$

0185

$01 \varepsilon 6$

0187

C 188

0189

C190

C 191

142 CONTINLE

C

WR ITE (JPRINT, 159)

159 FORMAT $1 \% 1 \%$ BACKGROUND CATA FCF EVERY TENTH POINT 1 $\mathrm{J} 10=\Lambda \mathrm{CCHAN} / 10$

DO $160 I=1, \mathrm{~J} 10$

$K=10 * I-9$

$160 \mathrm{TBL}(I)=\mathrm{TBL}(K)$

WRITE (JPRINT, 161) (TBL(I), I =1,J10)

C

161 FORMAT $(1, \cdot, 10(F 9.2,2 X)))$ CALIERATION OF DATA USING THO ENERGY STANDARDS.

READ (JREAD, 1002) EGAM 1, IF 1, EGA 2, IP 2,FPS,ERFW

1002 FORMAI $(4 X, F 6,1,4 X, 16, \sqrt{4 X, F E}, 1,4 X, I E, B X, F 7,2,3 X, F 7,2)$

C EGAMI IS THE ENERGY (KEV) CF THE FIRST CALIB.PEAK.

C EGAMI LEQ ZERO DELETES ANALYSIS CF THE GAMMA PEAKS.

C IPI IS THE PEAK CENTER CF ITE FIRST PEAK.

C EGAMZ IS THE ENERGY (KEV) CF THE SECCNO CALIE. PEAK.

C IP2 IS THE PEAK CENTER CF THE SECCND PEAK.

$C$ FPS IS THE FIRST PEAK SIGNA USEC IN PKANAL TC FIT THE FWHM.

QC $\rightarrow$ FPS LEC 0 IMPLIES FPS = FWHM CF FIRST CALIB.PEAK.

C ERFW IS THE RANGE THE FWHN IS ALLOHED TO CEVIATE FROM FPS.

C FPS ANC ERFW ARE GIVEN IN KEV.

IF (EGAMI) $146,146,145$

145 CONTINLE

CALL PKALIB INCCHAN, EGAP 1, IP1, EGAM2, IP2, SLP, WID1,WID2,

$1 T P C 1, T P C 21$

C Subrcutine pkalib calculates the fWhm, true peak centers of the

C CALIERATION PEAKS, ANS SLF TO CCNVERT FROM CHANNEL NO. TO ENERGY.

C PKALIB USES ADJUST TC CDRRECT FCR THE NCNLINEARITY OF THE SYSTEM. WR I TE (JPR INT, 122) NUMRUA, NOCHAN

122 FORMAT (IHI,4X,9H RUN $\Lambda C=, 15,5 X, 22 \mathrm{H}$ NUMBER CF CHANNELS $=$, I5) WR ITE (JPRINT, 123) IMAX

123 FORMAT (5X.41H CHANNEL NUMEER SLCPE CRITERION (IMAX) = , I5) WR ITE (JPRINT, 126) ECR

126 FORMAT $"$ " $4 X, "$ ERRGR CRITERICA FCR PEAK ANALYSIS (PER-CENT) $1 F 5.11$ WRITE (JPRINT, 125 ) DCR

125 FORMAT $(5 \times, 51 H$ SLCPE CRITERICA FCR EACKGROUND IN UNITS OF SQRT OF, $114 \mathrm{H}$ EACKGROUND $=$, F6.2) WRITE (JPRINT,1020) BGER

1020 FORMAT $15 \mathrm{X}, 65 \mathrm{H}$ PEAK LCCATICN CRITERICN IN UNITS OF SGRT OF BACKGR IOUND (EGER) $=$,F5.1) WRITE (JPRINT, 158 ) ERTN

158 FORMAT (', $4 X$, ERROR TERN REDLCTICN DUE TC SMOOTHING ',F5.3) WR ITE (JPRINT, 1018 ) LR,N2,N3,XA

1 C 18 FORMAT $15 X, 21 H$ LINEARITY RLN NLMEER, $15,5 X, 5 H \quad N 2=, 15,5 X$, $15 \mathrm{H} \wedge 3=, 15,5 X, 5 \mathrm{H} \quad X N=, F E . C)$ WRITE (JPRINT, 1019 ) FPS,ERFh 


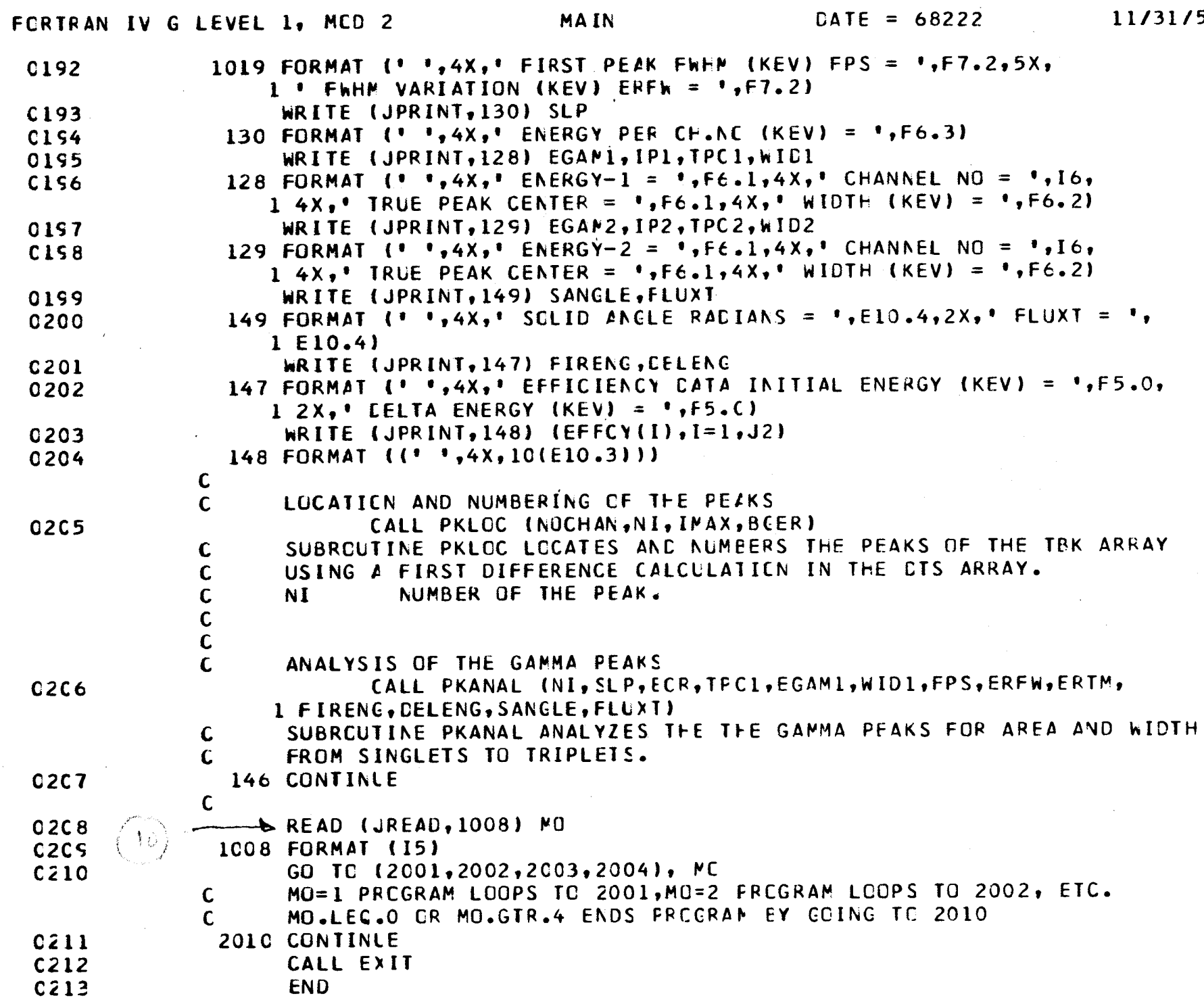




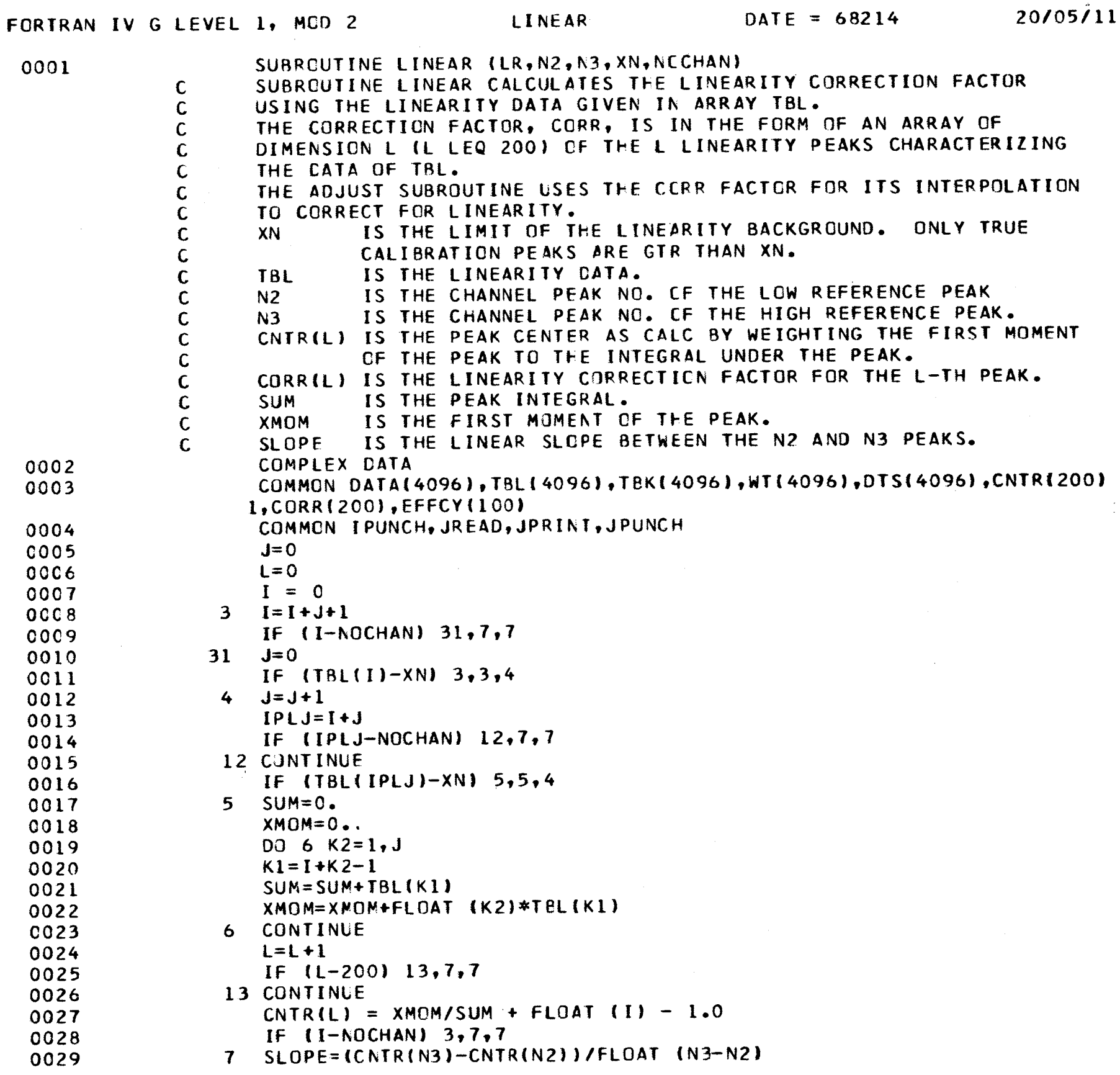




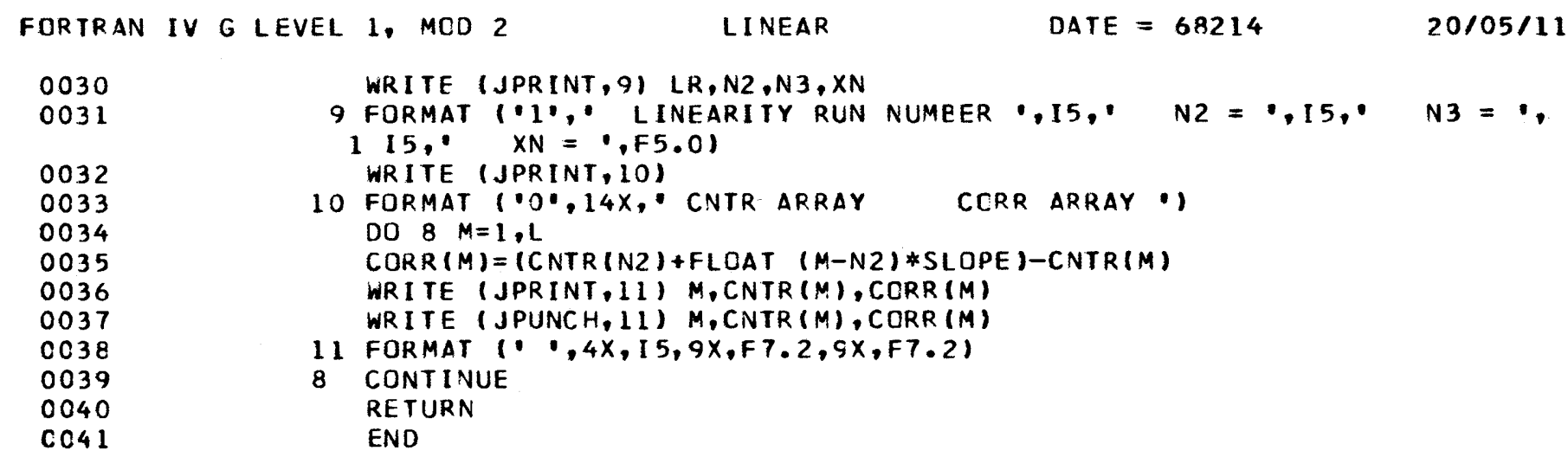




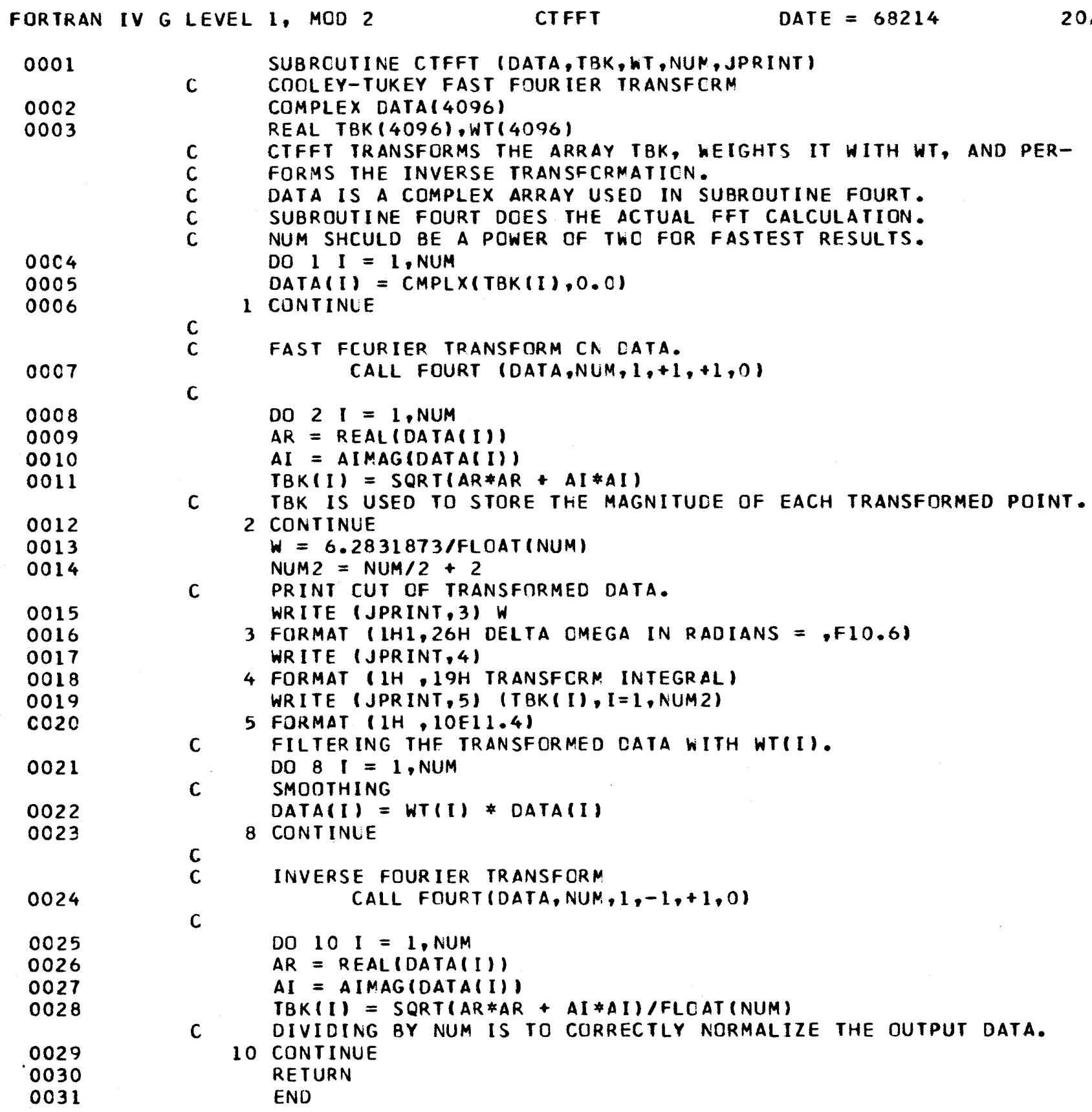

0001

0002

0003

$00 C_{4}$

0005

0006

0007

0008

0009

0010

0011

0012

0013

0014

0015

0016

0017

0018

0019

$\mathrm{CO20}$

0021

0022

0023

0024

0025

0026

0027

0028

0029

0030

0031

SUBRCUTINE CTFFT (DATA, TBK, WT, NUN, JPRINT)

C COOLEY-TUKEY FAST FOUR IER TRANSFCRM COMPLEX DATA $(4096)$ REAL TBK (4096), WT(4096)

C CTFFT TRANSFORMS THE ARRAY TBK, WEIGHTS IT WITH WT, AND PER-

C FORMS THE INVERSE TRANSFCRMATICN.

C DATA IS A COMPLEX ARRAY USED IN SUBROUTINE FOURT.

C SUBROUTINE FOURT DOES. THE ACTUAL FFT CALCULATION.

C NUM SHCULD BE A POWER OF TWD FOR FASTEST RESULTS. DO $1 I=1$, NUM DATAII $=$ CMPLX(TBK(I),0.0)

1 CONTINUE

C

FAST FCURIER TRANSFORM CN CATA.

C CALL FOURT (DATA,NUM, $1,+1,+1,0)$

DO $2 I=1$, NUM

$A R=R E A L$ (DATAII))

$A I=A I M A G$ (DATAII)

$T B K(I)=S Q R T(A R * A R+A I * A I)$

C TBK IS USED TO STORE THE MAGNITUDE OF EACH TRANSFORMED POINT. 2 CONTINUE $W=6.2831873 /$ FLOAT (NUM) NUM $2=N U M / 2+2$

C PRINT CUT OF TRANSFRRMED DATA. WR ITE (JPR INT, 3) W

3 FORMAT (1HI, 26H DELTA OMEGA IN RADIANS $=, F 10.6)$ WR ITE (JPRINT,4)

4 FORMAT (IH , 19H TRANSFCRM INTEGRAL) WRITE (JPRINT, 5) (TBK(I), I=1, NUM 2$)$

5 FORMAT (IH, 1OE 11.4 )

C FILTERING THF TRANSFORMED CATA WITH WTII). SMOOTHING DATAII) = WT(I) * DATAII)

8 CONTINLE

C

C INVERSE FOURIER TRANSFORM

C CALL FOURTI DATA, NUN, $1,-1,+1,0)$

DO $10 I=1$, NUM

$A R=$ REAL (DATA(I))

$A I=A I M A G(D A T A(I))$

TBKII $=$ SQRT (AR*AR + AI*AI)/FLCAT (NUM)

C DIVIDING BY NUM IS TO CORRECTLY NORMALIZE THE OUTPUT DATA. 10 CONTINUE

RETURN

END 


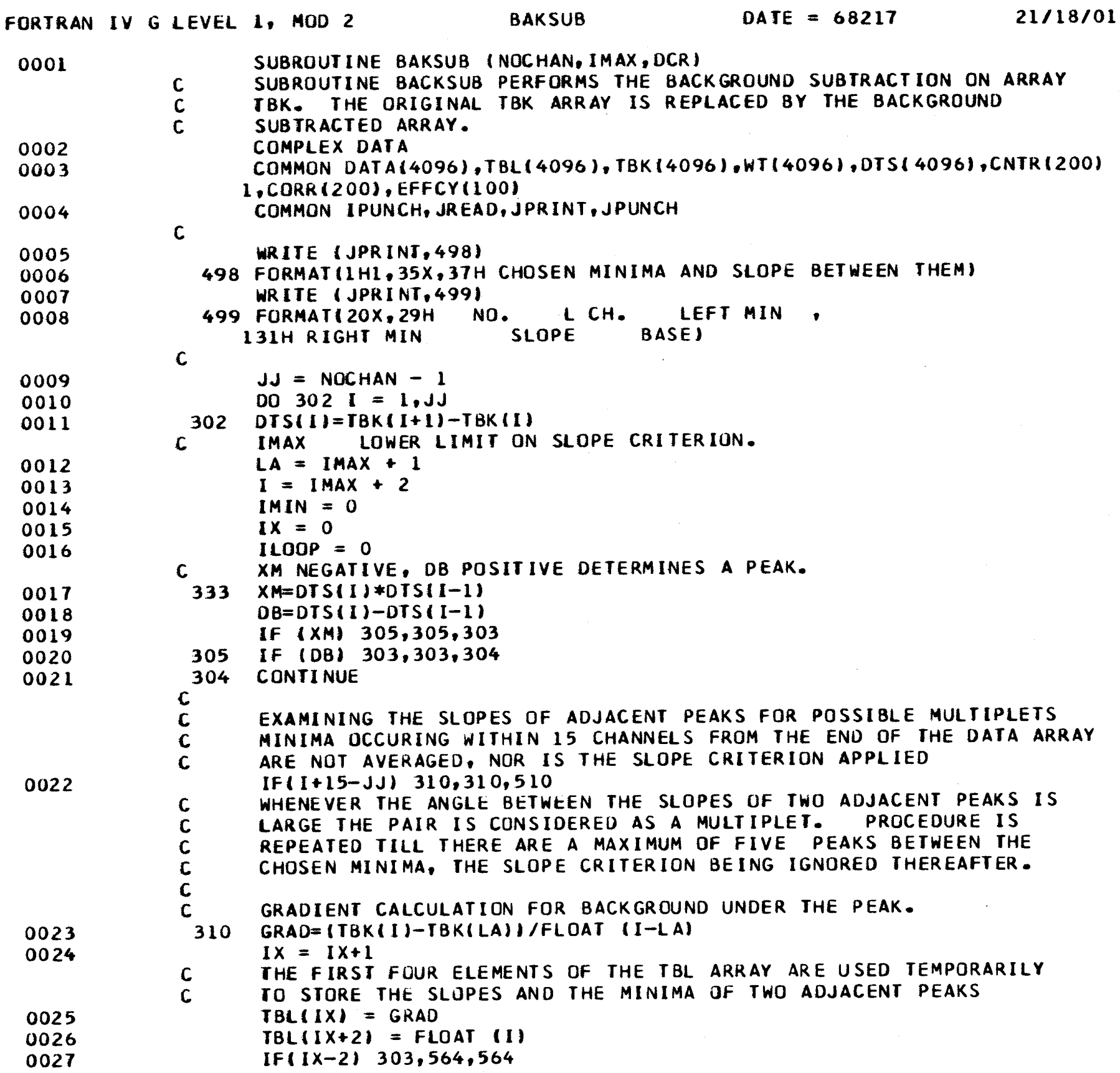

0001

0002

0003

0004

0005

0006

0007

0008

0009

0010

0011

0012

0013

0014

0015

0016

0017

0018

0019

0020

0021

0022

0023

0024

0025

0026

0027

SUBROUT INE BAKSUB (NOCHAN, IMAX, DCR)

C SUBROUTINE BACKSUB PERFORMS THE BACKGROUND SUBTRACTION ON ARRAY

C TBK. THE ORIGINAL TBK ARRAY IS REPLACED BY THE BACKGROUND

C SUBTRACTED ARRAY. COMPLEX DATA COMMON DATA(4096), TBL(4096), TBK (4096),WT(4096), DTS(4096),CNTR(200) 1. CORR (200), EFFCY $(100)$ COMMON I PUNCH, JREAD, JPRINT, JPUNCH

C

WRITE (JPR INT,498)

498 FORMAT ( 1 HI, 35X,37H CHOSEN MINIMA AND SLOPE BETWEEN THEM) WR ITE (JPRINT,499)

499 FORMATI20X,29H NO. LCH. LEFT MIN .

C 131 RIGHT MIN SLOPE BASE)

$$
J J=\text { NOCHAN }-1
$$$$
\text { DO } 302 I=1 . \mathrm{JJ}
$$

302 DTSI I $)=\operatorname{TBK}(I+1)-T B K(I)$

C IMAX LOWER LIMIT ON SLOPE CRITERION. $L A=I$ MAX +1

$I=I$ MAX +2

IMIN $=0$

$I X=0$

$I L O O P=0$

C XM NEGATIVE, DB POSITIVE DETERMINES A PEAK.

$333 \times M=D T S(I) * D T S(I-1)$

$D B=D T S(I)-D T S(I-1)$

IF (XM) $305,305,303$

305 IF (DB) $303,303,304$

304 CONTINUE

c

C EXAMINING THE SLOPES OF ADJACENT PEAKS FOR POSSIBLE MULTIPLETS

C MINIMA OCCURING WITHIN 15 CHANNELS FROM THE END OF THE DATA ARRAY

C ARE NOT AVERAGED, NOR IS THE SLOPE CRITERION APPLIED

IF (I+15-JJ) $310,310,510$

C WHENEVER THE ANGLE BETWEEN THE SLOPES OF TWO ADJACENT PEAKS IS

C LARGE THE PAIR IS CONSIDERED AS A MULTIPLET. PROCEDURE IS

C REPEATED TILL THERE ARE A MAXIMUM OF FIVE PEAKS BETWEEN THE

C CHOSEN MINIMA, THE SLOPE CRITERION BEING IGNORED THEREAFTER.

C GRADIENT CALCULATION FOR BACKGROUND UNDER IHE PEAK.

310 GRAD $=(T B K(I)-T B K(L A)) / F L O A T$ (I-LA)

$I X=I X+1$

C THE FIRST FOUR ELEMENTS OF THE TBL ARRAY ARE USED TEMPORARILY

C IO STORE THE SLUPES AND THE MINIMA OF TWO ADJACENT PEAKS

$T B L(I X)=$ GRAD

TBL $(I X+2)=$ FLOAT (I)

IF $(I X-2) \quad 303,564,564$ 


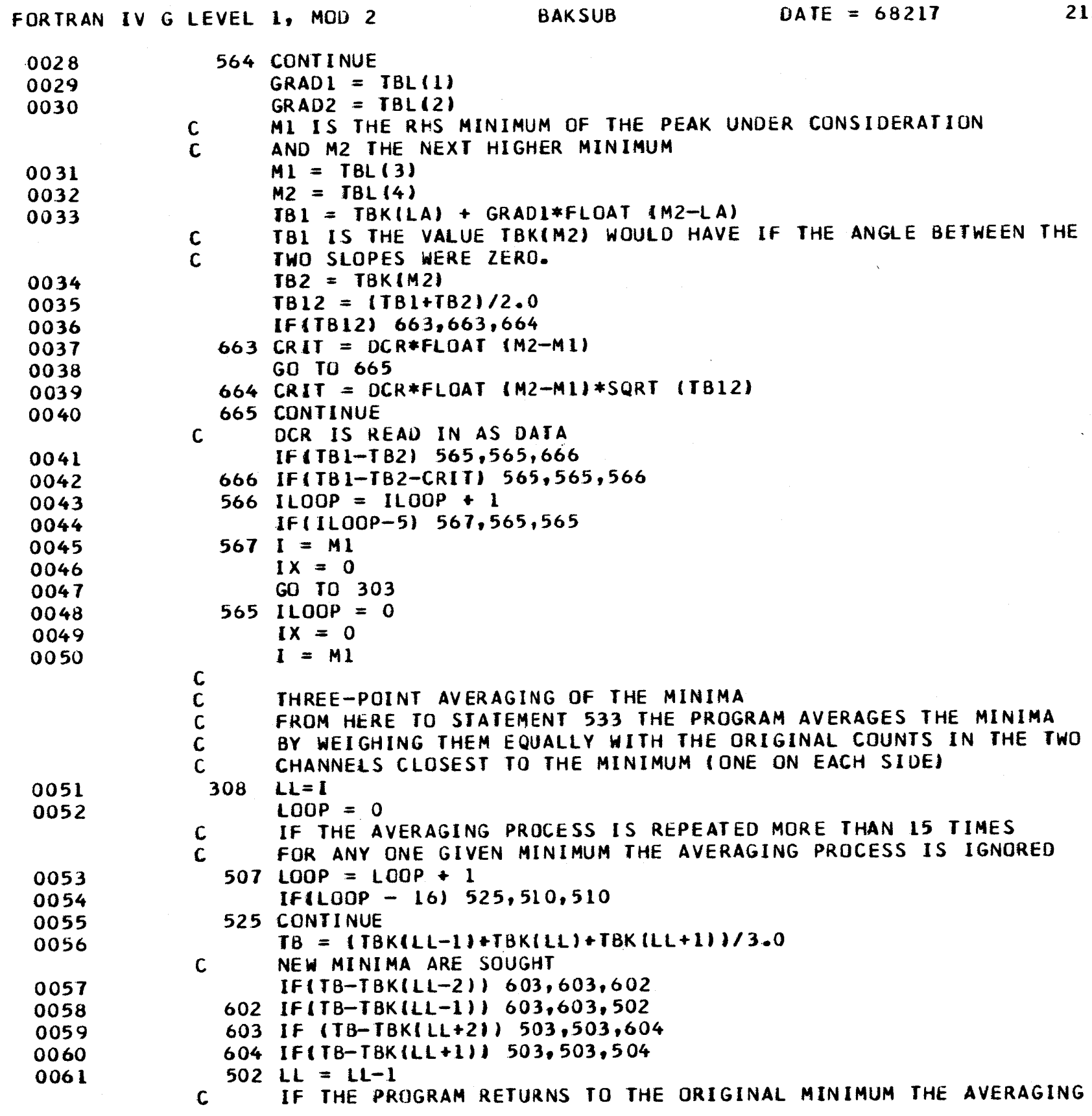




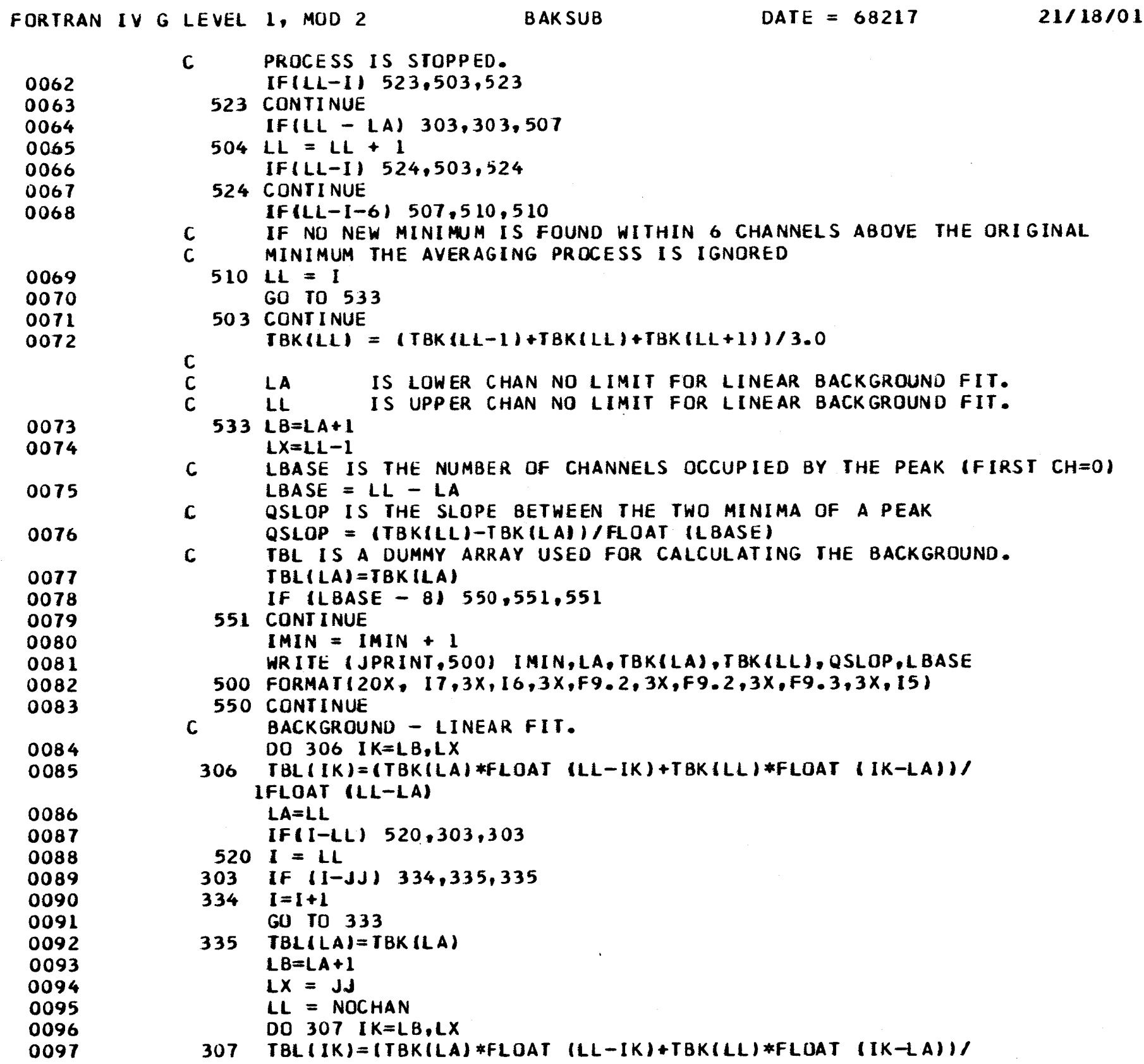




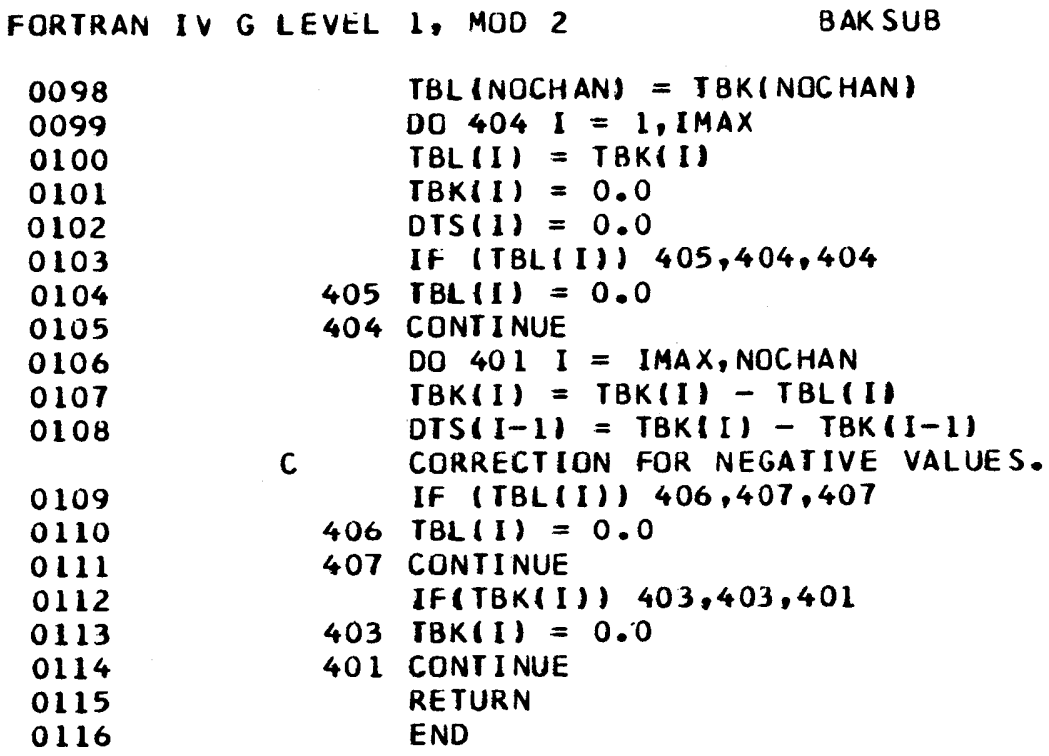




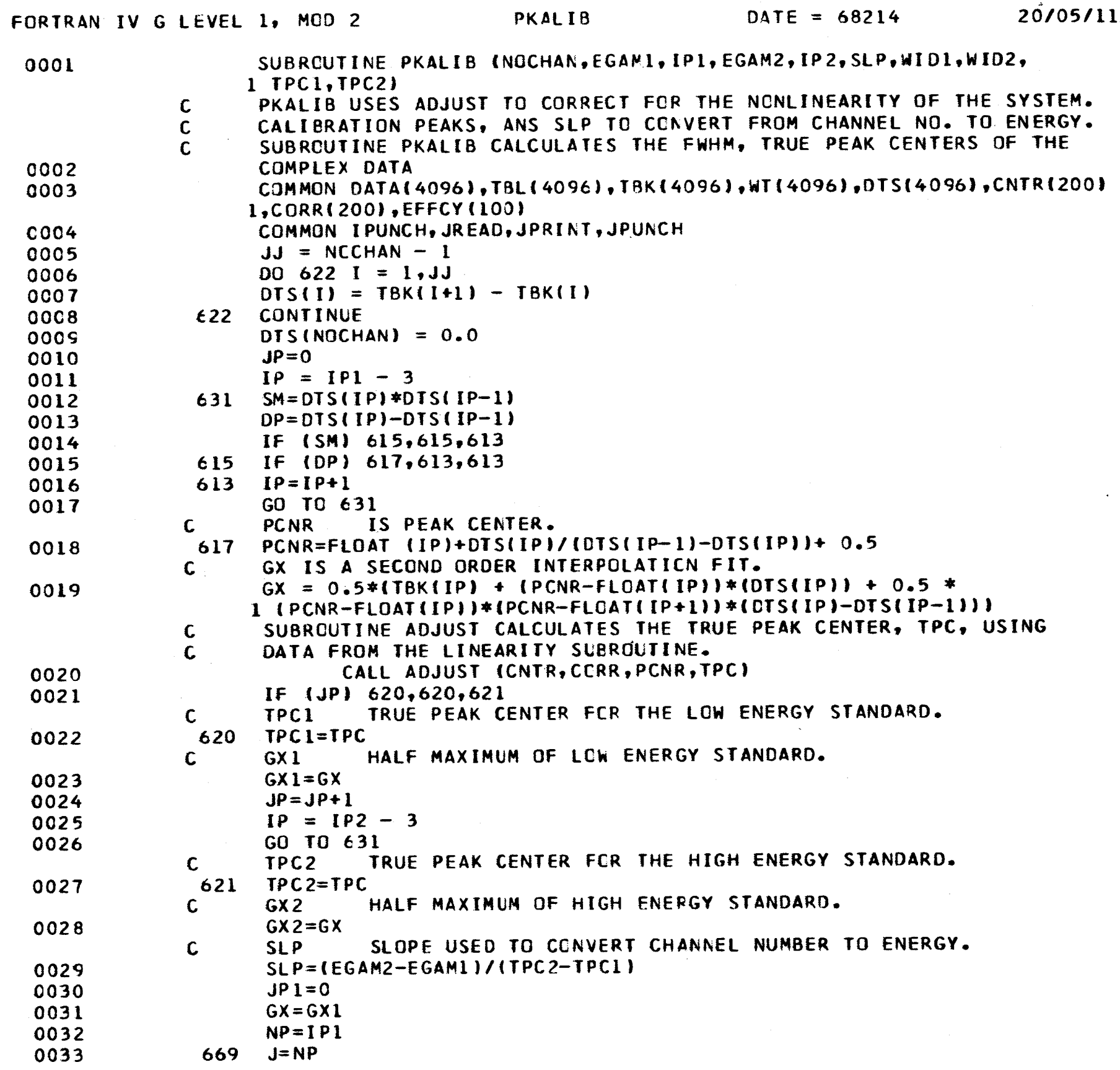




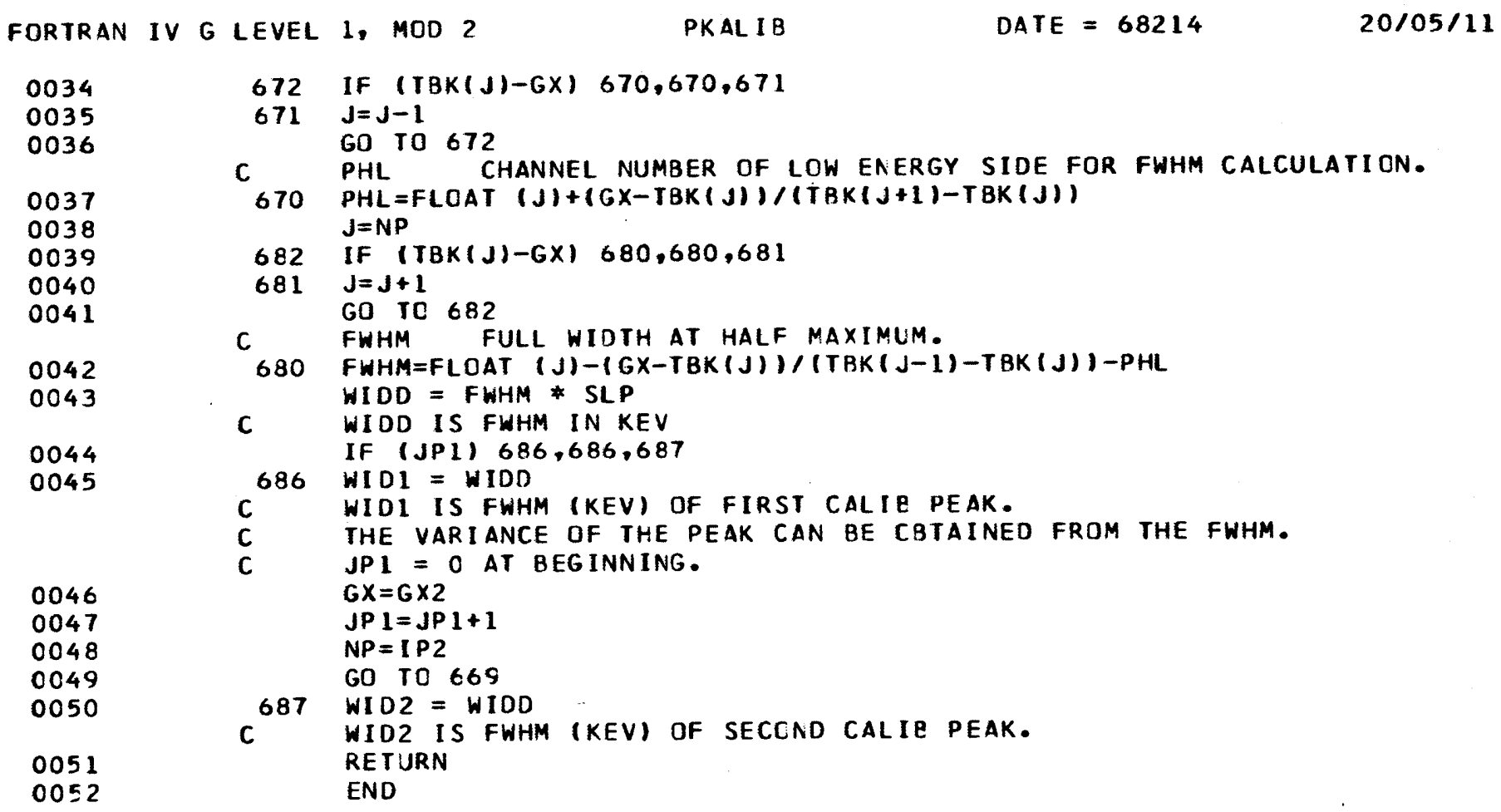




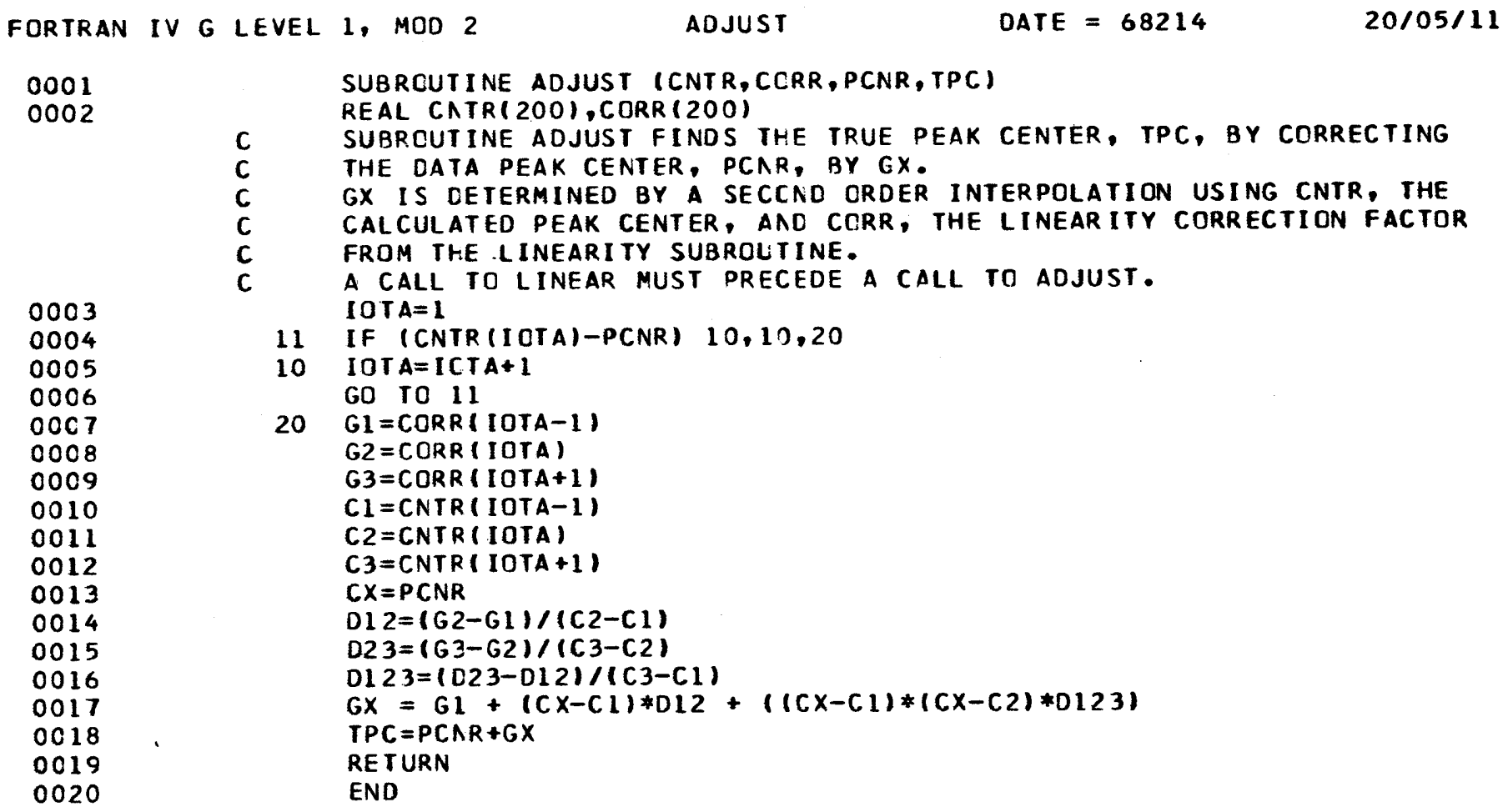

0001

0002

0003

0004

0005

0006

0067

0008

0009

0010

0011

0012

0013

0014

0015

0016

0017

0018

0019

0020

SUBRCUTINE ADJUST (CNTR, CCRR, PCNR, TPC) REAL CATR(200), CORR (200)

C SUBRCUTINE ADJUST FINDS THE TRUE PEAK CENTER, TPC, BY CORRECTING C THE DATA PEAK CENTER, PCAR, BY GX.

C GX IS DETERMINED BY A SECCND ORDER INTERPOLATION USING CNTR, THE C CALCULATED PEAK CENTER, AND CCRR, THE LINEARITY CORRECTION FACTOR C FROM THE LINEARITY SUBROLIIINE.

C A CALL TO LINEAR MUST PRECEDE A CALL TO ADJUST. IOTA $=1$

11 IF (CNTR (IOTA)-PCNR) $10,10,20$

10 IOTA=ICTA+1

GO TO 11

20 GI $=$ CORR $($ IOTA-1 $)$

G2 = CORR (IOTA)

G3 $=$ CORR $($ IOTA+1)

CI $=$ CNTR $($ IOTA-1)

C2 $=$ CNTR (IOTA)

C3 $=$ CNTR $($ IOTA+1)

$C X=P C N R$

$D 12=(G 2-G 1) /(C 2-C 1)$

$D 23=(G 3-G 2) /(C 3-C 2)$

D1 $23=(023-D 12) /\left(C_{3}-C_{1}\right)$

$G X=G 1+(C X-C 1) * D 12+((C X-C 1) *(C X-C 2) * 0123)$

$T P C=P C A R+G X$

RETURN

END 


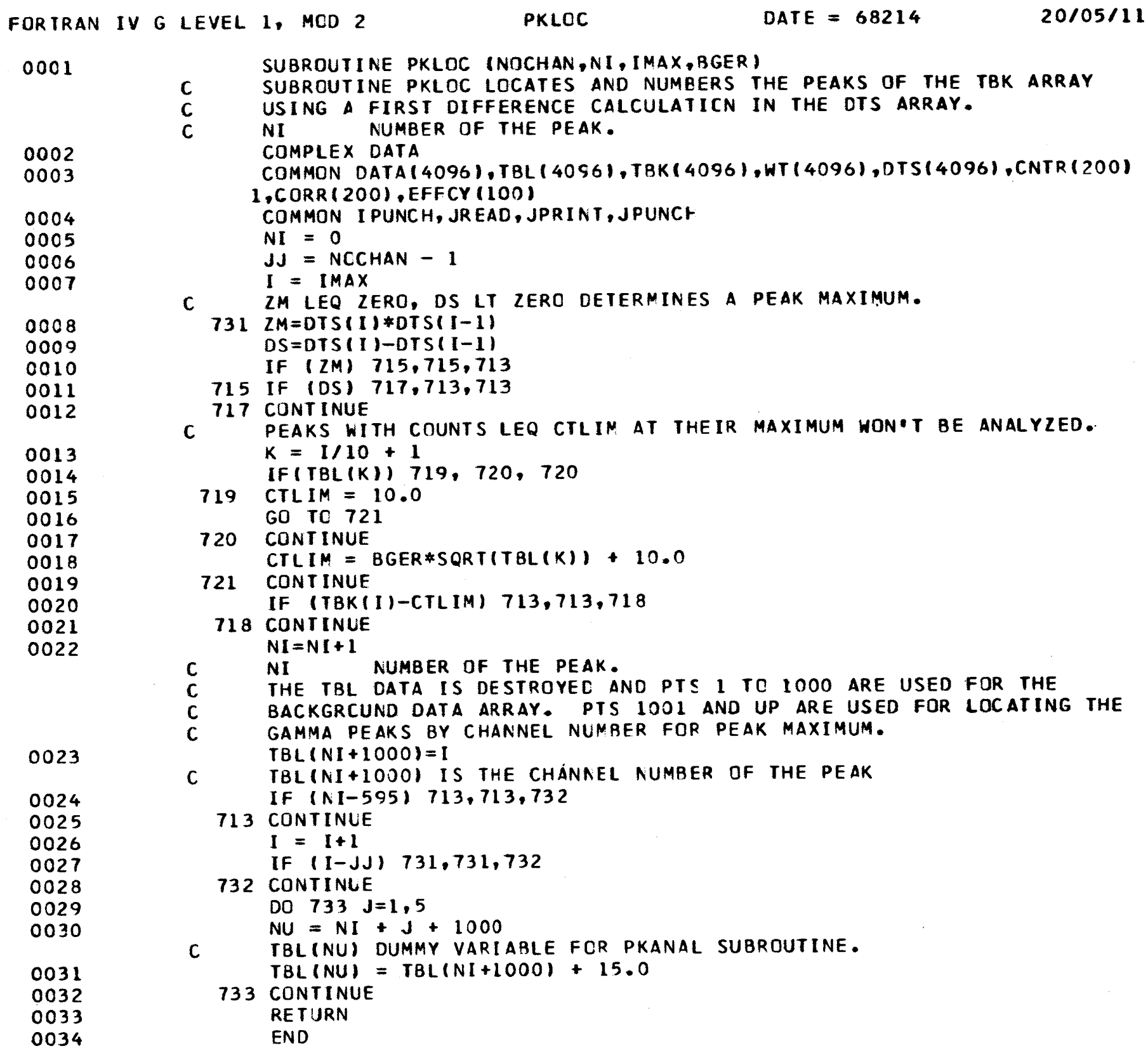




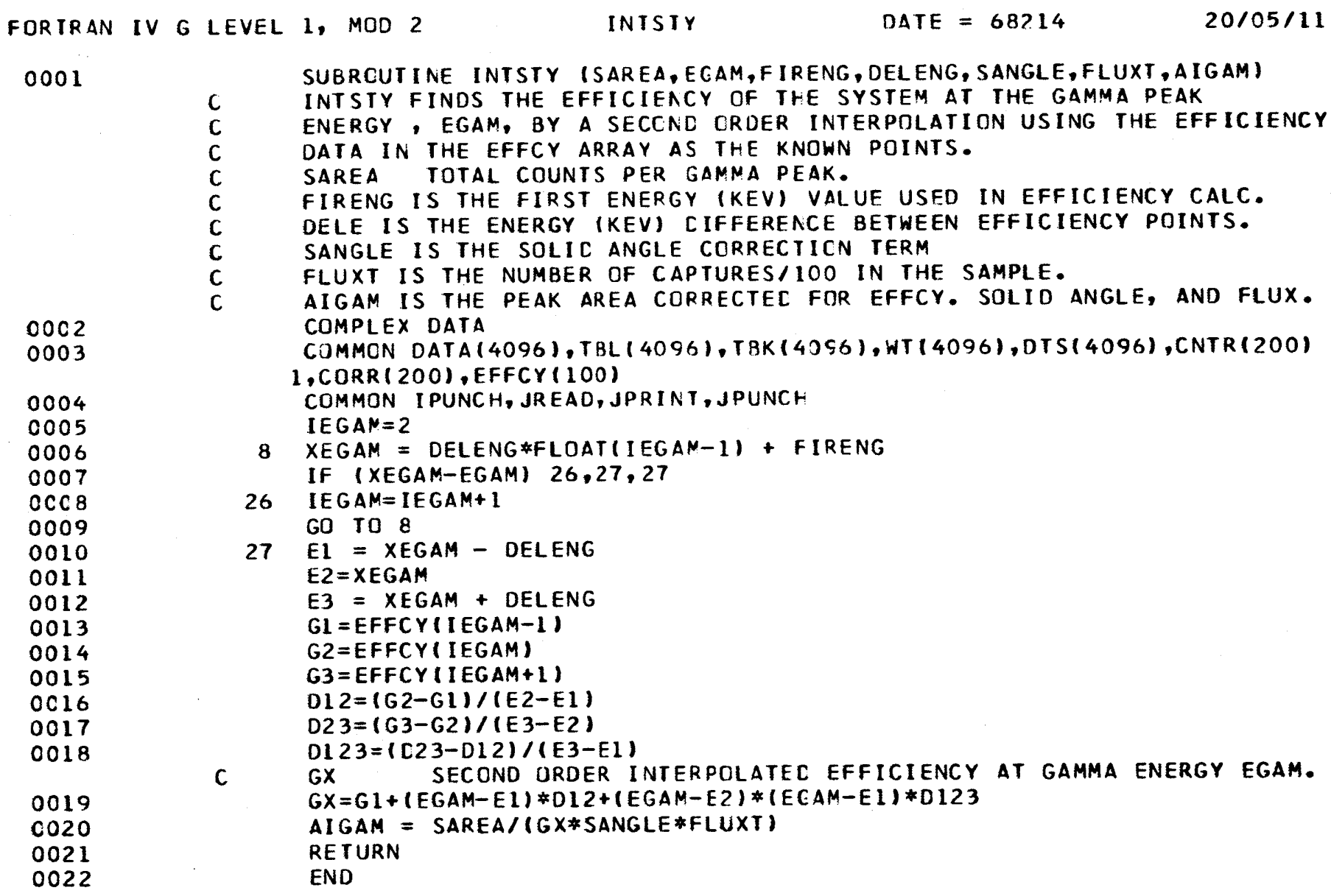

0021

0022

8 XEGAM = DELENG *FLOAT(IEGAM-1) + FIRENG IF (XEGAM-EGAM) $26,27,27$

26 IEGAM=IEGAM+1

$$
\text { GO TO } 8
$$

27 El = XEGAM - DELENG

$E 2=X E G A M$

$E 3=X E G A M+D E L E N G$

$G 1=E F F C Y(I E G A M-1)$

G2=EFFCY (IEGAM)

$G 3=E F F C Y(I E G A M+1)$

DI $2=(G 2-G 1) /(E 2-E 1)$

$D 23=(G 3-G 2) /(E 3-E 2)$

D1 $23=(C 23-D 12) /(E 3-E 1)$

C GX SECOND URDER INTERPOLATEC EFFICIENCY AT GAMMA ENERGY EGAM. $G X=G 1+(E G A M-E 1) * D 12+(E G A M-E 2) *(E G A M-E 1) * D 123$

AIGAM = SAREA/ $(G X * S A N G L E * F L U X T)$

RETURN

END 


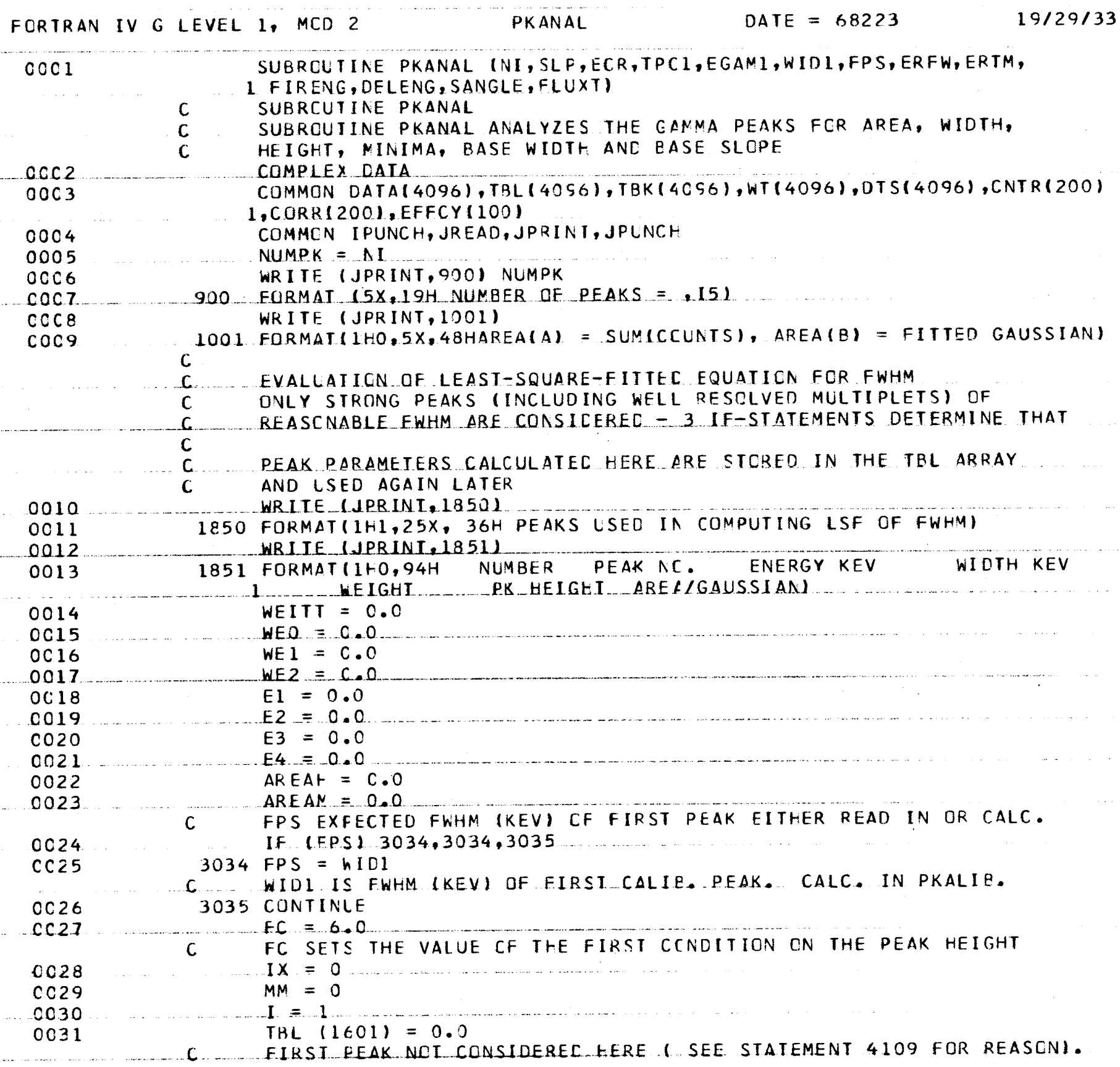


FCRTRAN IV G LEVEL 1, MCD 2

PKANAL

DATE $=68223$

$19 / 29 / 33$

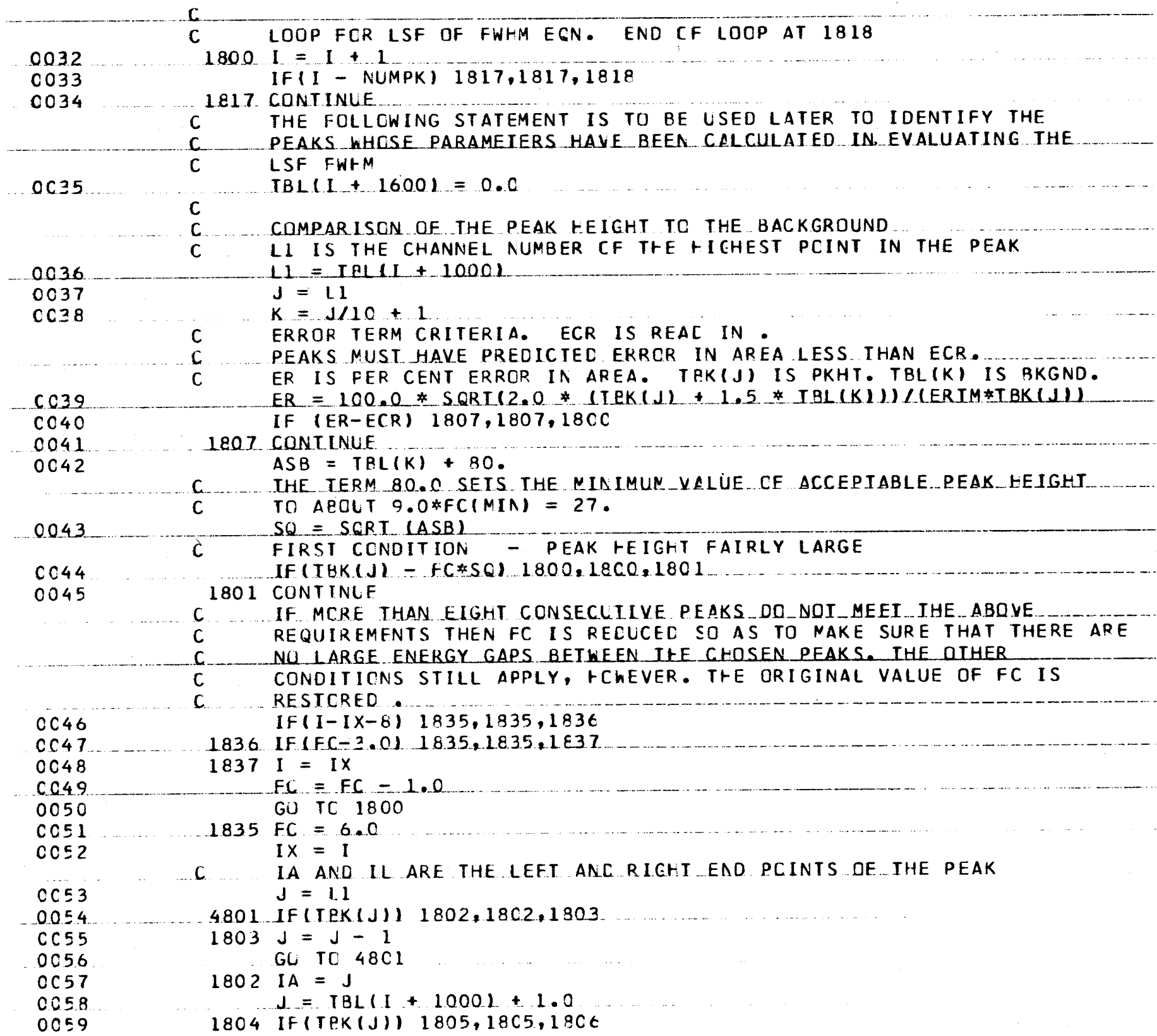




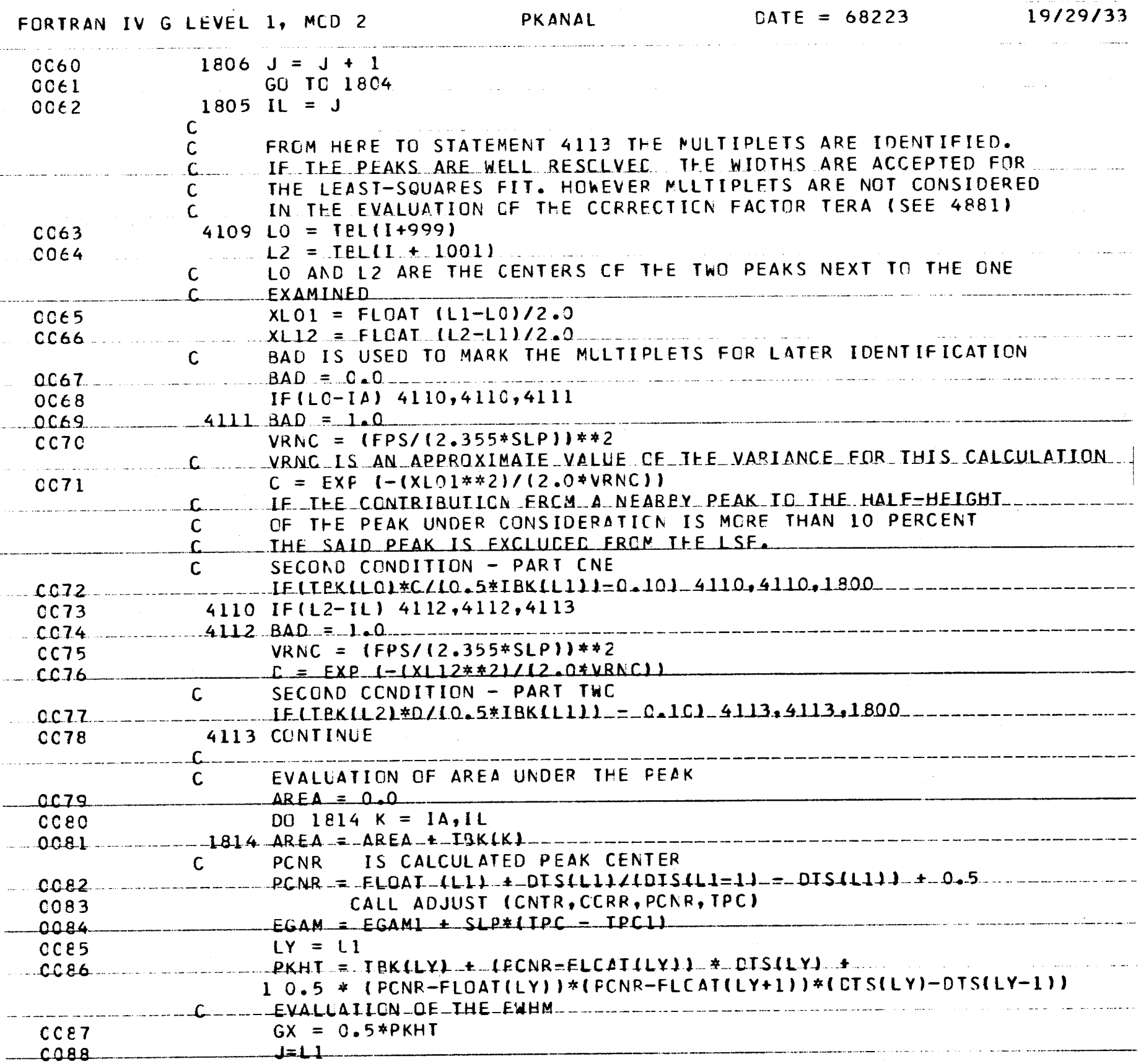




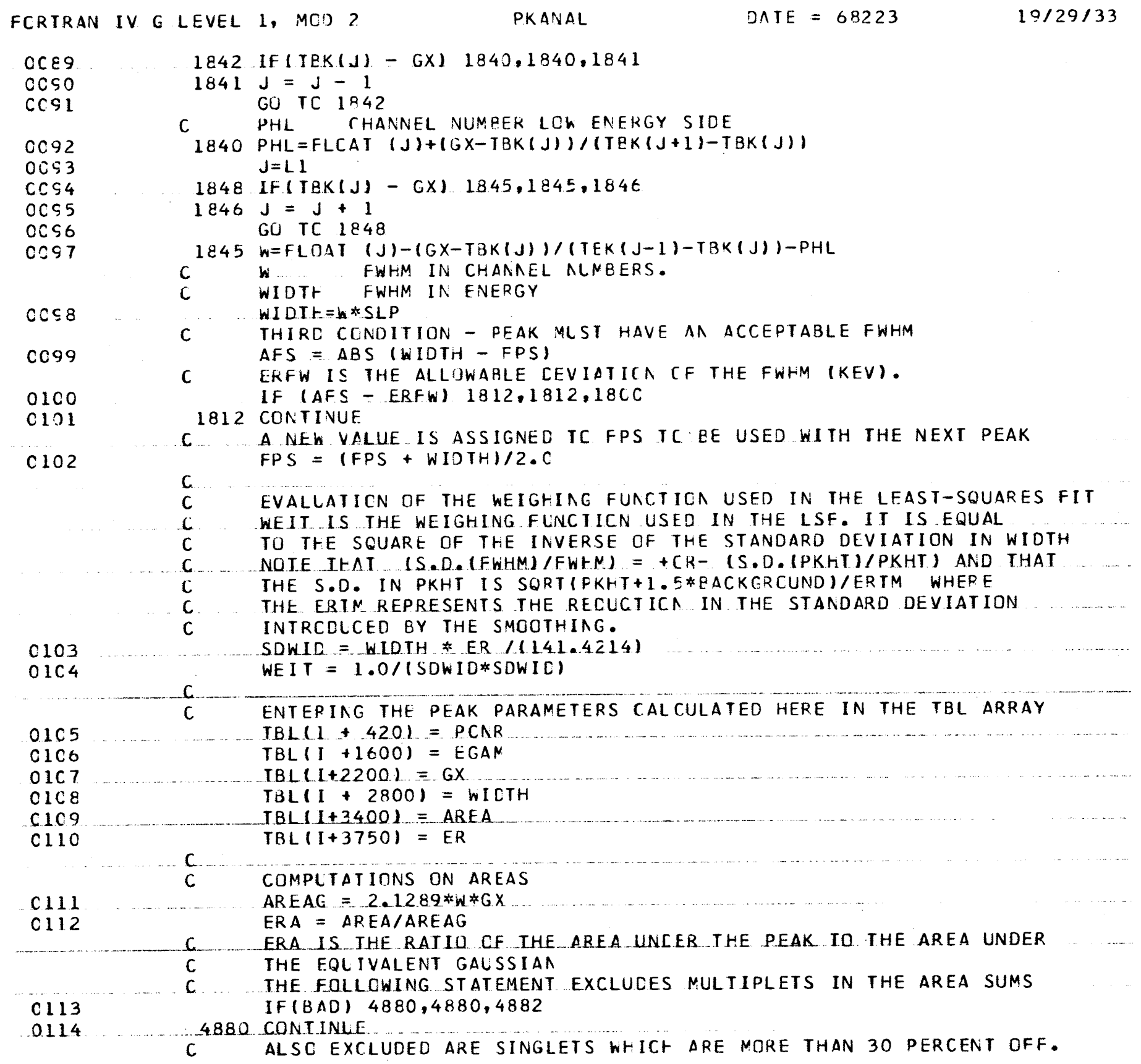


FCRTRAN IV G LEVEL 1, MCD 2.

PKANAL

DATE $=68223$

$19 / 29 / 33$

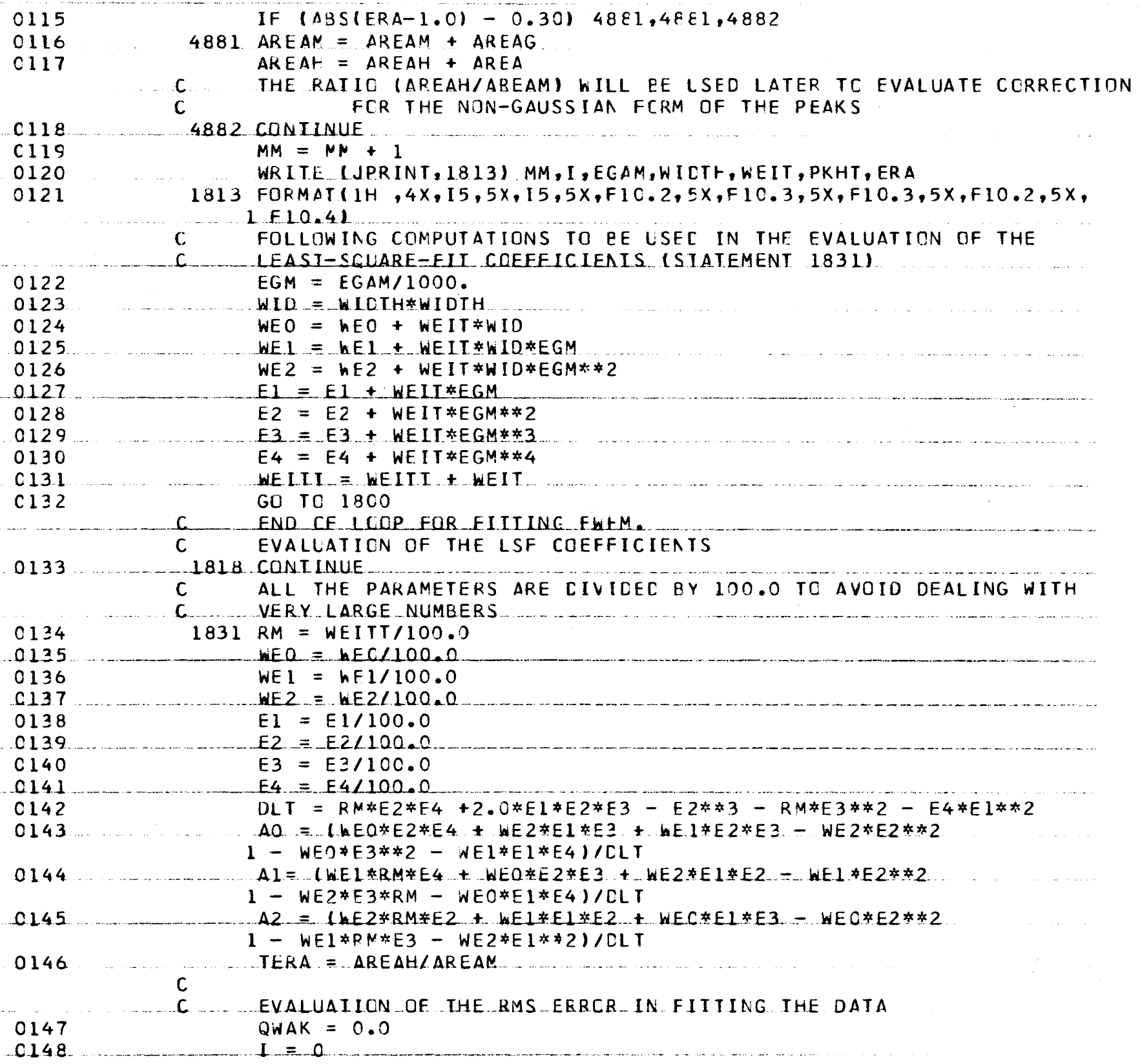


FORTRAN IV G LEVEL 1, MOD 2

PKANAL

DATE $=68223$

$19 / 29 / 33$

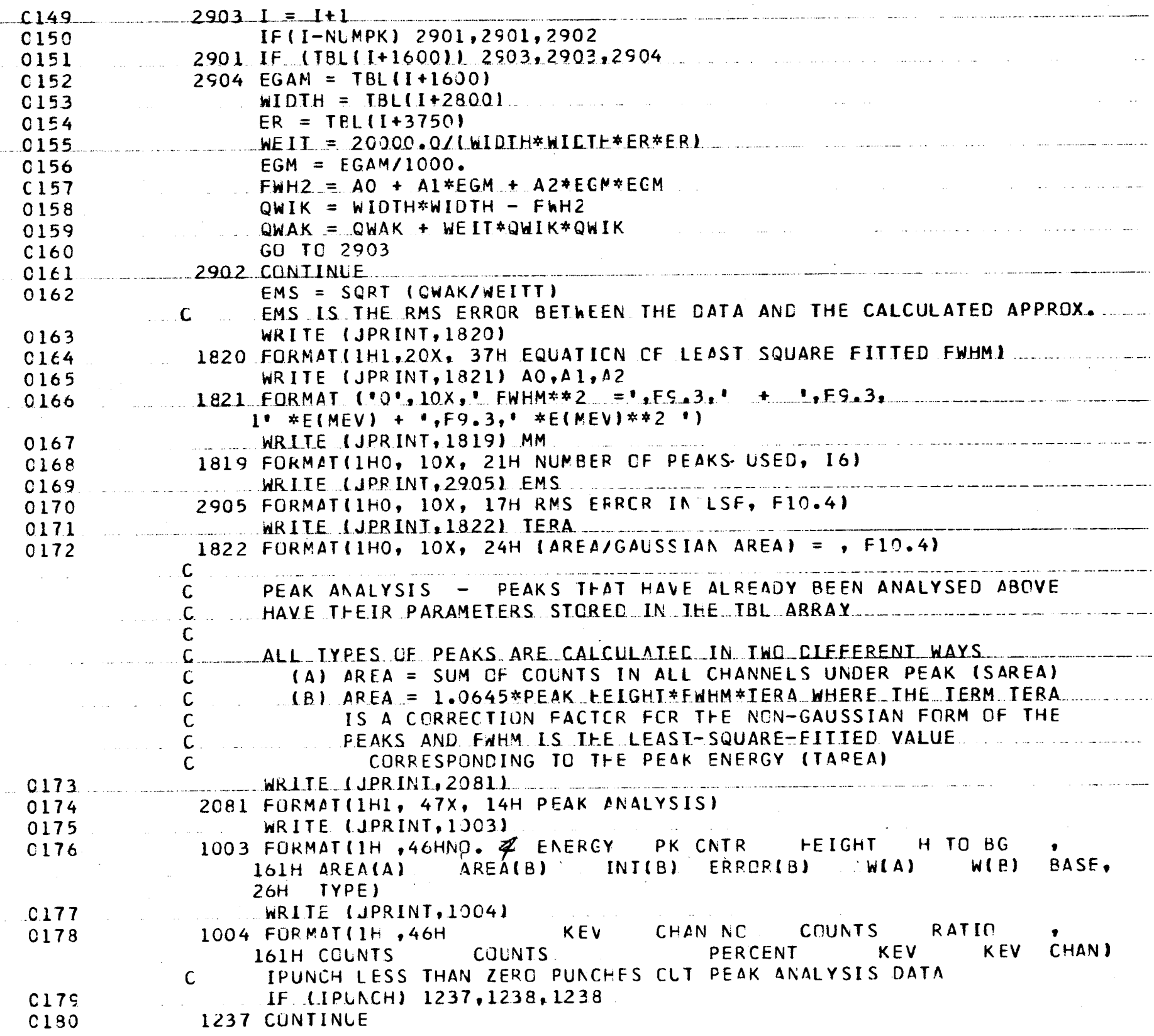




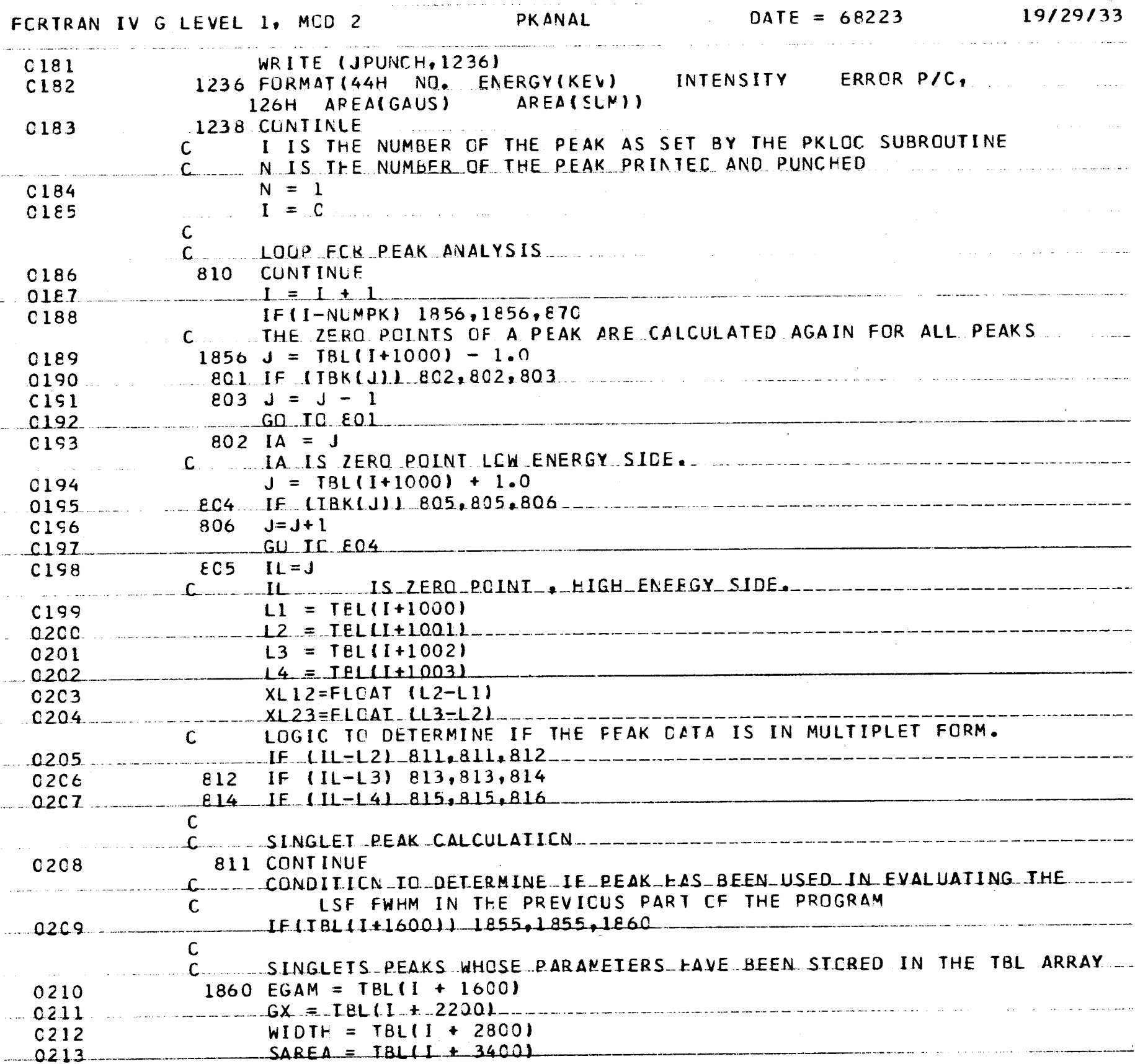




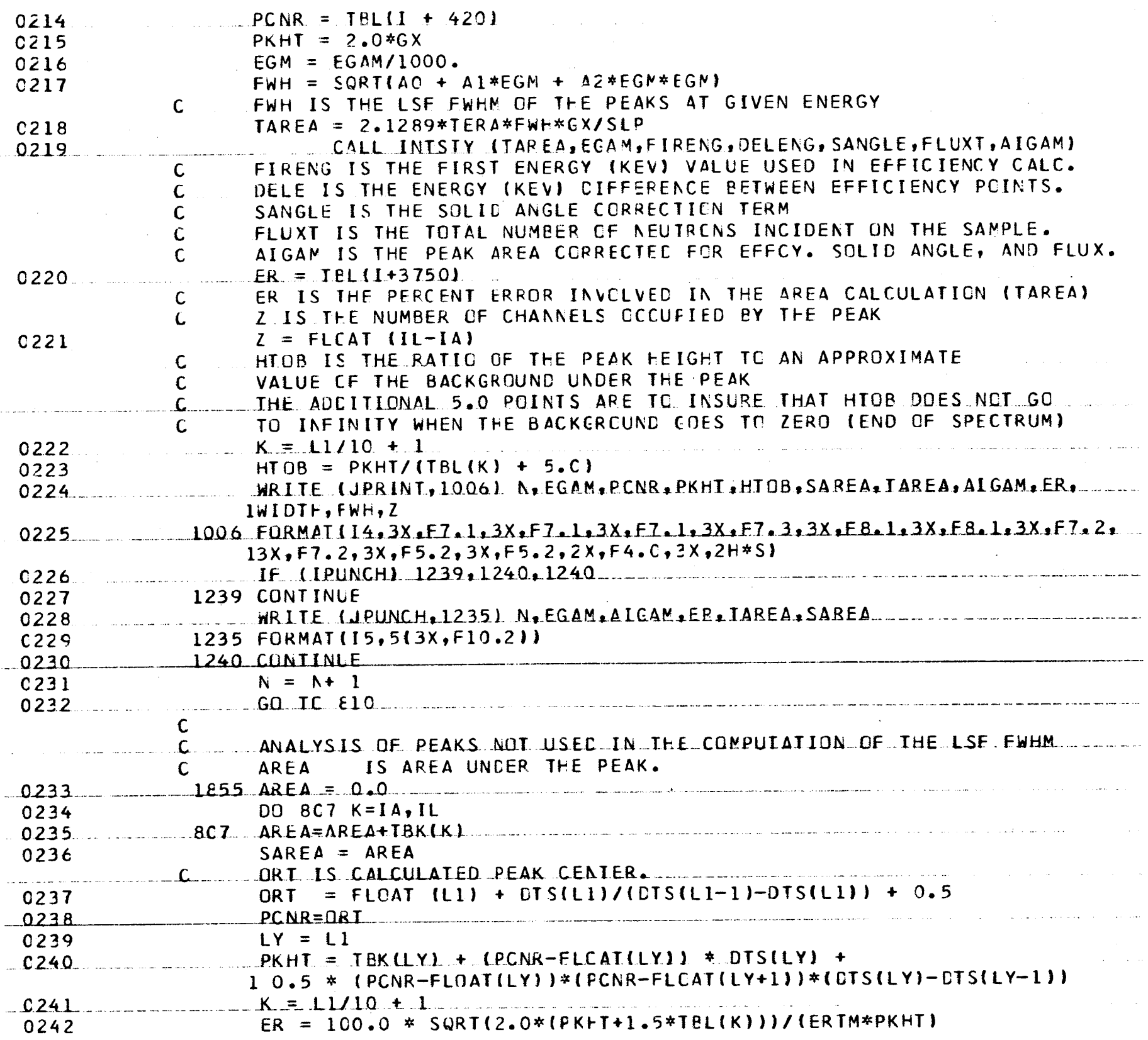


FCRTRAN IV G LEVEL 1, MCD 2

PKANAL

DATE $=68223$

$10 / 29 / 33$

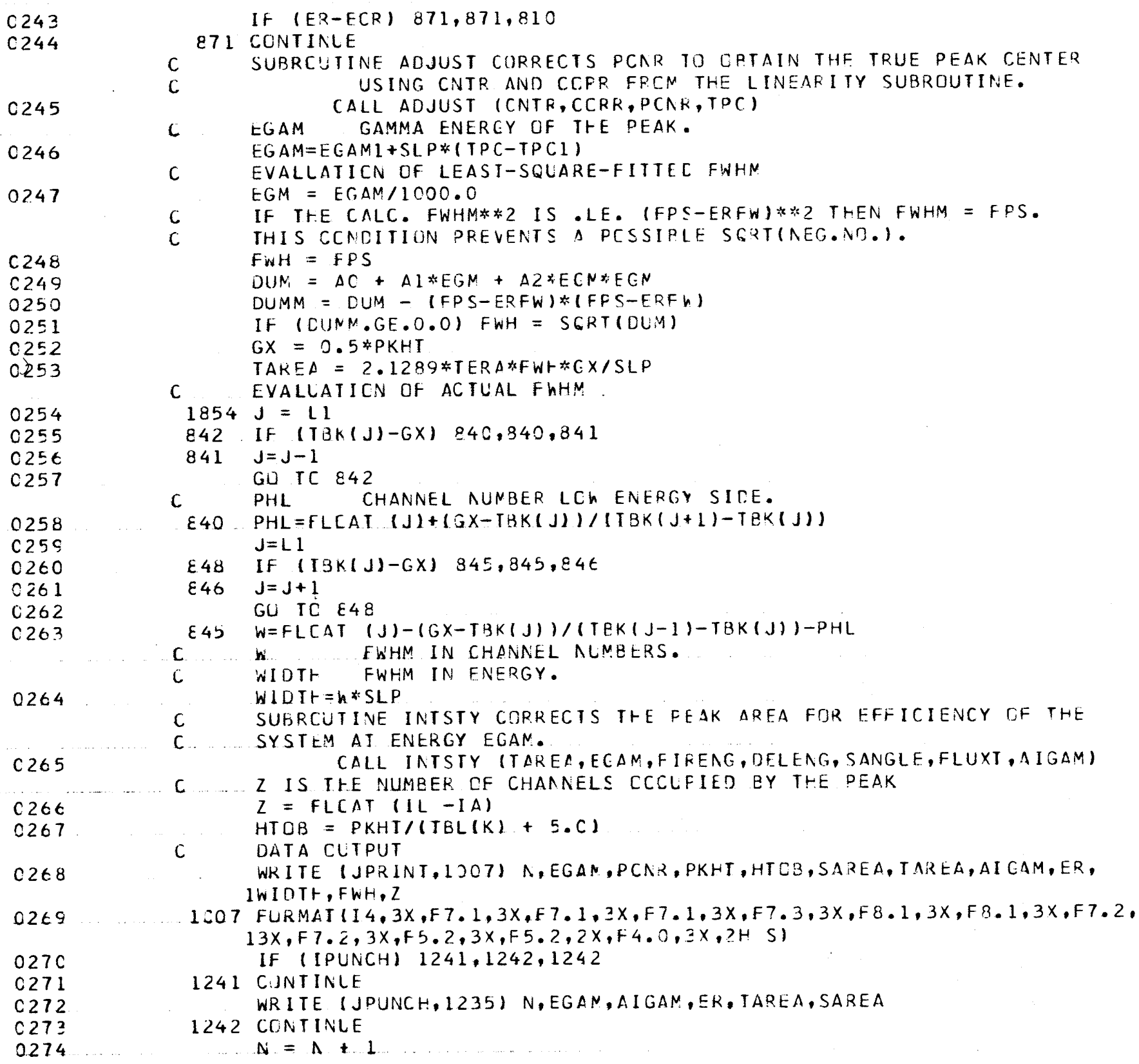

C 243

C244

0246

02.47

C 248

C 2.49

0250

0251

0252

0253

0254

0255

0256

C 257

0258

C $25 \mathrm{~s}$

0260

0261

C 262

C 263

0264

C 265

C 266

0267

0268

0269

$027 \mathrm{C}$

C271

C 272

C 273

0.274

IF (ER-ECR) $871,871,810$

871 CONTINLE

SUBRCUTINE ADJUST CORRECTS PCNR TO CPTAIN THF TRUE PEAK CENTER USING CNTR AND CCFR FPCM THE LINEARITY SUBROUTINE.

C CALL ADJUST (CNTF, CCRR,PCAR,TPC)

C EGAM GAMMA ENERGY OF THE PEAK.

EGAM $=E G A M I+S L P *(T P C-T P C I)$

C EVALLATICN OF LEAST-SQUARE-FITTEL FNHN

$E G M=E C, A M / 1000.0$

C IF THE CALC. FWHM *2 IS . LE. (FPS-ERFW) *2 THEN FWHM = FPS.

C THIS CCNDITIUN PREVENTS $\triangle$ PCSSIPLE SGRTINEG.NO.).

FWH $=$ FPS

$D U N_{i}=A C+A 1 * E G M+A 2 * E C N * E C N$

$D U M M=D U M-(F P S-E R F W) *(F F S-E R F h)$

IF (CUNM.GE.0.0) FWH $=$ SGRT (DUM)

$G X=0.5 * P K H I$

TAKEA $=2.1289 * T E R A * F W+C X / S L P$

C EVALLATICN OF ACTUAL FWHM:

$1854 \mathrm{~J}=\mathrm{LI}$

842 . IF $(\mathrm{TBK}(\mathrm{J})-G X) \quad 240,840,841$

$841 \mathrm{~J}=\mathrm{J}-1$

GU TC 842

C PHL CHANNEL NUNBER LCW ENERGY SICE.

$\varepsilon 40 \ldots$ PHL $=F L[A T(J)+(G X-T B K(J)) /(T B K(J+1)-T E K(J))$

$J=L 1$

E.48 If (I $3 K(J)-G X) \quad 345,845,84 t$

\&46 $\mathrm{J}=\mathrm{J}+1$

GU TC E48

\&4ל $W=F L[A T$ (J)-(GX-TBK(J))/(TEK(J-1)-TBK(J))-PHL

C .... FW'HM IN CHANNEL NLMEERS.

C WIDTR FWHM IN ENERGY.

WIDIt $=n *$ SLP

C SUBRCUTINE INTSTY CORRECTS THE FEAK AREA FOR EFFICIENCY CF THE

C. SYSTLM AI ENERGY EGAN.

CALL INTSTY (TAREA,ECAM,FIFENG, DELENG, SANGLE, FLUXT, A IGAM)

C .... Z IS THE NUMEER CF CHANNELS CCCLFIED EY THE PEAK

$Z=F L C A T(1 L-I A)$

$H T O B=P K H I /(T B L(K)+5 . C)$

C DATA CLITPUT

WR ITE (JPRINT, 1207 ) $\Lambda$, EGAN, PCNR, PKHT, HTCB, SAREA, TAREA, AICAM, ER, IWIOTH, FWH, Z

1507 FURMAI II $4,3 X, F 7,1,3 X, F 7,1,3 X, F 7,1,3 X, F 7,3,3 X, F 8,1,3 X, F 8,1,3 X, F 7,2$, $13 X, F 7,2,3 X, F 5,2,3 X, F 5,2,2 X, F 4,0,3 X, ? H$ SI

IF (IPUNCH) $1241,1242,1242$

1241 CINTIINLE

WR ITE (JPUNCH, 1235 ) N,EGAN, AIGAM, ER, IAREA, SAREA

1242 CONTINLE

$N=\Lambda+1$ 
FCRTRAN IV G LEVEL 1, MCD 2

PKANAL

DATE $=68223$

$19 / 29 / 33$

0275

C 276

C 277

C278

0279

0280

0281

0282

0283

C 284

C 285

0286

0287

C28 8

C 289

0290

C 291

0292

0293

C 254

C25 5

C256

0257

0298

C 299

0300

C3)1

0302

C 303

C 304

0305

C $3 \mathrm{C} 6$

$03 C 7$

0308

0309

C 310

GO TC $\& 10$

C DOUBLET PEAK CALCULATICN

C THE PRCCEDURE USED HERE IS SIMILAR TO THE SINGLET PEAK CALC.

C TWD GALSSIAN CURVES ARE FITIEC TC THE DATA.

$813 \quad A R E A=C$.

DO $827 \mathrm{~K}=\mathrm{IA}, \mathrm{IL}$

$827 \quad A R E A=A R E A+T B K(K)$

C

$$
\text { ORT } 1
$$

IS THE CALCULATED CENTER OF THE FIRST PEAK.

ORT 1 = FLOAT (LI) + DTS(L1)/(DTS(LI-1)-DISIL1)) + 0.5

C ORT2 IS THE CALCULATEC CENTER OF THE SECOND PEAK.

AN AVERAGE FWHM IS CALCULATED FCF IHE MULTIPLET IN ALL CASES

$P C N R=(C R T 1+O R T 2) / 2.0$

CALL ADJUST (CNTR, CCRR, PCNR, TPC)

$E G A M=E G A M 1+S L P \#(T P C-T P C 1)$

$E G M=E G A M / 1000$.

$F W H=F P S$

$D U M=A O+A 1 * E G M+A 2 * E G N * E G M$

DUMM $=$ DUM - (FPS -ERFW) * (FPS-ERFW)

IF (CUNM.GE.0.0) FWH = SGRT(CUM)

WIDTH = FWH

VRNC $=(F W H /(S L P * 2.3547 \varepsilon)) * 2$

$C=\operatorname{EXP}(-(X L 12 * 2) / 12 * \operatorname{VRNC}))$

C L... L1 IS THE CHANNEL NLMBER CE THE NAXIMUM DF THE FIRST PEAK.

C L2 IS THE CHANNEL NLNEER CF THE MAXIMUM OF THE SECOND PEAK. $A R E A L=\triangle R E A *(T B K(L 1)-T B K(L 2) * C) /(1(T E K(L 1)+T B K(L 2)) *(1,-C))$

$A R E A 2=A R E A *(\operatorname{TBK}(L 2)-T B K(L 1) * C) /((T P K(L 1)+\operatorname{TBK}(L 2)) *(1,-C))$

$L Y=L 1$

DCCE $=1.0645 *$ TERA*FWH/SLF

DENON $=1.0-C * * 2$

PCNR = ORT1

PKHT = TRK $(L Y)+(F C N R-F L C A T(L Y)) *$ OTS $(L Y)+$

$10.5 *(P C N R-F L O A T(L Y)) *(P C A R-F L C A T(L Y+1)) *(C T S(L Y)-D T S(L Y-1))$

PKHTI = PKHT

PCNR = CRT2

$L Y=L 2$

PKHT $=$ TBK(LY) + (PCNR-FLCAT(LY) ) * DTS $(L Y)+$

$10.5 *(P C N R-F L J A T(L Y)) *(P C N R-F L C A I(L Y+1)) *(C T S(L Y)-D T S(L Y-1))$

PKHT2 = PKHT

C FIRST PEAK DATA CALCULATICA.

PKHT = (PKHT 1 - C*PKHT2)/CENCN

IF IPKHT.LE.0.01 GC IO \&S.

$K=11 / 10+1$

$E R=100.0 * S Q R T(2.0 *(F K H T+1.5 * T E L(K))) /(E R T N * P K H T)$

If $(E R-E C R) \quad 872,972,892$

E72 PCNR $=D R T 1$

TAREA = CCOE*PKHT 


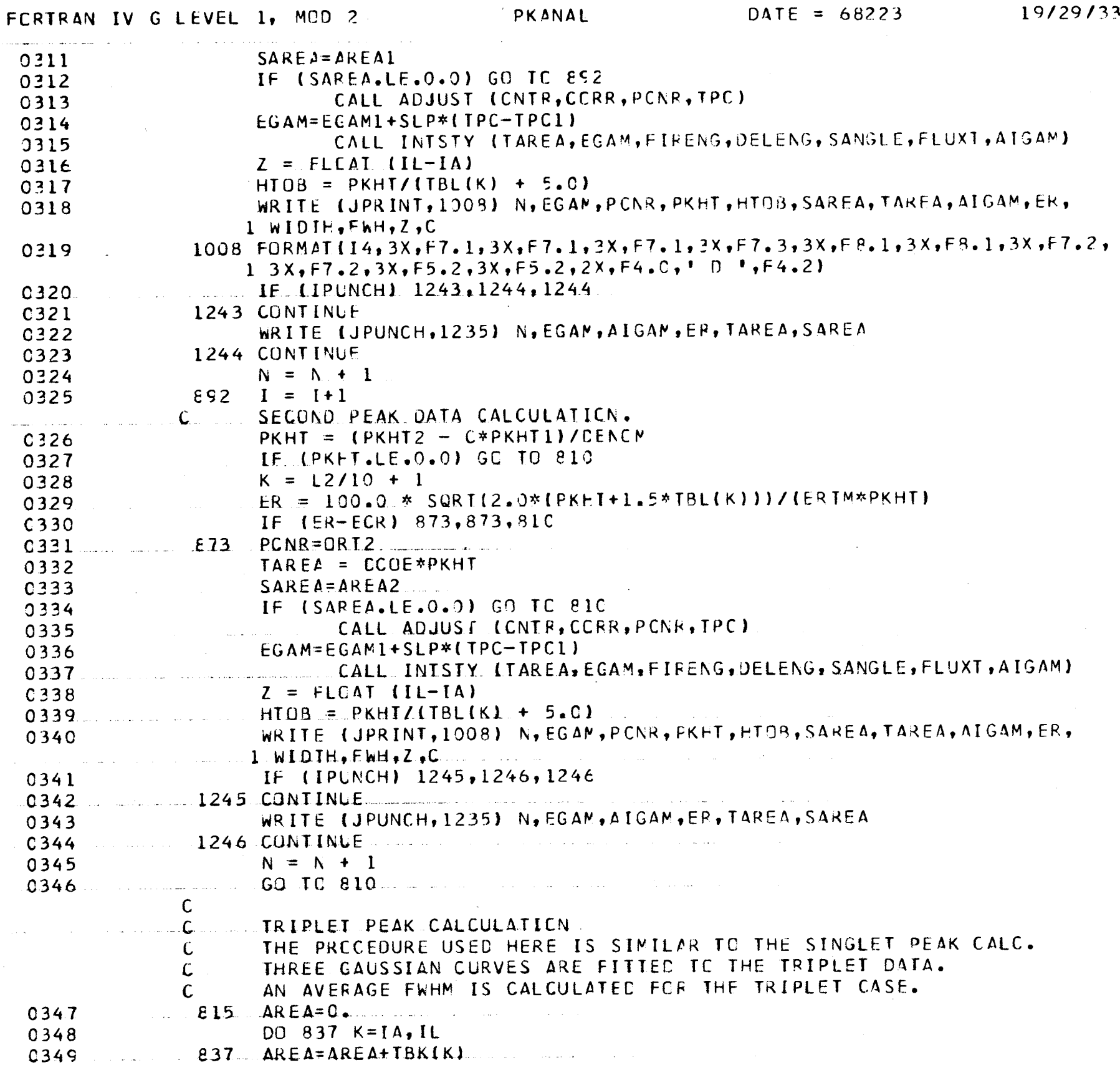


FCRTRAN IV G LEVEL 1, MCD 2

PKANAL

DATE $=68223$

$19 / 29 / 33$

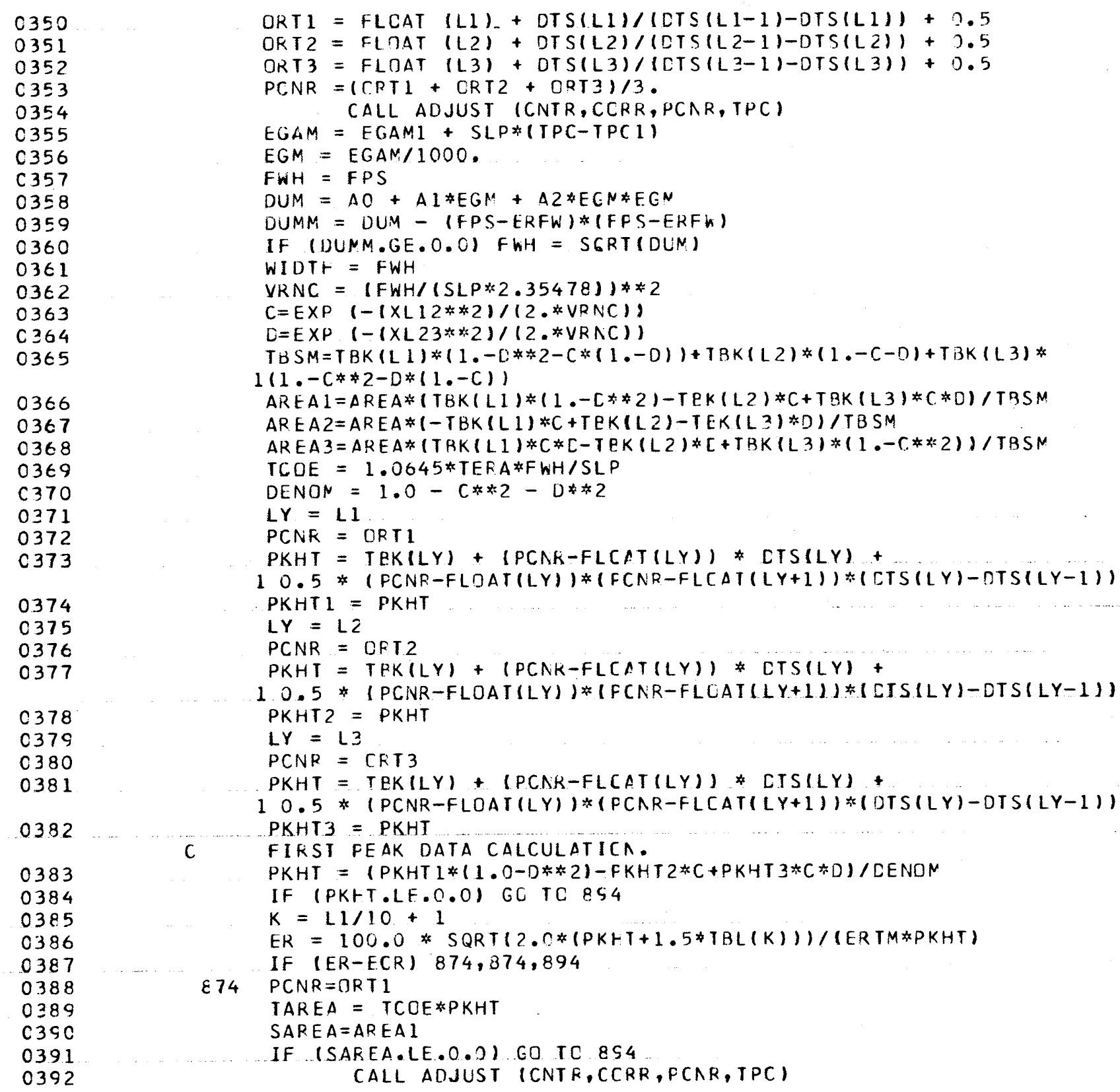




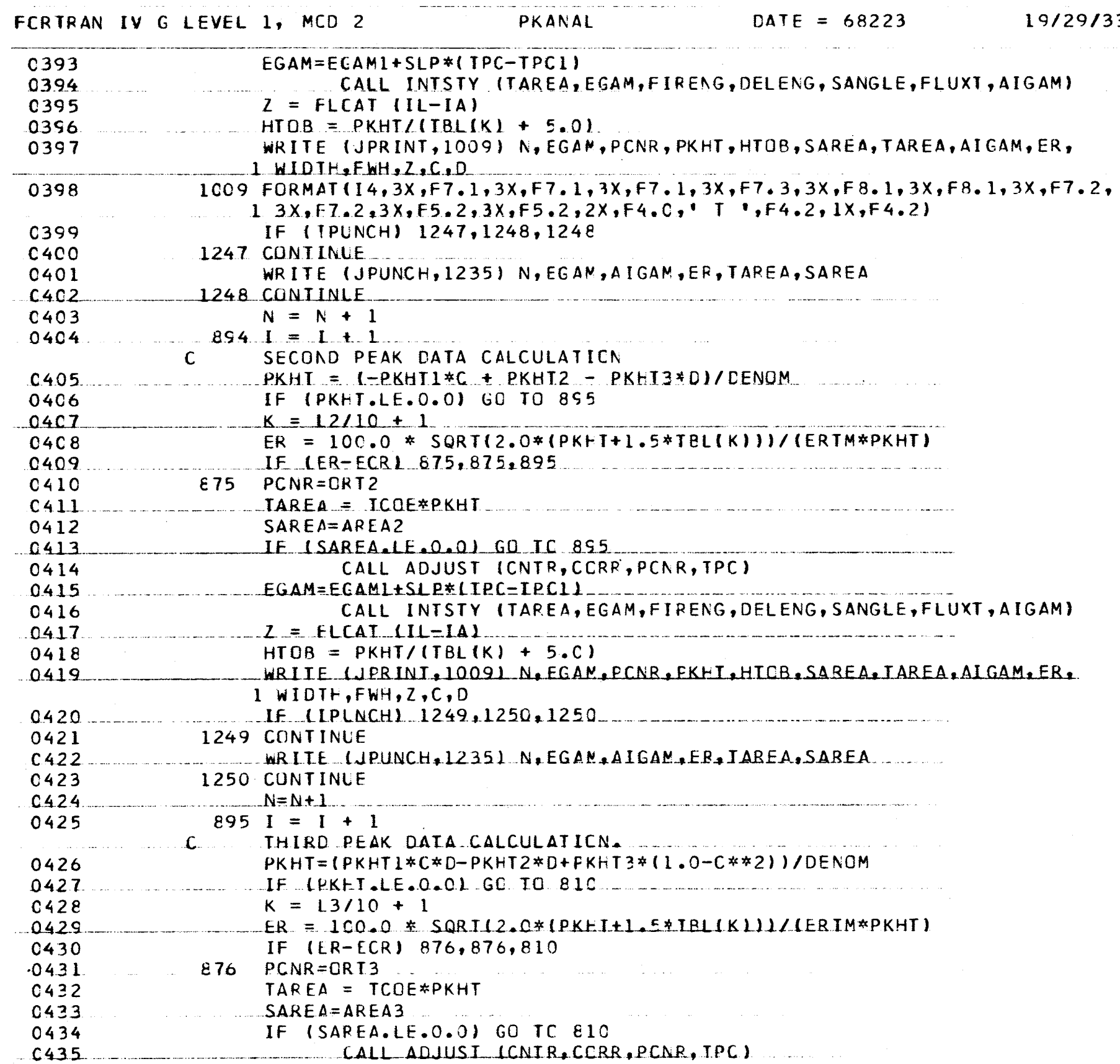


FORTRAN IV GLEVEL 1, MCD 2

PKANAL

$D A I E=68223$

$19 / 29 / 33$

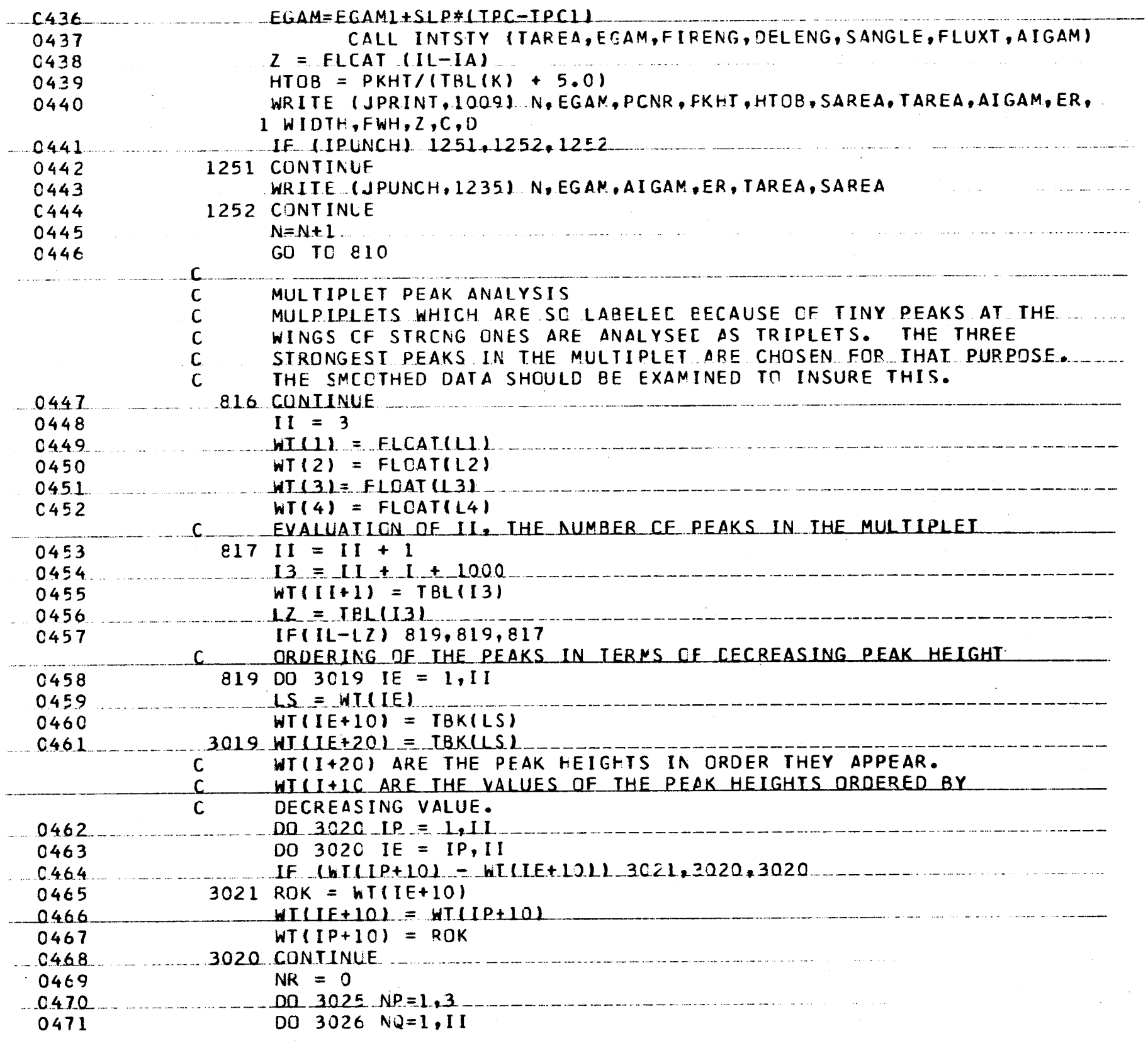




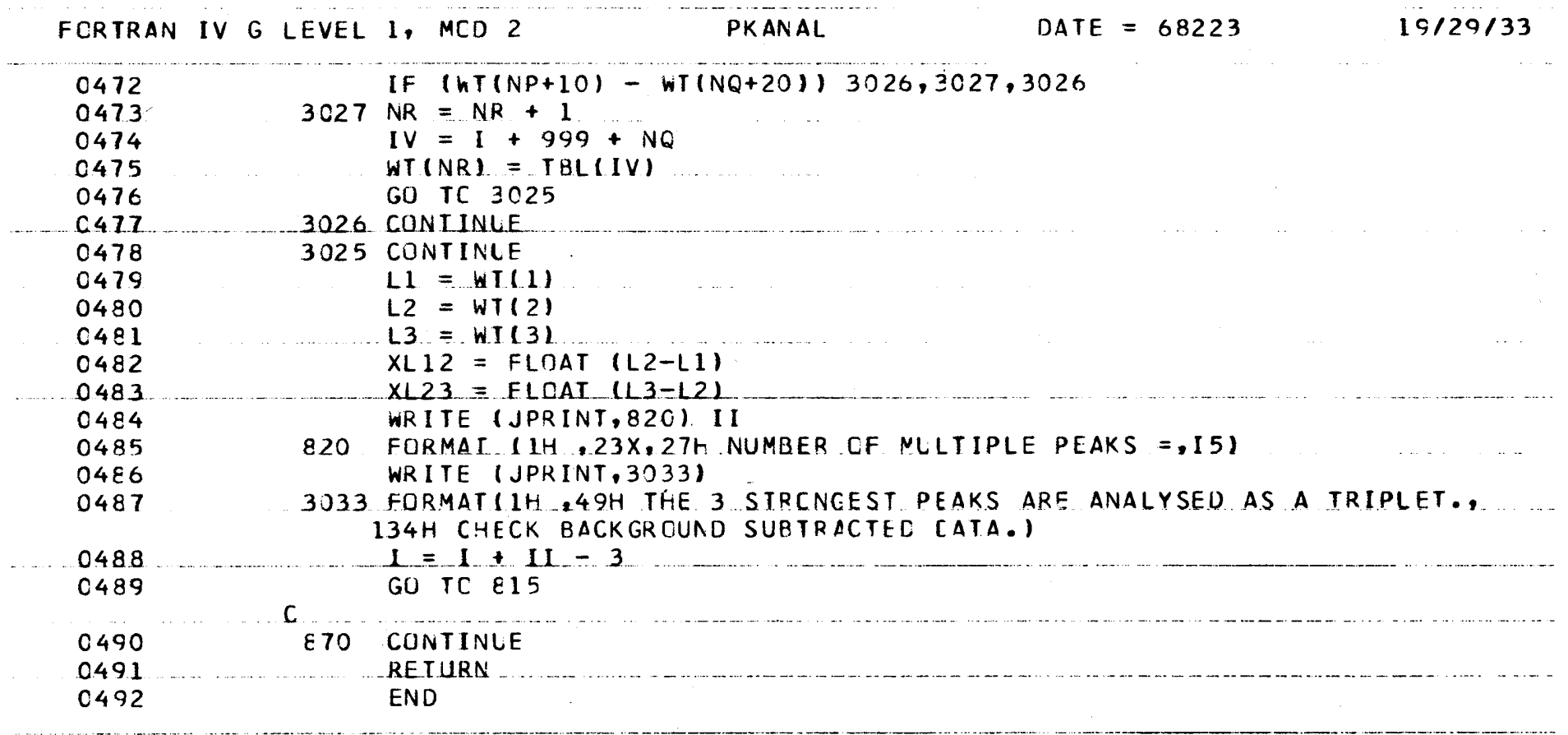




$$
\text { CTFP }
$$

C THE COOLEY-TUKEY FAST FOURIER TRANSFORM IN USAST BASIC FORTRAN

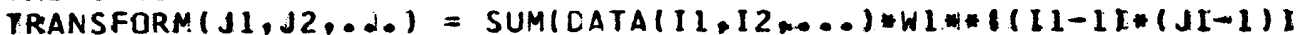
*W2**((I2-1)*(J2-1)I*-d.l. WHERE II ANO JI RUN AROM 1 TO NN(1) AND WI=EXP(ISIGNE2API* SORT(-1) ANN(II), ETC: THERE IS NO LIMIT ON THE DIMENSIONALITY (NUMBER OF SUBSCRIPTSI OF THE DATA ARRAY. IF AN INVERSE TRANSFORM (ISIGN $=+1$ ) IS PERFORMED UPON AN ARRAY OF TRANSFORMED (ISIGNa-1) DATA, THE ORIGINAL DATA WILL REAPPEAR, MULTIPLIED BY NN(1)*NN(2):-.. THE ARRAY OF INPUT OATA MAY BE REAL DR COMPLEX, AT THE PROGRAMMERS OPIION, WITH A SAVING DE UP TO FORTY PER CENT IN RUNNING TLME FOR REAL OVER COMPLEX. IFOR FASTEST TRANSFORM OF REAL DATA, NNIIL SHOULD BE EVEN.) THE TRANSFORM VALUES ARE ALWAYS COMPLEX, AND ARE RETURNED IN THE ORIGINAL ARRAY CF DATA. REPLACING THE INPUT DATA. THE LENGTH OF EACH DIMENSION OF THE DATA ARRAY MAY BE ANY INTEGER THE PROGRAM RUNS FASTER ON COMPOSITE INTEGERS IHAN ON PRIMES. AND IS PARTICULARLY FAST ON NUMBERS RICH IN FACTORS OF TWO. IIMING IS IN FACT GIVEN BY THE FOLLOWING FORMULA: LET NTOT BE THE TOTAL NUMBER OF POINTS (REAL OR COMPLEX) IN THE DATA ARRAY. THAT IS, NTOT=NN(1)*NN(2)*... DECCMPOSE NTOT INTO ITS PRIME FACTORS, SUCH AS 2*:K2 *3**K3*5*K5*..: LET SUM2 BE THE SUM OF ALL IHE FACTORS OF TWO IN NTOT, THAT IS, SUM2 $=2 * K 2$. LET SUMF BE THE SUM OF ALL OTHER FACTORS OF NTOT, THAT IS, SUMF $=3 * K 3+5 * K 5+\ldots$ THE TIME TAKEN BY A MULTIDIMENSIONAL TRANGFORM ON THESE NTOT DATA IS $T=$ TO NTOT*(T1+T2*SUM2+T3*SUMF). ON THE CDC 3300 (FLOATING POINT ADD TIME = SIX MICROSECONDS). T 73000 NTOT $\$(600 * 40 *$ SUM2* I75*SUMF): MICROSECONDS ON COMPLEX DATA.

IMPLEMENTATION OF THE DEFINITION BY SUMMATION WILL RUN IN A TIME PROPORTIONAL TO NTOT $(N N(1)+N N(2)+\ldots)$. FOR HIGHLY CCMPOSITE NTOT THE SAVINGS OFFERED BY THIS PROGRAM CAN BE DRAMATIC. A ONE-DIMENSIONAL ARRAY $40 C 0$ IN LENGTH WILL BE TRANSFORMED IN 4 CO0 $1600+$ $40 *(2+2+2+2+2)+175 *(5+5+5))=14.5$ SECONDS VERSUS ABOUT 4 COO* $4000 * 175 ; 2800$ SECONDS FOR THE STRAIGHTFORWARD TECHMIQUE.

THE CALLING SEQUENCE IS--

CALL FOURT (CATA,NN, NDIM, ISIGN, IFORM, WORK)

DATA IS THE ARRAY USED TO HCLD THE REAL AND INAGINARY PARTS OF THE DATA ON INPUT AND THE TRANSFCRM VALUES ON OUTPUI. IT IS A MULTIDIMENSIONAL FLOATING POINT ARRAY. WITH THE REAL ANC IMAGINARY PARTS OF A DATUM STORED INMEDIATELY ADJACENT IN STORAGE (SUCH AS FORTRAN IV PLACES THEM). THE EXTENT OF EACH DIMENSICN IS GIVEN IN THE INTEGER ARRAY NN, OF LENGIH NDIM. ISIGN LS - 1 TO INDICATE A FORWARD TRANSFORM (EXPONENTIAL SIGN IS -) AND +1 FOR AN INVERSE TRANSFORM (SIGN IS +). IFORM IS + I IF IHE DATA AND THE TRANSFORM VALUES ARE COMPLEX. IT IS 0 IF THE DATA ARE REAL BUT THE IRANSFORM VALUES ARE COMPLEX. IF IT IS O, THE IMAGINARY PARTS OF THE DATA SHOULD BE SET TO ZERO. AS EXPLAINED ABOVE, THE TRANSFORM VALUES ARE ALWAYS COMPLEX AND ARE STORED IN ARRAY CATA. WORK IS AN ARRAY USED FOR WCRKING STORAGE. IT IS NCT NECESSARY IF ALL THE CIMENSIONS OF THE DATA ARE POWERS OF TWC. IN IHIS CASE IT MAY BE REPLACED BY O IN THE CALLING SEQUENCE. THUS, USE OF POWERS OF TWO CAN FREE A GOCD DEAL OF STORAGE. IF ANY DIMENSION IS NOT A POWER OF TWO, THIS ARRAY MUST BE SUPPLIED. IT IS FLOATING POINT, ONE DIMENSIONAL OF LENGTH EQUAL TO TWICE IHE LARGEST ARRAY DIMENSLON (I.E. NN(I)). THAT IS NOT A POWER OF 


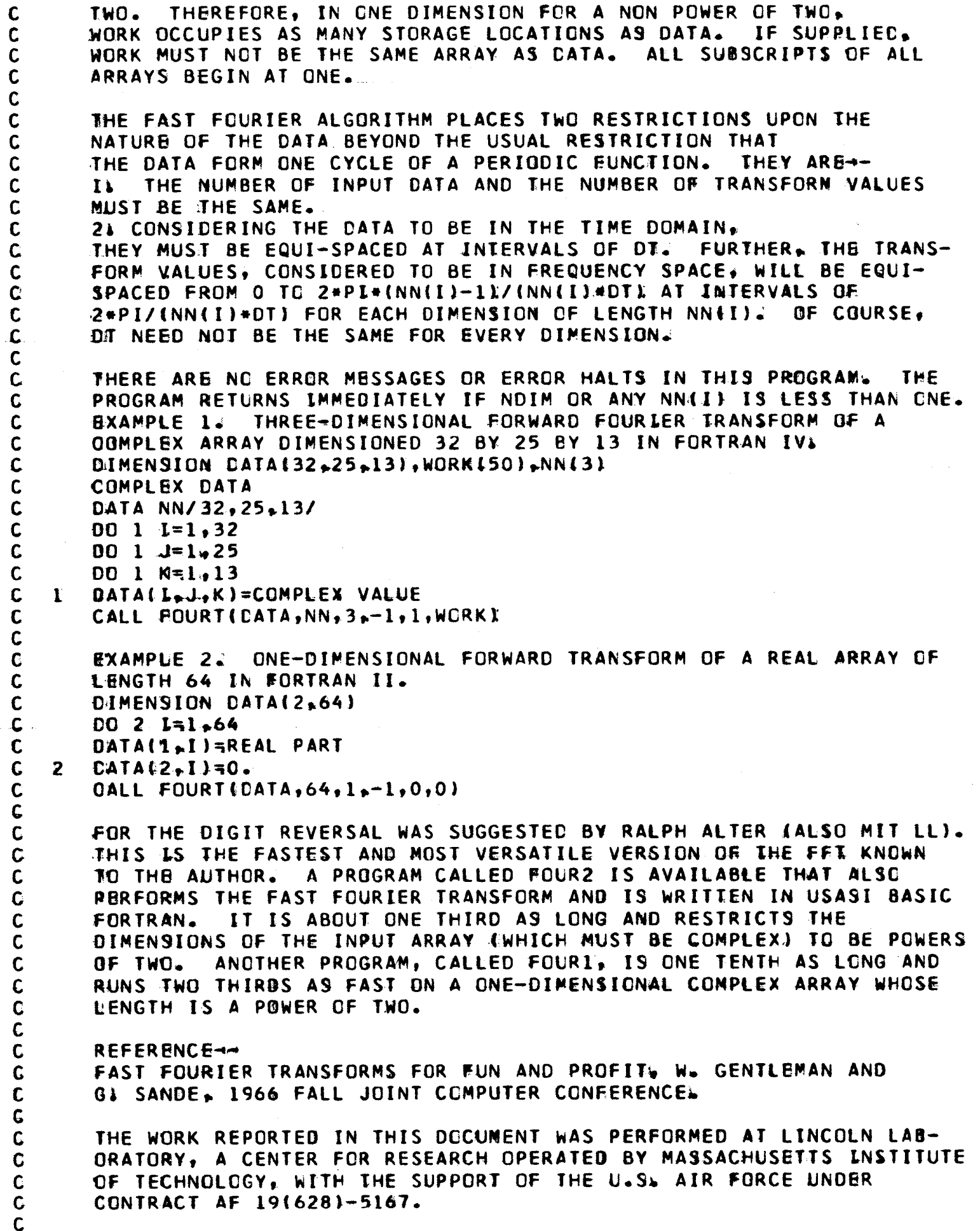




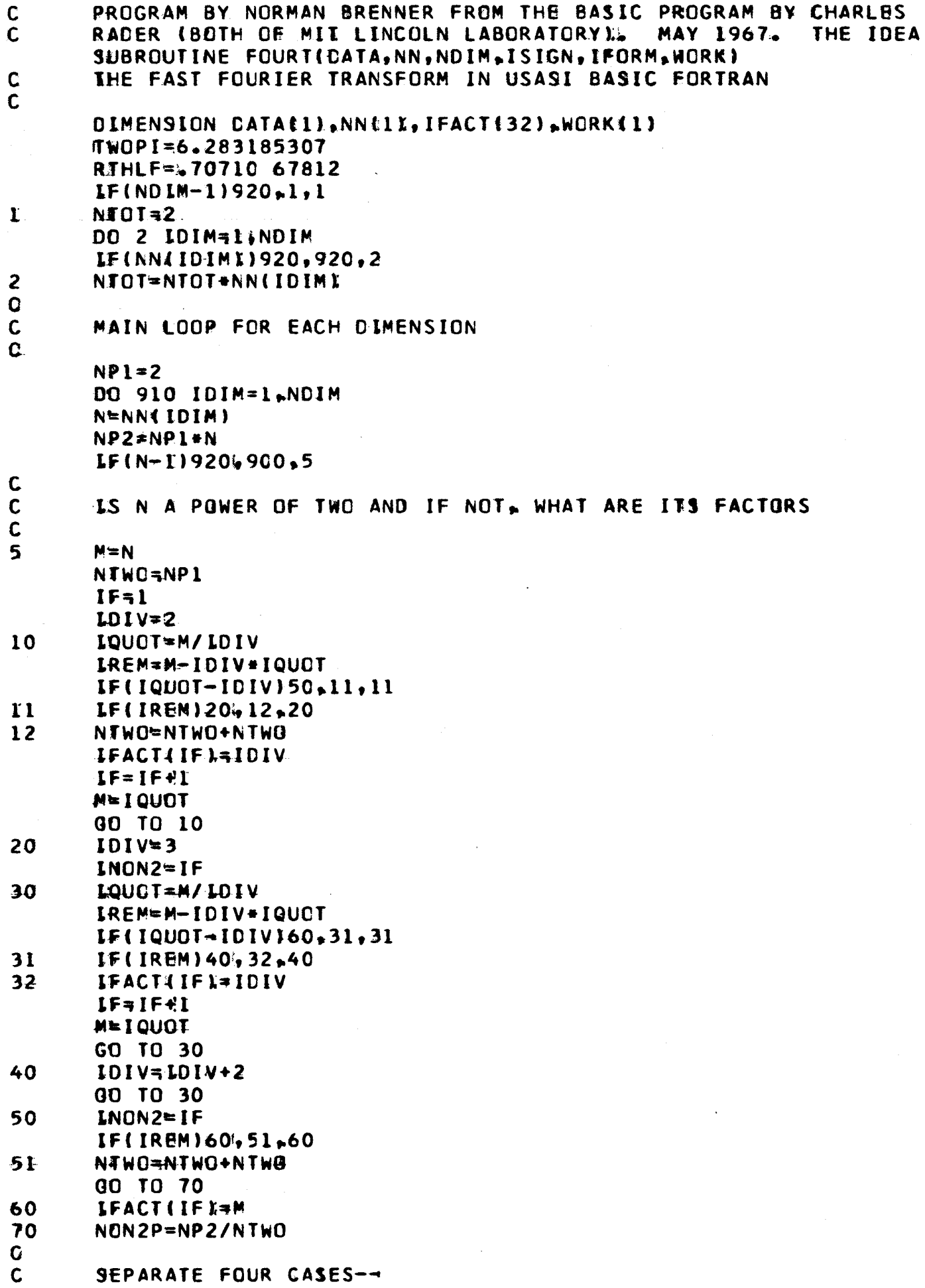




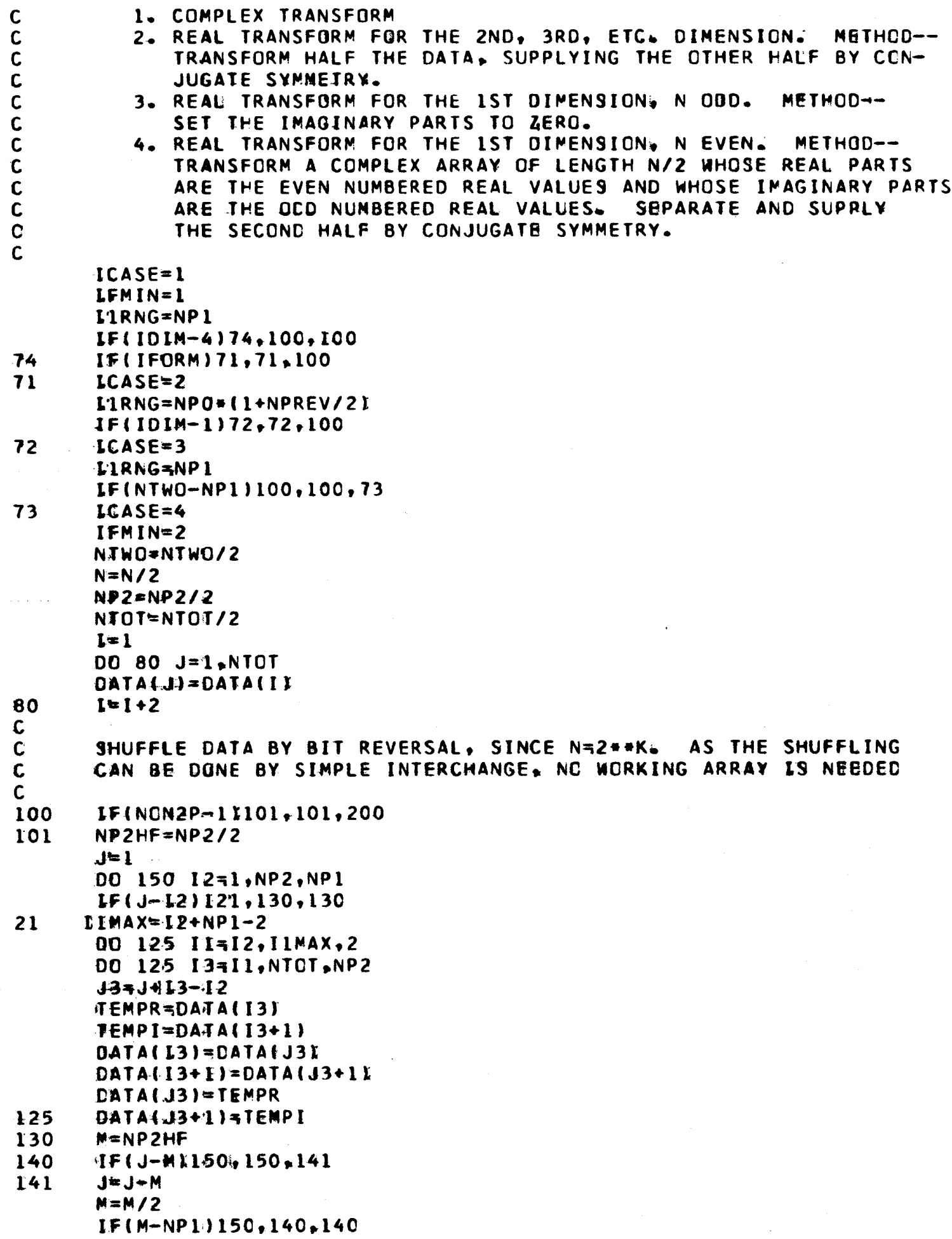




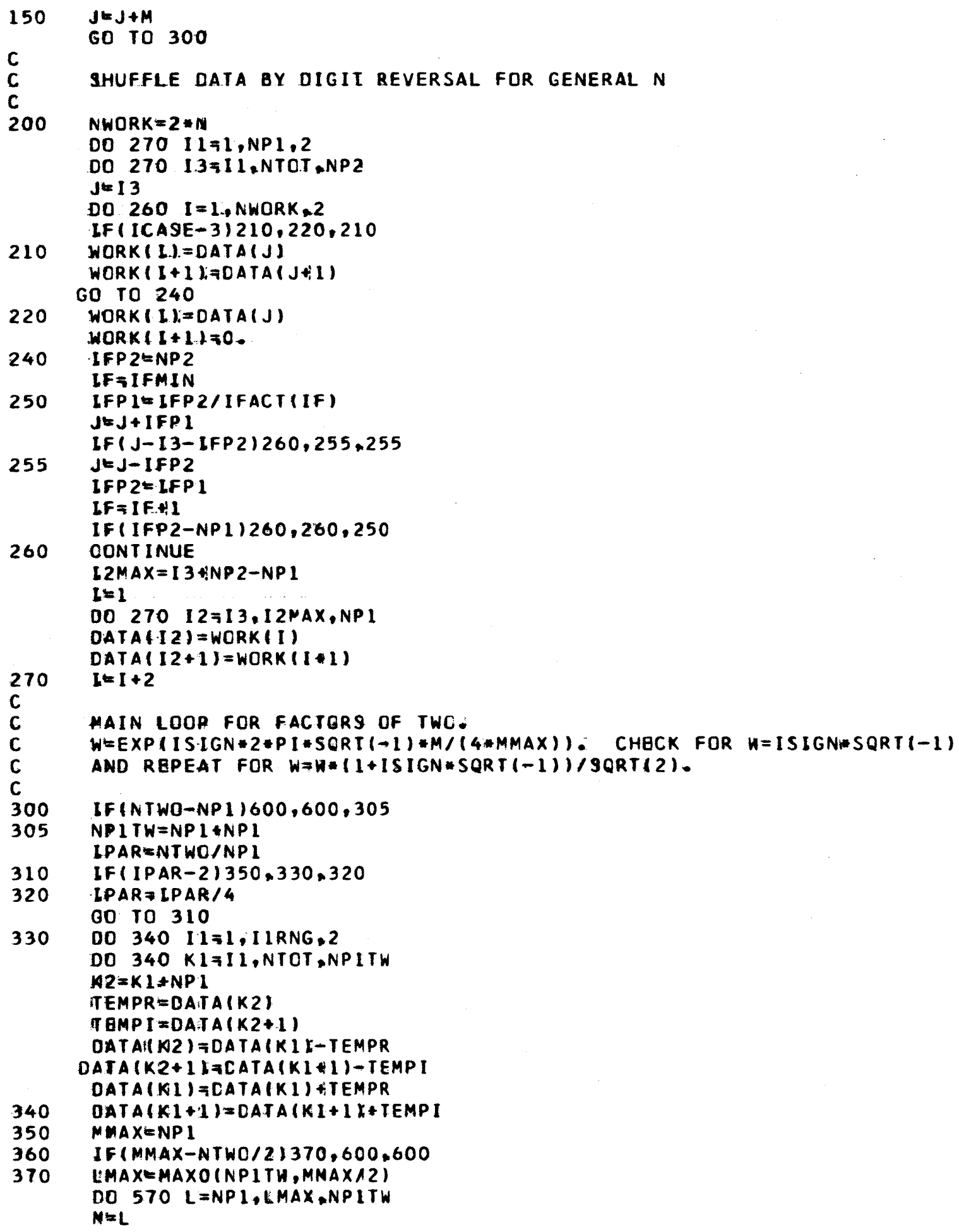




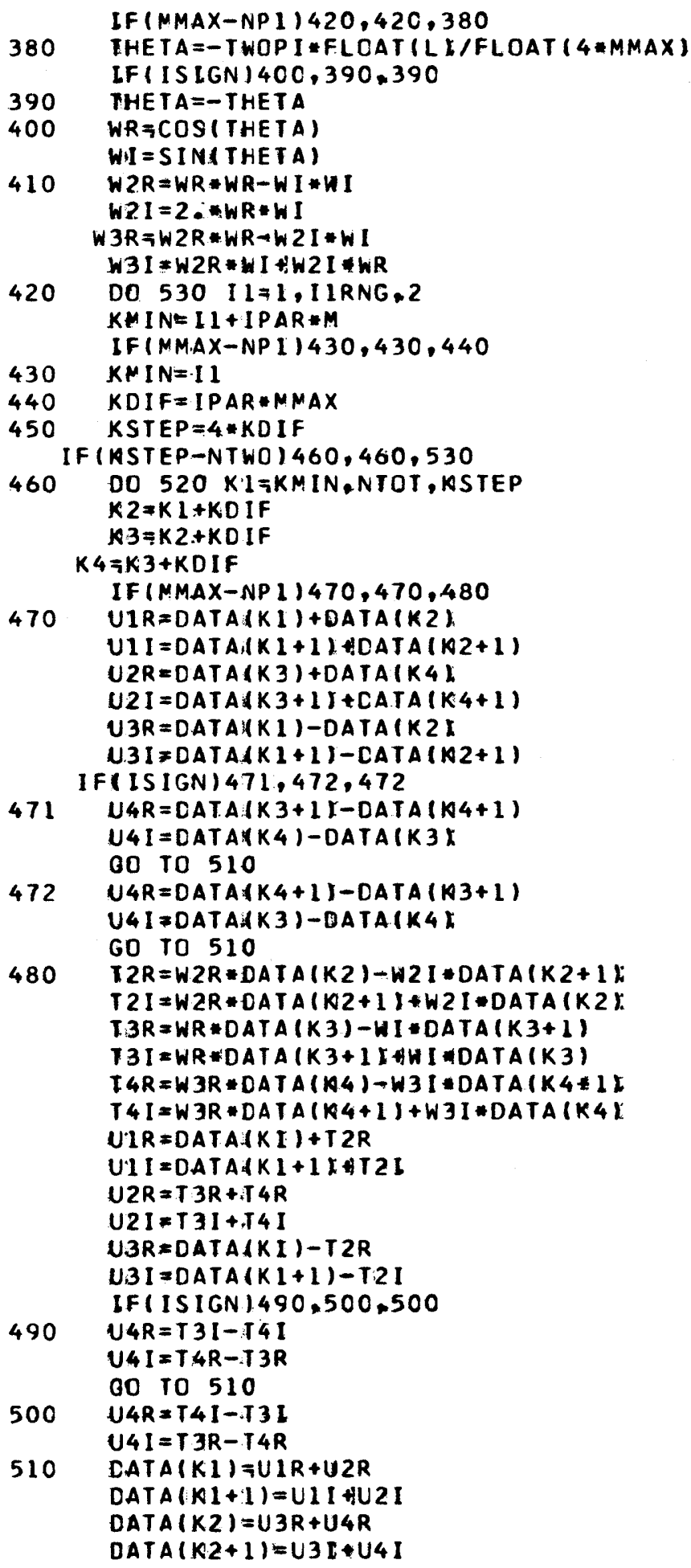




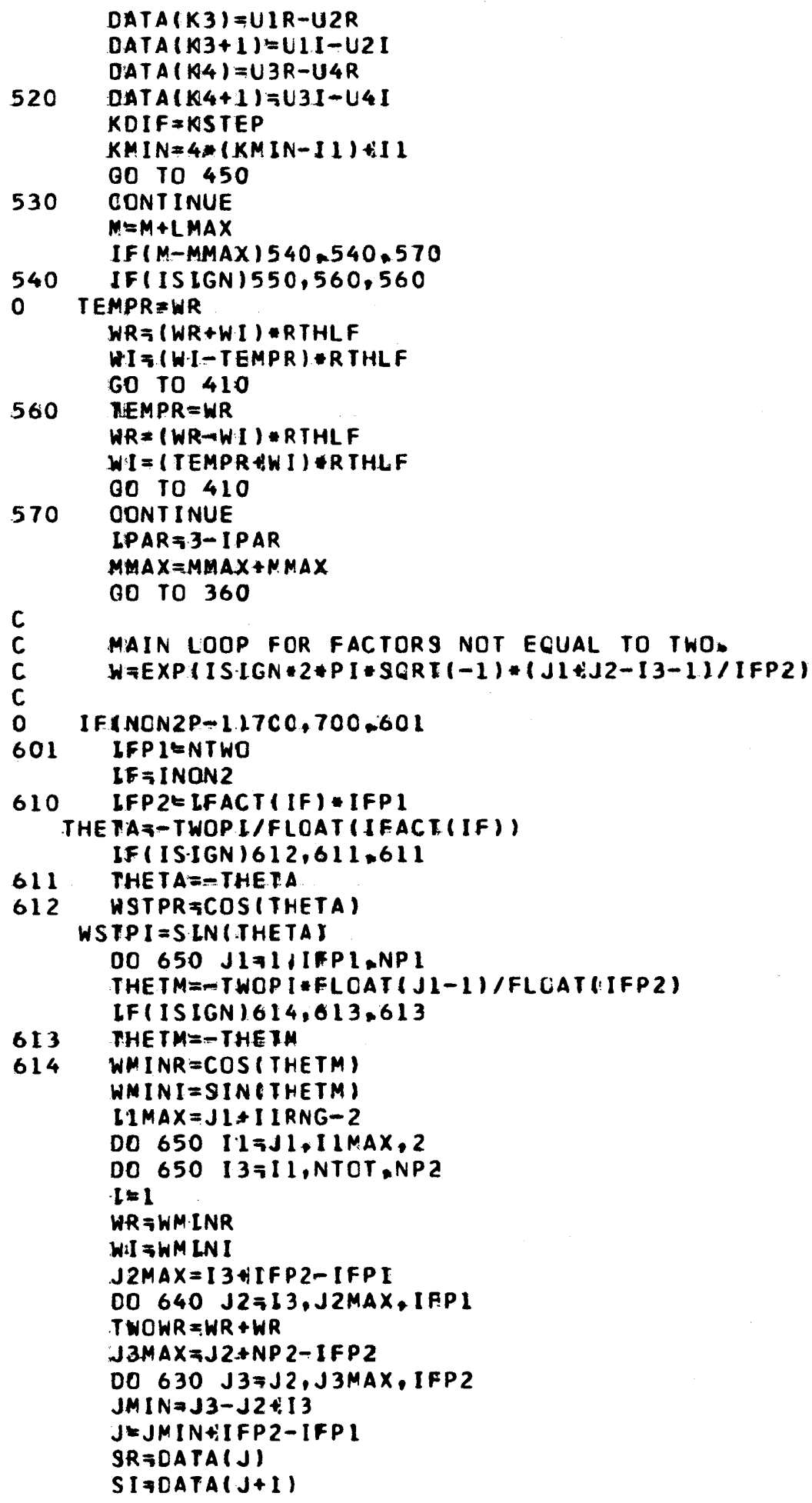




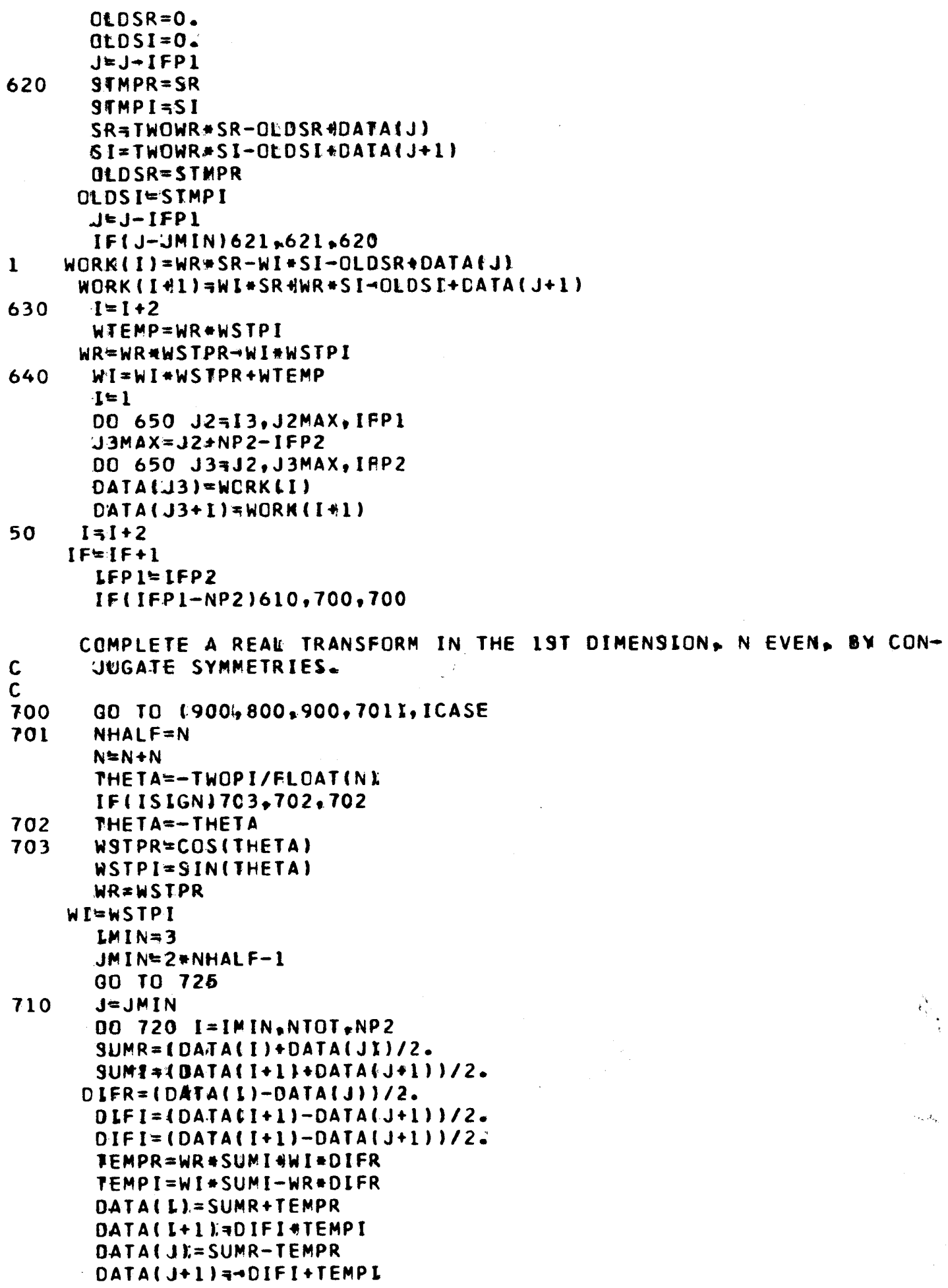




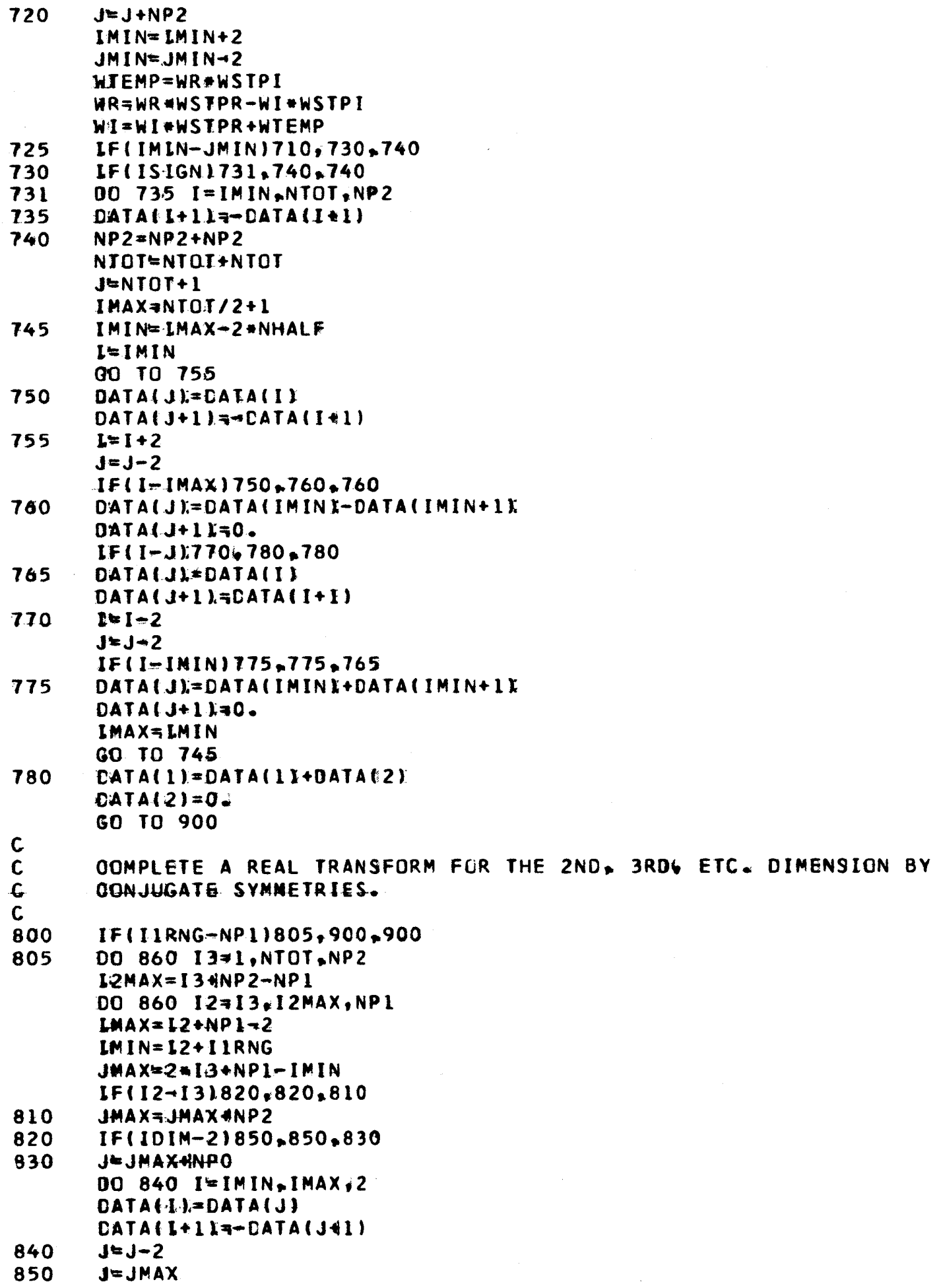




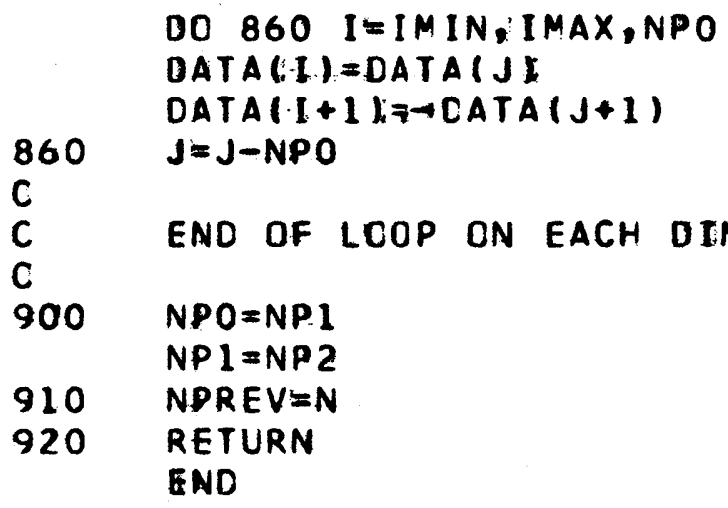




\section{APPENDIX B}

List of GAMANL input. Table B.I lists the cards in the order in which they appear in the data deck. The parameters are indicated and the formats used are shown below the parameters. Cards labeled (2)b and (7) represent a group of data cards giving the Iinearity and Gamma Spectra Data, respectively. For a 4096 channel spectrum, 512 data cards are required to read in the Gamma Spectra Data.

Table B.2 explains each of the input parameters in greater detail, and Table B.3 shows a typical input deck. 
11) Variable $\begin{aligned} & \text { TABLE B.I } \\ & \text { FORMAT }\end{aligned}$

FORMAT

$(4 I 5,15 . \phi, I 5)$

(2a) for LIN.LE. zero

Variable Previously Calc. Iinearity Correction data, CNTR and CORR arrays

FORMAT

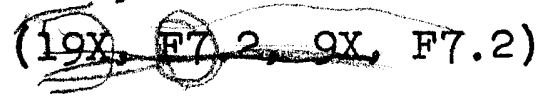

(2b) for LIN.GT. zero

Variable Linearity Data, TBL array

FORMAT

$((\mathrm{IX}, 7(\mathrm{~F} \sigma . \phi, 1 \mathrm{X})) /(8(\mathrm{~F} 6.0,1 \mathrm{X})))$

(3) Variable

S1G1, MWTLO1, WTC1, WTF1, SIG2, MWTLO2, WTC2, WTF2

FORMAT

(F5.0, I5, 2F5.2, F5.0, I5, 2F5.2)

(4) Variable J2, FIRENG, DELENG

FORMAT

(I5, 2F5.0)

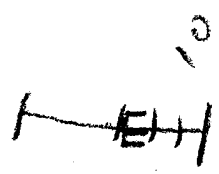

(5) Variable Efficlency Data Array, EFFCY.

FORMAT

(7 (E) 3 )

(6) Variable NUMRUN, NOCHAN, IMAX, DCR, ECR, BGER, IPUNCH, ERTM, SANGLE, FLUXT

FORMAT (3I5, F5.0, 2F5.1, I5, F5.0, 2E10.4)

(7) Variable Gamma Spectra Data, TBK array FORMAT $((7 X, 7(F 6.0,1 X)) /(8(F 6.0,1 X)))$

(8) Variable EGAM1, IP1, EGAM2, IP2, FPS, ERFW FORMAT $(4 \mathrm{X}, \mathrm{F} 6.1,4 \mathrm{X}, \mathrm{I} 6,4 \mathrm{X}, \mathrm{F} 6.1,4 \mathrm{X}, \mathrm{I} 6$, $3 X, F 7.2,3 X, F 7.2$ )

(9) Variable MO

FORMAT 
Card Variable

(1)

LR

NOCHAN

N2

N3

$\mathrm{XN}$

IIN

(2a) CNTR

(2b) TBL

(3) $\rightarrow$ SIGI

$\rightarrow$ MWTLOI

$\rightarrow$ WTCI

WTFI

$\rightarrow S 1 G 2$

$\rightarrow$ MWTLO2

$\rightarrow$ WTC2

$\rightarrow W T F 2$

(4) J2

FIRENG
Function

Linearity run number

Number of channels in linearity run, generally 4095

First calibration peak for linearity data, if there are 100 peaks $\mathrm{N} 2=20$

Second calibration peak for linearity data, if there are 100 peaks N3 $=80$

Background limit for linearity data, peaks must have counts greater than $\mathrm{XN}$ in order to be analysed

LIN.LEQ.O uses previously calculated linearity data, in which case NOCHAN is the number of peaks being read in under FORMAT (19X, F7.2, 9X, F7.2) IIN.GTR. 0 calculates inearity correction factors using subroutine IINEAR

CNTR(I) is channel number at which correction $\operatorname{CORR}(I)$ is to be applied to correct for system nonlinearity Iinearity Data Deck TBL(I), I=I, NOCHAN The width of the Gaussian used in the smoothing calculation. Typical value SIGI $=128$

Cutoff channel at which the smoothing weighting function begins to decrease from WTCI + WTFI MWTOI $=512$

The constant term in the smoothing function WTCl $=0.0$

The varying term in the smoothing function $W T F I=1.00$

The width of the Gaussian used in the improved resolution calculation Typical value $S I G I=128$.

Channel about which the imp. res. weighting function deviates from WTC2. MWTLO2 $=412$

Constant term in imp. res. function WTC2 $=0.90$

Varying term indicative of how much imp. res. Is desired WTF2 $=2.00^{\circ}$

Number of points in EFFCY, efficiency array. $\quad \mathrm{J} 2=19$

First energy value of EFFCY data (in keV) FIRENG $=1000$ 
Card Variable

DEIENG

(5) EFFCY

(6)

$\begin{aligned} & \text { NUMRUN } \\ & \text { NOCHAN } \\ \rightarrow & \text { IMAX } \\ \cdots & \text { DCR } \\ \cdots & \text { ECR } \\ \rightarrow & \text { BGER }\end{aligned}$

IPUNCH

$\rightarrow$ ERTM

SANGLE

FLUXT

(7) TBK

(8) EGAMI

IPI

EGAM2

IP2

\section{Function}

Difference in energy between EFFCY points (in keV) DELENG $=500$

Data represents efficiency data at equally spaced energy points. Obtained from experimental results

Run Number of Data Spectra

Number of Data Points $2^{N}-1$

Channel Number at which analysis is to begin

Slope criterion used in BAKSUB to determine if multiplet peaks are present

Error criterion used in PKANAL, peaks with percent errors in area greater than ECR are not analysed

Background factor for peak height. Peaks with heights less than or equal to BGER X SQRT(background) + 10.0 are not analysed.

If $<0$ Peak analysis data from PKANAL Is punched out.

If $=0$ no punched output

If $=$ I smoothed data punched out

$\checkmark$ If $=2$ smoothed, background subtracted data punched out

$v$ If $=3$ improved resolution data punched out.

Correction factor, used in error term calculation, due to smoothing

Solid angle factor used in INTSTY

Flux, cross-section, time, and misc. correction factor used in INTSTY

Data Deck TBK(I), $I=I$, NOCHAN

Energy (in keV) of first calibration peak. EGAMI 0 deletes the peak analysis

Peak center of first calibration peak. Program starts search for calibration peak at IPI-4 channels. Also need TBK(IPI) to be greater than the halfmaximum of the calibration peak height Energy (keV) of second calibration peak. Peak center of second calibration peak. 
Card $\quad$ Variable

\section{Function}

$\therefore$ FPS

First peak FWHM (keV), used in PKANAL to fit the FWHM. FPS.LE. zero implies FPS $=$ FWHM of first calibration peak.

(9)<smiles>CC(C)C(C)(C=O)C(C)C</smiles>

Allowable range for FWHM to vary from FPS.

MO.LE.O or MO.GT.4 ends the program

MO $\sum$ l loops to 2001 to accept more data MO $=2$ loops to 2002 to accept more data MO $=3$ loops to 2003 to accept more data $M O=\frac{3}{4} 100 \mathrm{ps}$ to 2004 to accept more data 
TABLE B.3

C SAMPLE GAMANL INPUT DECK

\begin{tabular}{crr}
$/ 1 G . S Y S I N$ & & \\
$20 D^{*}$ & & \\
23 & 132.26 & -8.94 \\
2 & 173.35 & -6.94 \\
\hline 3 & 214.07 & -4.56 \\
-4 & 255.44 & -2.84
\end{tabular}

C LINEARITY CORRECTION FACTORS FOR 93 PEAKS, AS PREVIOUSLY CALC.

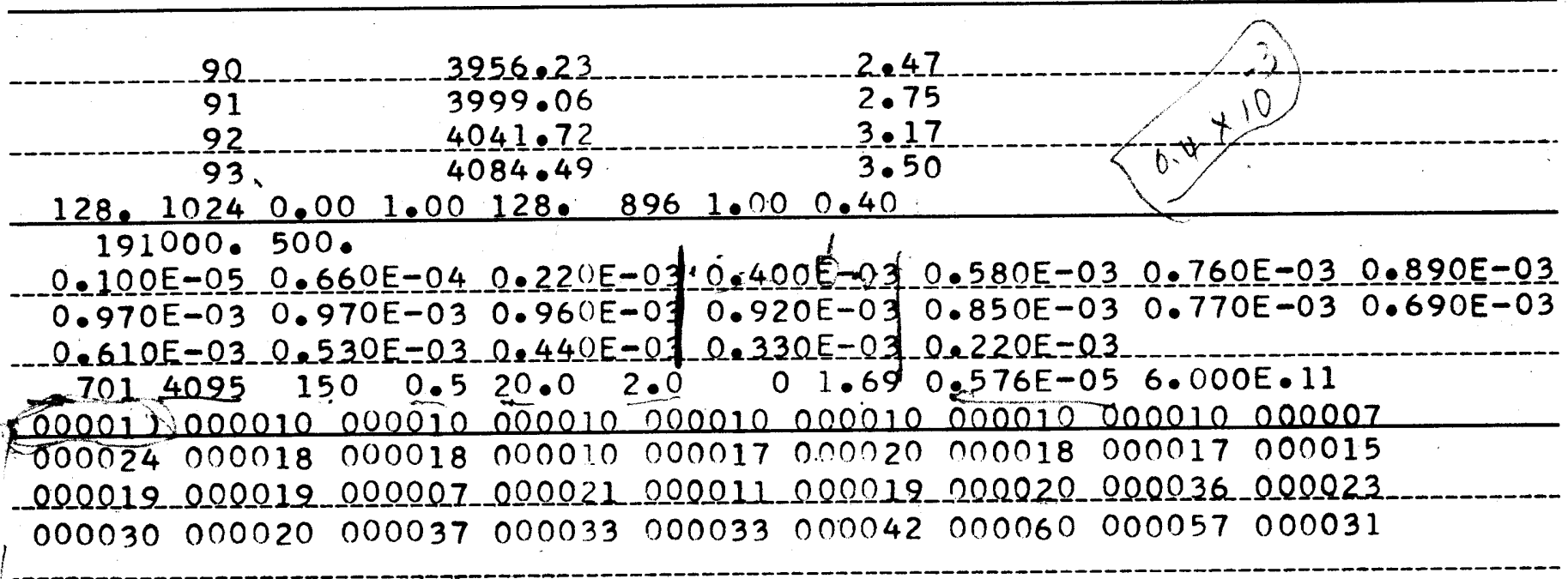

gAMMA SPECTRA DATA DECK CHANNELS 1 TO 4095

\begin{tabular}{|c|c|c|c|c|c|}
\hline $\begin{array}{r}000017000014 \\
-000016 \_0 \Omega 0 \Omega 21\end{array}$ & $\begin{array}{r}000019 \\
-\Omega 0018\end{array}$ & $\begin{array}{r}000017000015 \\
000027[000015\end{array}$ & $\begin{array}{r}000020 \\
-000012\end{array}$ & $\begin{array}{r}000022000016 \\
-\Omega 0012[0000<06\end{array}$ & $\begin{array}{r}004071 \\
004 \Omega 79\end{array}$ \\
\hline $\begin{array}{ll}000022 & 000024 \\
00017 & 110011\end{array}$ & $\begin{array}{l}000020 \\
000016\end{array}$ & $\begin{array}{ll}000021 & 000014 \\
00015 & 0015019\end{array}$ & $\begin{array}{l}000014 \\
000211\end{array}$ & $\begin{array}{l}000022000010 \\
00017000015 \\
00017\end{array}$ & $\begin{array}{r}004087 \\
004095\end{array}$ \\
\hline 2223.3 & 563 & 7367.7 & 2963 & $7 \cdot 20$ & $3 \cdot 00$ \\
\hline
\end{tabular}


APPINDIX C

Output from GAMANL, PKANAL subroutine, listing gamma spectral peaks and results. The data recorded was from an Iron sample irradiation in the M.I.T. Triple-Coincidence $\gamma$-Spectrometer ( 1 ). 
PEAKS USED IN COMPUTING LSF OF FWHM

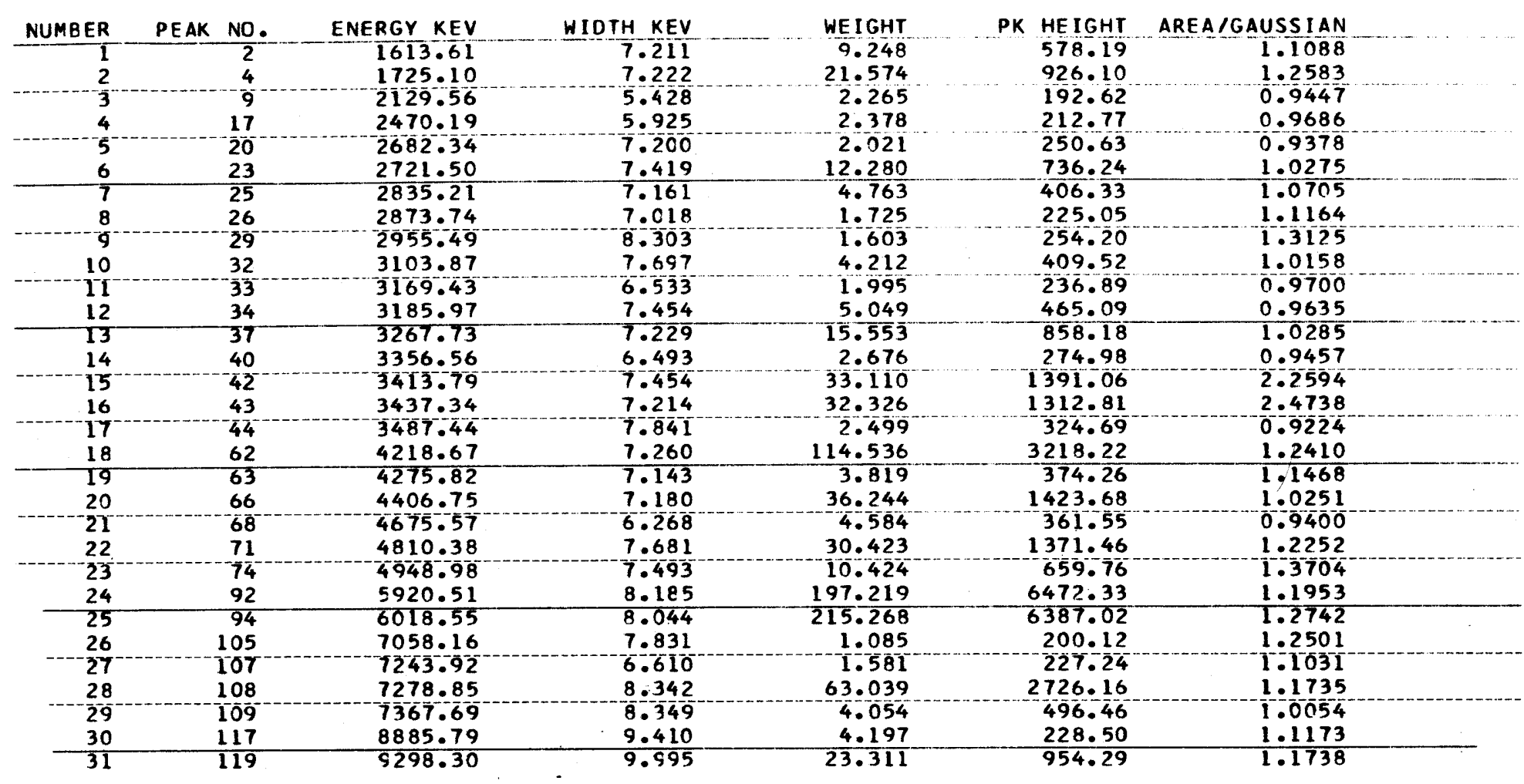

RUN NO $=701$ NUMBER OF CHANNELS $=4095$

CHANNEL NUMBER SLOPE CRITERTON TIMAX) = 150

ERROR CRITERION FOR PEAK ANALYSIS (PER-CENT) 20.0

SLOPE CRITER ION FOR BACKGROUND IN UNITS OF SQRT CF BACKGROUND $=0.50$

PEAK LOCATION CRITERION IN UNITS OF SQRT CF BACKGROUND (BGER) $=2.0$

ERROR TERM REDUCTIONN DUE TO SMOOTHING 1.690

LINEARITY RUN NUMBER $393 \quad$ N2 $=20 \quad N 3=80 \quad X N=10$.

FIRST PEAR FWHM TKEV) FPS $=-7.20$ FKHM VARIATION (KEV) ERFW $=3.00$

ENERGY PER CH.NC (KEV) $=2.145$

ENERGY-I $=2223.3$ CHANNEL NO $=563$ TRTE PEAK CENTER $=562.6$ WIDTH (KEV) $=7.06$ ENERGY-2 $=7367.7 \quad$ CHANNEL NO $=2963 \quad$ TRUE PEAK CFNTER $=2961.0 \quad$ WIDTH (KEV) $=8.35$

SOLTD ANGLE RADTANS $=0.5760$ E 05 FLUXT $=0.6000 E 12$

EFFICIENCY DATA INITIAL ENERGY (KEV) = 1000. DELTA ENERGY (KEV) = 500 .

$0.100 E=050.660 E-040.220 E-030.400 E-030.580 E-030.760 E-030.890 E-030.970 E-030.970 E-030.960 E-033$ $\begin{array}{llllllllllll}0.920 E-03 & 0.850 E-03 & 0.770 E-03 & 0.690 E-03 & 0.610 E-03 & 0.530 E-03 & 0.440 E-03 & 0.330 E-03 & 0.220 E-03\end{array}$

NUMBER OF PEAKS $=119$

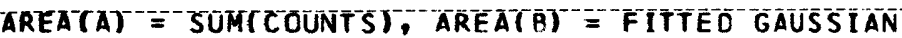




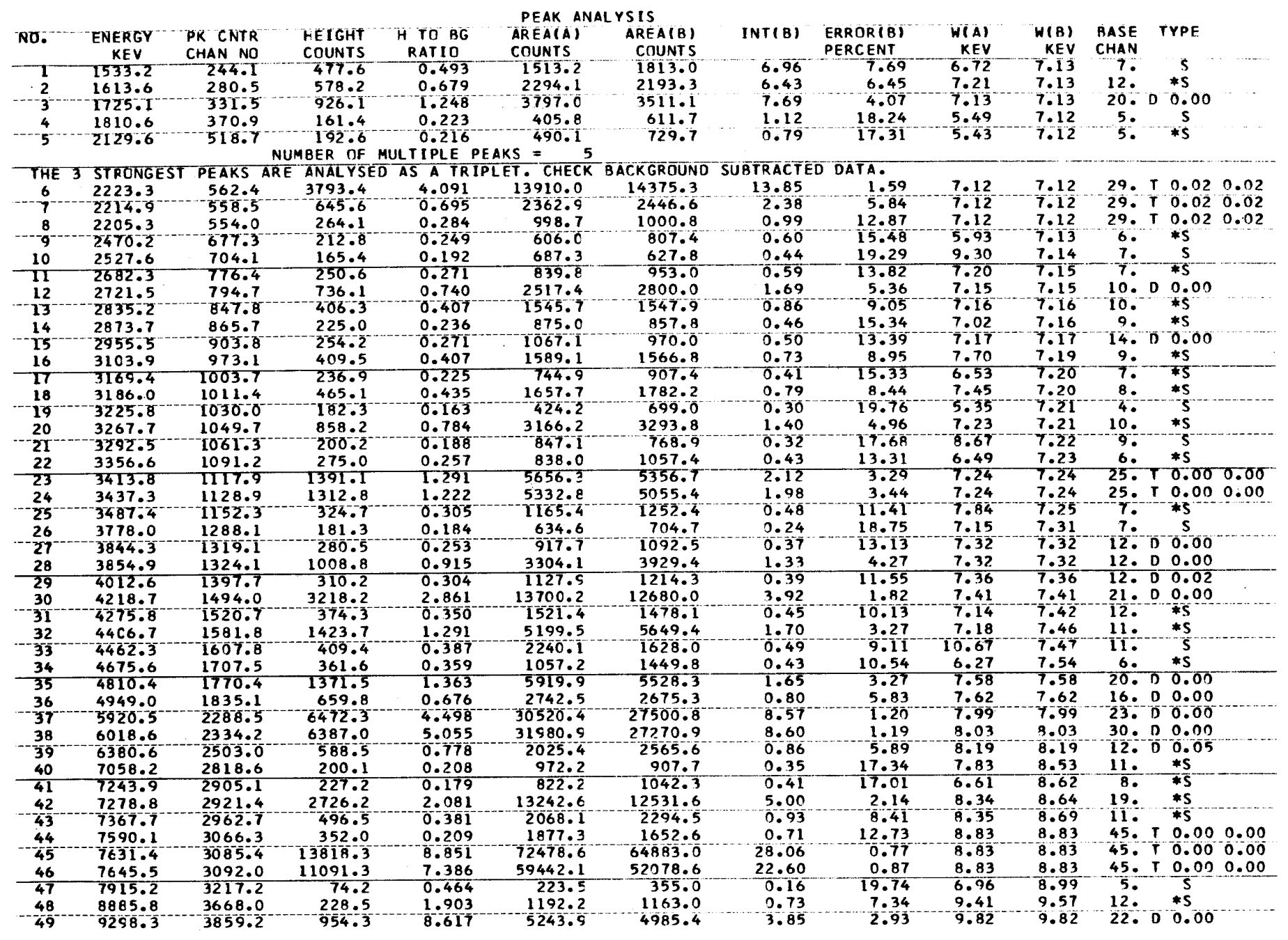




\section{APPENDIX D \\ Correction for System Nonlinearity}

In order to correct for the nonlinearity of the data collecting system (gamma detector, amplifier and multichannel analyser) a method described by Heath, et al. (11) is used. A high precision dc voltage standard (0-10 volt output) with an absolute accuracy of 1 part in $10^{4}$ is used in conjunction with a mercury relay pulser to perform the linearity check. Test pulses are inserted into the 4096 channel analyser through the preamplifer with a uniform voltage spacing. The choice of spacing depends on the gain settings of the system.

Usually 100 equally spaced peaks are put into the analyser. Two peaks, one near the low energy end and the other near the high energy end of the spectrum, are assumed to have zero linearity correction factor and the remaining peaks are fitted linearly to those two standard peaks. The standard peaks chosen could be, for example, the twentieth and the eightieth peaks. The actual peak center at channel C compared with the predicted peak center for linearity at the same channel gives the correction factor for the nonlinearity of the system at channel $C$.

Subroutine LINEAR calculates these correction factors and stores them in array CORR, it also needs an array CNTR to store the peak center at which the correction factor applies.

Subroutine ADJUST performs the Iinearity correction to a given peak center, PCNR, by use of a second order interpolation using the CNTR and CORR arrays to determine the true peak center, TPC.

It is possible to bypass the linearity correction calculation by either deleting the subroutines from the program, which means rewriting parts of the program, or by reading in Iinearity correction factors which are all zero. This can be done by appropriately arranging the input deck, see Appendix B. 
84

APPENDIX E

Background Calculation

Subroutine BAYSUB performs the background calculation and subtraction on the spectra. Basically the program finds the peaks by using a first difference calculation and sets the background as a linear fit from minima to minima of the peak. However in the case of partially resolved peaks the minima must be excluded. To do this, a slope criteria is established which sets a maximum value for the slope of the background. When the angle between the slopes of the background of two adjacent peaks is greater than the slope criterion the pair will be considered as a multiplet. This procedure is repeated for up to a maximum of five peaks. The slope criteria is expressed as DCR in the input list and is multiplied by the difference in channel numbers between two minima and by the square root of the background at the upper minima.

To make the minima of a peak more representative of the true background, the counts in the two channels, one on each side of the minima, are added to the minima counts, and the average is taken. New minima are sought using this averaged value, and $i t$ is these new minima from which the Inear background fit under the peak is calculated.

BAKSUB also prints out the lower channel number of each peak, the number of counts in the lower and upper channel numbers, the slope between the two minima of a peak, and the width of the peak in channels. 


\section{APPENDIX F \\ Intensity Calculation}

Subroutine INTSTY calculates the intensity of a gamma ray at energy $E$ after being given its area as calculated in PKANAL. There are several options open to the user in converting from the area in counts to some other quantity. Basically as INTSTY is written the area is divided by two constants, SANGLE and FLUXT, and also by a quantity GX which varies with the energy of the gamma peak being considered.

For thermal neutron capture gamma spectra, the number of gamma rays of energy $E$ per 100 neutrons captured is the quantity of interest. Thus the factor SANGLE represents the solid angle geometry factor for the detector as well as any minor correction factors; FLUXT represents the total number of neutron captures in the sample divided by 100; and GX is the detector efficiency at energy $E$ as obtained by second order energy interpolation of data in the EFFCY array.

The parameters SANGLE, FLUXT, and EFFCY are inputed to the program and are determined by previous calculations. 


\section{References}

1. V. J. Orphan and N. C. Rasmussen, "A Ge(Li) Spectrometer for Studying Neutron Capture Gamma Rays", Nucl. Instr. and Methods, 48, No. 2 (1967).

2. Application of Computers to Nuclear and Radiochemistry, National Academy of Sciences, National Research Council NAS-NS 3107 (1962).

3. R. G. Helmer, et al., "Photopeak Analysis Program for Photon Energy and Intensity Determinations", Nucl. Instr. and Methods, 57 (1967).

4. M. A. Mariscotti, "A Method for Automatic Idertification of Peaks in the Presence of Background and Its Application to Spectrum Analys1s" Nucl. Instr. and Methods, 20 (1967) pp. 309-320.

5. T. Inouye and N. C. Rasmussen, "A Computer Method for the Analysis of Complex Gamma-Ray Spectra", Trans. of the ANS 10, 1, p.38 (1967).

6. T. Inouye, "The Super Resolution of Gamma-Ray Spectrum", Nucl. Instr. and Methods, 30, (1964).

7. J. Hamawi, Ph.D. thesis, M.I.T. Dept. of Nucl. Engr. (To be published).

8. J.W. Cooley and J.W. Tukey, "An Algorlthm for the Machine Calculation of Complex Fourler Series," Math. Comput., 19, 297 (1965).

9. Program FOURT avallable from IBM Program Information Department, 40 Sawmill River Road, Hawthorn, New York 10532 
10. N. C. Rasmussen, Y. Hukai, T. Inouye and V. J. Orphan "Thermal Neutron Capture $\gamma$-Ray Spectra of the Elements", MITNE-85 (prepublication)

11. R. Heath, et al., IEEE Trans. on Nuclear Science, NS-13, 3, (June 1966) 445-456. 